\title{
Patterns of Lung Cancer Care and Associated Health Outcomes Among Elderly Medicare Fee For Service Beneficiaries in West Virginia and in the United States
}

\author{
Pramit Amrutlal Nadpara \\ West Virginia University
}

Follow this and additional works at: https://researchrepository.wvu.edu/etd

\section{Recommended Citation}

Nadpara, Pramit Amrutlal, "Patterns of Lung Cancer Care and Associated Health Outcomes Among Elderly Medicare Fee For Service Beneficiaries in West Virginia and in the United States" (2013). Graduate Theses, Dissertations, and Problem Reports. 4984.

https://researchrepository.wvu.edu/etd/4984

This Dissertation is protected by copyright and/or related rights. It has been brought to you by the The Research Repository @ WVU with permission from the rights-holder(s). You are free to use this Dissertation in any way that is permitted by the copyright and related rights legislation that applies to your use. For other uses you must obtain permission from the rights-holder(s) directly, unless additional rights are indicated by a Creative Commons license in the record and/ or on the work itself. This Dissertation has been accepted for inclusion in WVU Graduate Theses, Dissertations, and Problem Reports collection by an authorized administrator of The Research Repository @ WVU.

For more information, please contact researchrepository@mail.wvu.edu. 
Patterns of Lung Cancer Care and Associated Health Outcomes Among Elderly Medicare Fee For Service Beneficiaries in West Virginia and in the United States

Pramit Amrutlal Nadpara

\author{
Dissertation Submitted to the \\ School of Pharmacy \\ at West Virginia University \\ in partial fulfillment of the requirements \\ for the degree of \\ Doctor of Philosophy \\ in \\ Pharmaceutical and Pharmacological Sciences
}

S. Suresh Madhavan, MBA, Ph.D., Chair

Cindy Tworek, Ph.D., M.P.H.

Usha Sambamoorthi, Ph.D.

Michael Hendryx, Ph.D.

Mohammed Almubarak, MD

Department of Pharmaceutical Systems and Policy

Morgantown, West Virginia

2013

Keywords: Lung cancer, Elderly, Neoplasm, Medicare, and Disparities

Copyright 2013 Pramit Amrutlal Nadpara 


\section{Abstract \\ Patterns of Lung Cancer Care and Associated Health Outcomes Among Elderly Medicare Fee For Service Beneficiaries in West Virginia and in the United States}

\section{Pramit Amrutlal Nadpara}

The elderly carry a disproportionate burden of lung cancer in the US. Although significant improvements have been made during the past decade in cancer treatment, substantial disparities still exist in guideline-based lung cancer care and outcomes. Such variation in lung cancer care is a cause for major concern in rural areas like West Virginia (WV). The purpose of this study was to do a comprehensive evaluation of variations in lung cancer care and associated health outcomes in the elderly. This retrospective study was conducted using SEER-Medicare and WVCR-Medicare linked data files for the years 2002-2007. As part of the project, three studies were conducted. In the first study, we compared geographic variations in clinical guideline-based lung cancer care and associated health outcomes among elderly Medicare Fee-for-service (FFS) beneficiaries. The study found disparities in receipt of minimally appropriate care in both the WV and US populations. Receipt of minimally appropriate care was found to be associated with longer survival times. In the second study, we compared geographic variations in timeliness of lung cancer care and found significant variation in delays in diagnosis and treatment in both the WV and US populations. However, non-timely care was not associated with poorer prognosis. The third study determined the patterns of receipt of tobacco-use cessation counseling services and found such services to be received by more than half of all beneficiaries. Overall, the findings highlight the critical need to address disparities in receipt of guideline-based appropriate and timely lung cancer care among Medicare FFS beneficiaries. The findings also reveals the urgent need for future cancer prevention efforts directed towards promoting smoking cessation in the rural WV population. In the long run, such cancer prevention efforts can help to reduce lung cancer incidence, which in turn can help to reduce the geographic disparities in lung cancer mortality. 


\section{DEDICATION}

This dissertation is dedicated to my mother (Chandrikaben Amrutlal Nadpara, B.A.), my father (Amrutlal Manjibhai Nadpara, B.E. (Electrical)), and my brother (Dr. Rishit Amrutlal Nadpara, MD, M.B.B.S.). 


\section{ACKNOWLEDGEMENTS}

This project was supported by grant number 1R24HS018622-01 (PI: S. Madhavan) from

the Agency of Healthcare Research and Quality. The content is solely the responsibility of the authors and does not necessarily represent the official views of the Agency for Healthcare Research and Quality.

There are several individuals who helped me directly or indirectly in the completion of this dissertation, and I am truly grateful to all of them. I would like to acknowledge the role of my mentor and chair Dr. S. Suresh Madhavan in providing me with the financial, emotional, and intellectual support that made the completion of this project possible. His guidance and support over the past few years has been instrumental in shaping my career. Another individual without whom this project would not have been possible is Dr. Cindy Tworek. Dr. Tworek was my major advisor during my early years at West Virginia University, and she also helped me in all aspects of the study. I am truly indebted to Dr. Madhavan and Dr. Tworek for their support.

I would also like to acknowledge the role of Dr. Usha Sambamoorthi, Dr. Michael Hendryx, and Dr. Mohammad Almubarak in the completion of this project. The comments and suggestions from them have markedly improved the quality of work that was undertaken as a part of this project. I am thankful for having these wonderful individuals as a part of my committee.

I would also like to acknowledge Myra Fernatt, Dr. Alana Hudson, and Dr. Loretta Haddy from West Virginia Cancer Registry; Commissioner Nancy Atkins, and Nora Antlake from West Virginia Bureau of Medical Services for their administrative and material support. 
I would like to acknowledge the support provided by Dr. Ginger Scott, and my friends and colleagues in the department. Over the course of my graduate education, these individuals have provided me with the emotional support that was needed especially since my family was far away. I am thankful to them for their friendship.

Finally, I would like to acknowledge my family for their support and encouragement all my life. I feel blessed to have wonderful and amazing parents (Chandrikaben Amrutlal Nadpara, Amrutlal Manjibhai Nadpara), brother (Dr. Rishit Amrutlal Nadpara), and wife (Purvi Pramit Nadpara). 


\section{TABLE OF CONTENTS}

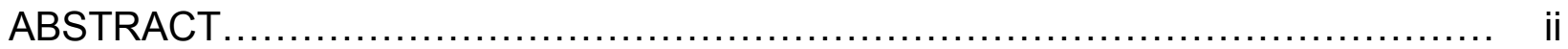

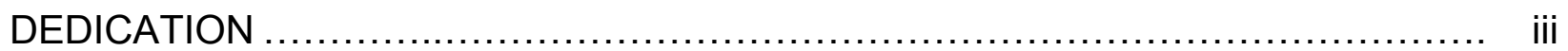

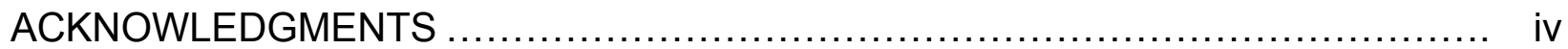

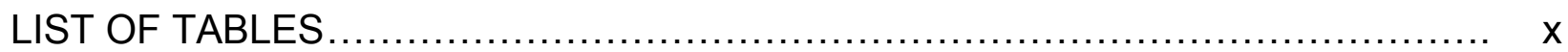

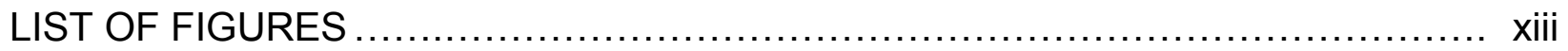

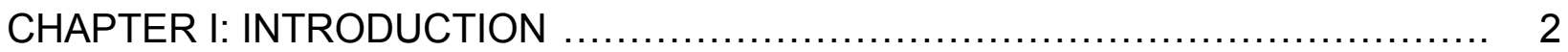

Overview of Lung Cancer .................................................... 2

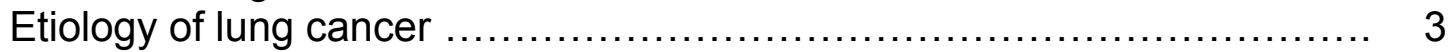

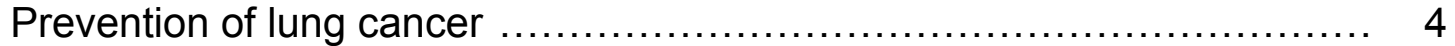

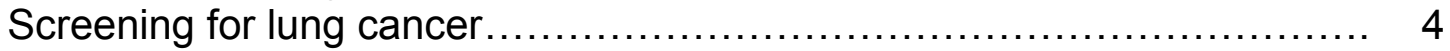

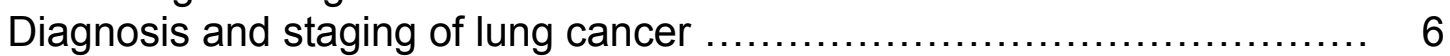

Treatment of lung cancer................................................ 7

Healthcare utilization and costs associated with lung cancer $\ldots \ldots \ldots \ldots \ldots \ldots \ldots$

Evidence Based Lung Cancer Care ......................................... 8

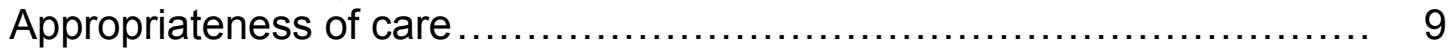

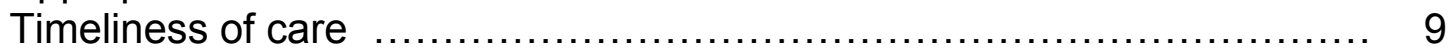

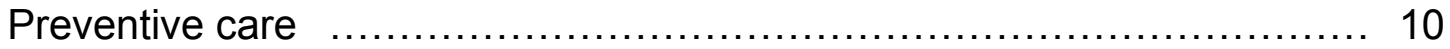

Disparities in Lung Cancer Care and Health Outcomes ........................ 10

Geographic Variation ................................................ 12

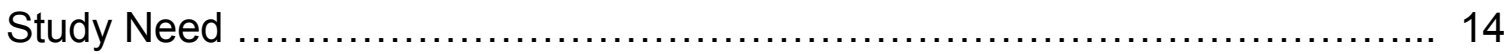

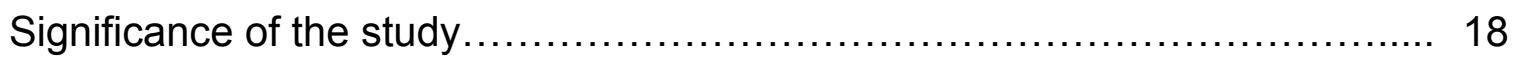

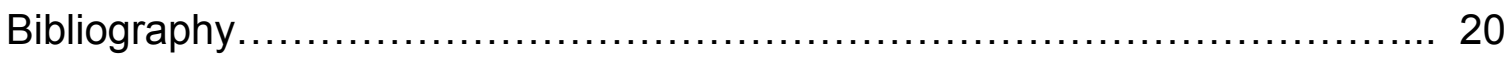

CHAPTER 2: APPROPRIATENESS OF LUNG CANCER CARE AND ASSOCIATED HEALTH OUTCOMES AMONG ELDERLY MEDICARE FEE-FOR-SERVICE BENEFICIARIES IN WEST VIRGINIA AND IN THE UNITED STATES ........ 30

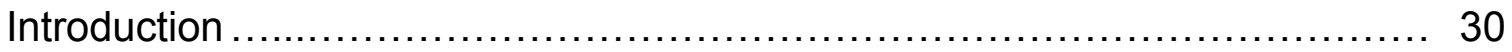

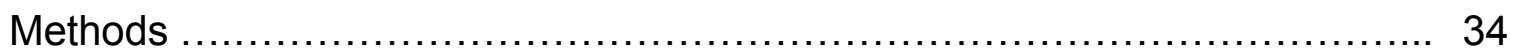

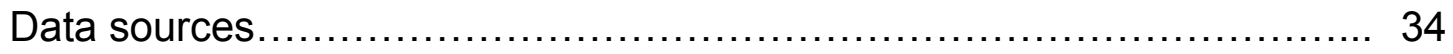

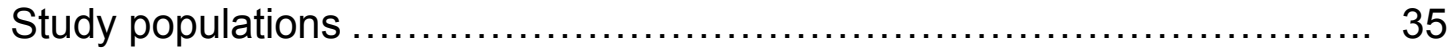

Assessing receipt of clinical guideline based lung cancer care ............. 36 


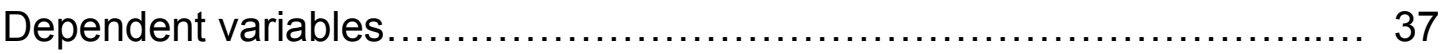

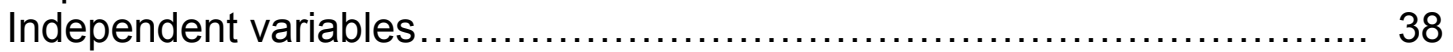

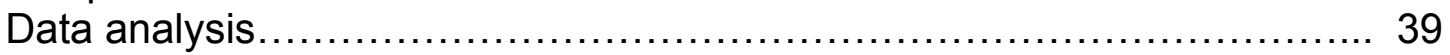

Results........................................................................ 41

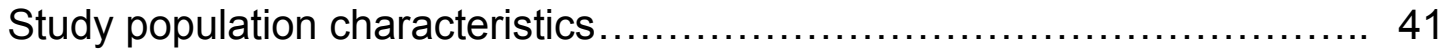

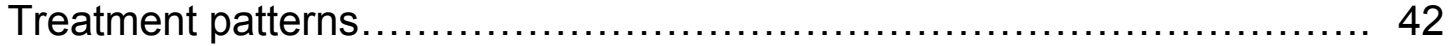

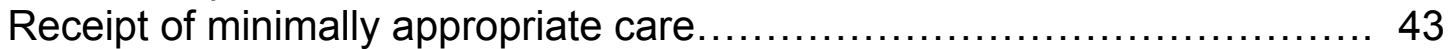

Factors associated with receipt of minimally appropriate care.............. 44

Survival benefits associated with receipt of minimally appropriate care..... 45 Lung cancer mortality risk associated with non-receipt of minimally appropriate care ........................................................... 46

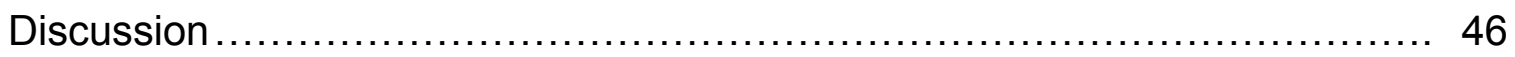

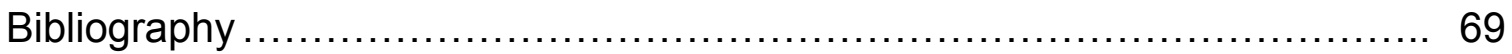

\section{CHAPTER 3: TIMELINESS OF LUNG CANCER CARE AND ASSOCIATED} HEALTH OUTCOMES AMONG ELDERLY MEDICARE FEE-FOR-SERVICE BENEFICIARIES IN WEST VIRGINIA AND IN THE UNITED STATES ......... 75

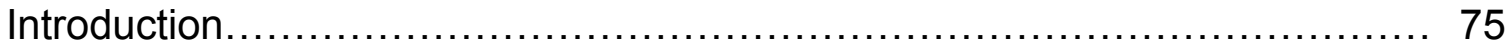

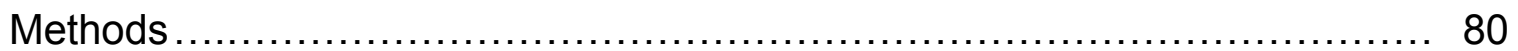

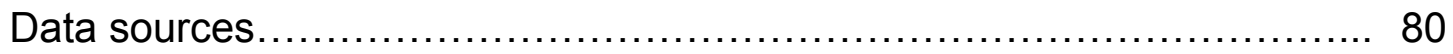

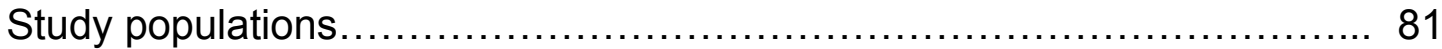

Assessing delays in diagnosis and treatment........................... 82

Assessing receipt of timely lung cancer care, based on

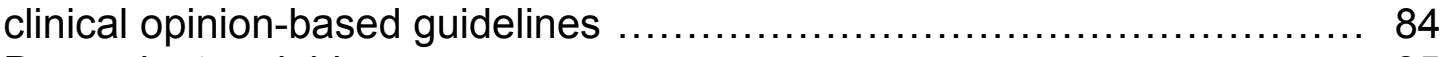

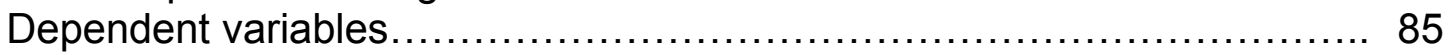

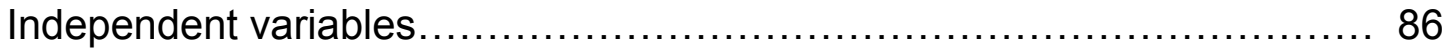

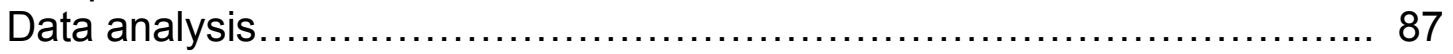

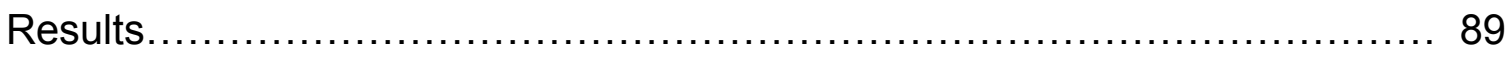

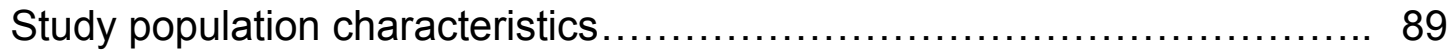

Delays in diagnosis and treatment ....................................... 90

Receipt of timely care ................................................. 91

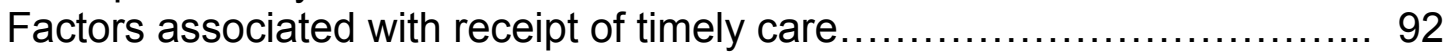

Survival outcomes by receipt of timely care ............................... 93

Lung cancer mortality risk associated with non-receipt of timely care ........ 94

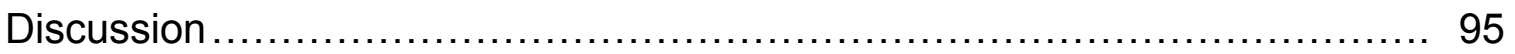

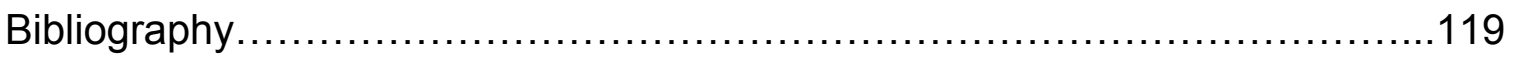


CHAPTER 4: PATTERNS OF RECEIPT OF TOBACCO-USE CESSATION COUNSELING SERVICES AND ASSOCIATED HEALTH OUTCOMES AMONG ELDERLY MEDICARE FEE-FOR-SERVICE BENEFICIARIES WITH LUNG CANCER, AND WITH A HISTORY OF TOBACCO USE, IN WEST VIRGINIA 126

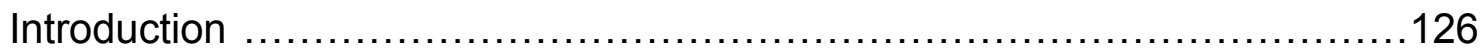

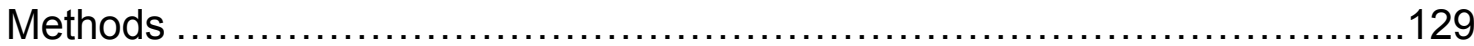

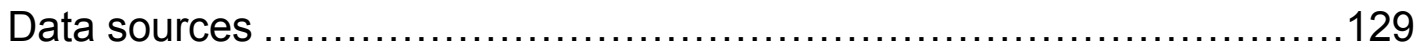

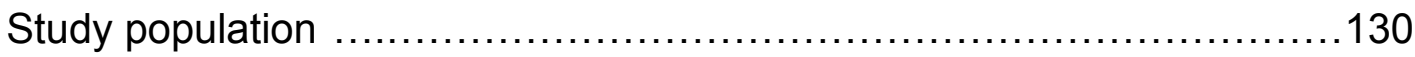

Assessing receipt of tobacco-use cessation counseling services ..........132

Dependent variables ...................................................132

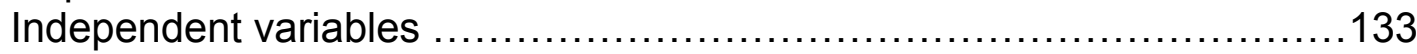

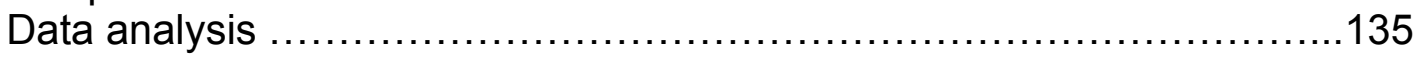

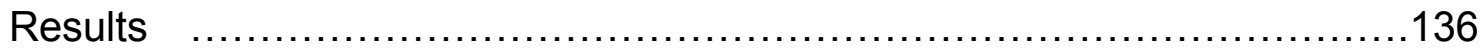

Receipt of tobacco-use cessation counseling services ..................137

Factors associated with receipt of tobacco-use cessation counseling services ....................................................137

Survival benefits associated with receipt of tobacco-use cessation counseling services .......................................... 138

Lung cancer mortality risk associated with non-receipt of tobacco-use cessation counseling services .............................138

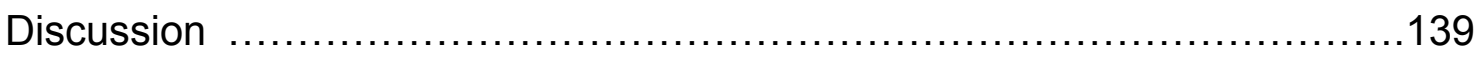

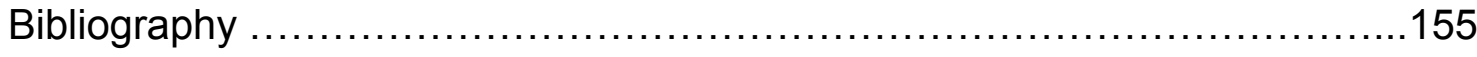

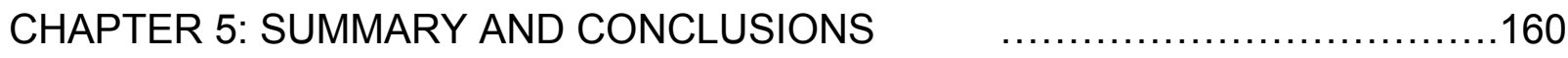

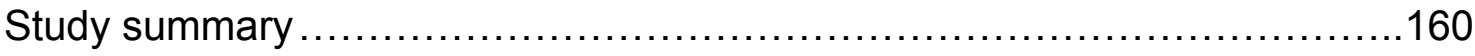

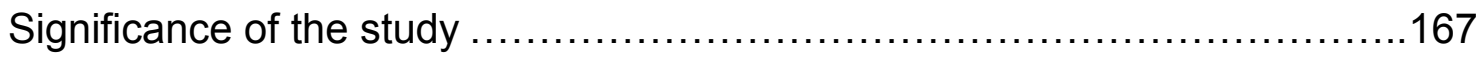

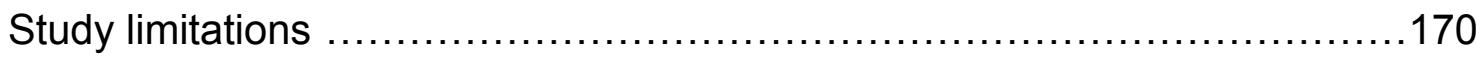

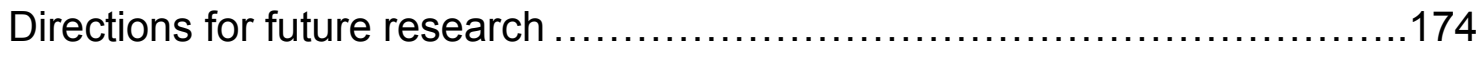

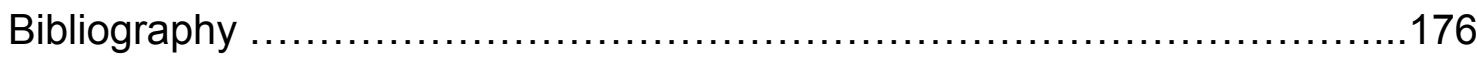

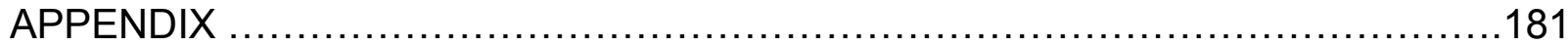

Appendix 2.1. List of International Classification of Diseases (ICD-9) diagnosis and procedure codes, Healthcare Common Procedure Coding System (HCPCS) codes, Current Procedural Terminology (CPT) codes and revenue center codes, 
used to identify lung cancer specific treatments and procedures in Medicare claim data files............................................................... 182

Appendix 3.1. List of International Classification of Diseases (ICD-9) diagnosis and procedure codes, Healthcare Common Procedure Coding System (HCPCS) codes, Current Procedural Terminology (CPT) codes, revenue center codes, and Health Care Financing Administration (HCFA) provider specialty codes, used to identify symptoms associated with lung cancer, provider specialty, and lung cancer specific treatments and procedures in Medicare claim data files 183

Appendix 4.1. List of International Classification of Diseases (ICD-9) diagnosis and procedure codes, Healthcare Common Procedure Coding System (HCPCS) codes, Current Procedural Terminology (CPT) codes and revenue center codes, used to identify lung cancer specific treatments, procedures, and other health

care services in Medicare claim data files.... 


\section{LIST OF TABLES}

Table 2.1. Descriptive characteristics of continuously enrolled Medicare Fee-for-service beneficiaries with incident diagnosis of lung cancer in West Virginia and in the United States, July 2003 through December 2006.................... 56

Table 2.2. Descriptive characteristics by type of treatment among continuously enrolled Medicare Fee-for-service beneficiaries with incident diagnosis of lung cancer in West Virginia and in the United States, July 2003 through

December 2006.

Table 2.3. Descriptive characteristics by receipt of minimally appropriate clinical guideline based lung cancer care among continuously enrolled Medicare Fee-for-service beneficiaries with incident diagnosis of lung cancer (Stages I-III) in West Virginia and in the United States, July 2003 through December 2006.

Table 2.4. Minimally appropriate clinical guideline based lung cancer care by cancer type and stage, among continuously enrolled Medicare Fee-for-service beneficiaries with incident diagnosis of lung cancer (Stages I-III) in West Virginia and in the United States, July 2003 through December 2006

Table 2.5. Factors associated with receipt of minimally appropriate clinical guideline based lung cancer care among continuously enrolled Medicare Fee-forservice beneficiaries with incident diagnosis of lung cancer (Stages I-III) in West Virginia and in the United States, July 2003 through December 2006.

Table 2.6. Three-year median survival time and survival rate by cancer type and stage, and by receipt of minimally appropriate clinical guideline based lung cancer care, among continuously enrolled Medicare Fee-for-service beneficiaries with incident diagnosis of lung cancer (Stages I-III) in West Virginia and in the United States, July 2003 through December 2004

Table 2.7. Lung cancer mortality risk associated with non-receipt of minimally appropriate clinical guideline based lung cancer care, among continuously enrolled Medicare Fee-for-service beneficiaries with incident diagnosis of lung cancer (Stages I-III) in West Virginia and in the United States, July 2003 through December 2004

Table 3.1. Descriptive characteristics of continuously enrolled Medicare Fee-for-service beneficiaries with incident diagnosis of lung cancer in West Virginia and in the United States from 2003 through 2006. 
Table 3.2. Earliest symptoms reported among continuously enrolled Medicare Fee-forservice beneficiaries with incident diagnosis of lung cancer in West Virginia and in the United States from 2003 through 2006

Table 3.3. Delays in diagnosis and treatment among continuously enrolled Medicare Fee-for-service beneficiaries with incident diagnosis of lung cancer in West Virginia and in the United States from 2003 through 2006

Table 3.4. Delays (in days) in diagnosis and treatment in relation to clinical characteristics among continuously enrolled Medicare Fee-for-service beneficiaries with incident diagnosis of lung cancer in West Virginia and in

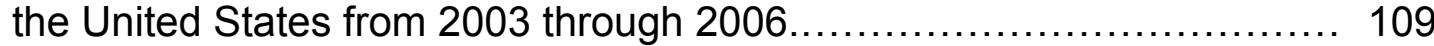

Table 3.5. Descriptive characteristics by receipt of timely lung cancer care, based on clinical opinion-based guidelines, among continuously enrolled Medicare Fee-for-service beneficiaries with incident diagnosis of lung cancer in West Virginia and in the United States from 2003 through 2006................ 111

Table 3.6. Factors associated with receipt of timely lung cancer care, based on clinical opinion-based guidelines, among continuously enrolled Medicare Fee-forservice beneficiaries with incident diagnosis of lung cancer in West Virginia and in the United States from 2003 through 2006

Table 3.7. Three-year median survival time and survival rate by cancer type, and by receipt of timely lung cancer care, based on clinical opinion-based guidelines, among continuously enrolled Medicare Fee-for-service beneficiaries with incident diagnosis of lung cancer in West Virginia and in the United States from 2003 through 2004.

Table 3.8. Lung cancer mortality risk associated with receipt of non-timely lung cancer care, based on clinical opinion-based guidelines, among continuously enrolled Medicare Fee-for-service beneficiaries with incident diagnosis of lung cancer in West Virginia and in the United States from 2003 through

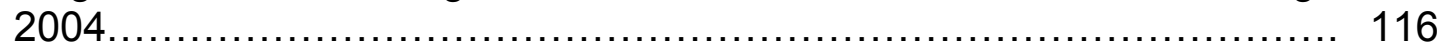

Table 3.9. Adjusted lung cancer mortality risk associated with receipt of non-timely lung cancer care, based on clinical opinion-based guidelines, by cancer type and stage, among continuously enrolled Medicare Fee-for-service beneficiaries with incident diagnosis of lung cancer in West Virginia and in the United States from 2003 through 2004

Table 4.1. Descriptive characteristics of continuously enrolled Medicare Fee-for-service beneficiaries with an incident diagnosis of lung cancer and with a history of tobacco use in West Virginia, July 2005 through October 2007 
Table 4.2. Descriptive characteristics by receipt of tobacco-use cessation counseling services, among continuously enrolled Medicare Fee-for-service beneficiaries with an incident diagnosis of lung cancer and with a history of tobacco use in West Virginia, July 2005 through October 2007

Table 4.3. Factors associated with receipt of tobacco-use cessation counseling services among continuously enrolled Medicare Fee-for-service beneficiaries with an incident diagnosis of lung cancer and with a history of tobacco use in West Virginia, July 2005 through October 2007

Table 4.4. Lung cancer mortality risk associated with non-receipt of tobacco cessation counseling services among continuously enrolled Medicare Fee-for-service beneficiaries with an incident diagnosis of lung cancer (Stages I-IV) and with a history of tobacco use in West Virginia, July 2005 through December 2005 


\section{LIST OF FIGURES}

Figure 2.1. Algorithm adapted from American College of Chest Physicians (ACCP) evidence-based guidelines for diagnosis and management of lung cancer published in January, 2003, and used to determine receipt of minimally appropriate clinical guideline based lung cancer care.....

Figure 2.2. Kaplan-Meier survival estimates with $95 \%$ confidence limits by receipt of minimally appropriate clinical guideline based lung cancer care among continuously enrolled Medicare Fee-for-service beneficiaries with incident diagnosis of lung cancer (Stages I-III) in West Virginia and in the United States, July 2003 through December 2004. Curves (unadjusted) show cause-specific mortality

Figure 3.1. Kaplan-Meier survival curves by cancer stage, and by receipt of timely lung cancer care, based on clinical opinion-based guidelines, among continuously enrolled Medicare Fee-for-service beneficiaries with incident diagnosis of lung cancer in West Virginia and in the United States from 2003 through 2004. Curves (unadjusted) show cause-specific mortality........ 104

Figure 4.1. Algorithm adapted from American College of Chest Physicians (ACCP) evidence-based guidelines for diagnosis and management of lung cancer published in January, 2003, and used to determine receipt of minimally appropriate clinical guideline based lung cancer care...................... 146

Figure 4.2. Kaplan-Meier survival curves (with $95 \%$ confidence limits) by receipt of tobacco-use cessation counseling services among continuously enrolled Medicare Fee-for-service beneficiaries with an incident diagnosis of lung cancer (Stages I-IV) and with a history of tobacco use in West Virginia, July 2005 through December 2005. Curves (unadjusted) show cause-specific mortality. 
CHAPTER 1 


\section{CHAPTER 1:}

\section{INTRODUCTION}

\section{Overview of Lung Cancer}

Lung cancer is the cancer that starts in the lungs. In the United States (US), lung cancer is the second most diagnosed cancer in both men and women. During 2012, an estimated 226,160 new cases of lung cancer were expected to be diagnosed, representing about $14 \%$ of all cancer diagnoses. ${ }^{1}$ The elderly carry a disproportionate burden of lung cancer, as approximately $81 \%$ of those living with lung cancer are 60 years of age or older. ${ }^{2}$ This pattern is expected to persist as the estimated number of elderly in the US doubles to nearly 70 million by 2030 . Based on cell histology, there are two main types of lung cancer: (1) Non-small cell lung cancer, and (2) Small cell lung cancer. Non-small cell lung cancer (NSCLC) is the most common type of lung cancer, and it makes up about $80 \%$ of all lung cancer cases. ${ }^{3}$ It usually grows and spreads more slowly than Small cell lung cancer (SCLC).

In the US, lung cancer is also the leading cause of cancer deaths in both men and women. ${ }^{1 ; 2}$ It causes more deaths than the next three most common cancers combined (colon, breast, and prostate). ${ }^{1 ; 2 ; 4}$ In women, the deaths from lung cancer surpassed those due to breast cancer in $1987 .{ }^{2}$ In men, approximately $31 \%$ of cancer deaths are attributable to lung cancer. The number of deaths due to lung cancer has increased approximately 4.3\% between 1999 and 2008, from 152,156 to 158,656 . $^{5}$ While the number of deaths among men has reached a plateau, the number is still rising among women. ${ }^{5}$ The age-adjusted death rate for lung cancer is higher for men (63.6 
per 100,000$)$ than for women $(39.0$ per 100,000$)$. It is also higher for Blacks (53.4 per $100,000)$ as compared to Whites $(50.2$ per 100,000$)$. While Black men have a far higher age-adjusted lung cancer death rate than White men, Black and White women have similar rates. ${ }^{1 ; 2}$

Substantial geographic variation in lung cancer incidence and mortality rates has also been observed in the US. In 2009, Kentucky (KY) followed by West Virginia (WV) had the highest age-adjusted lung cancer incidence rate (KY: 96.9 per 100,000, WV: 82.7 per 100,000$)$, and mortality rate (KY: 69.0 per 100,000, WV: 67.0 per 100,000). ${ }^{6}$ These state-specific rates were parallel to smoking prevalence rates, and are much higher than the average US lung cancer incidence and mortality rates (64.3 per 100,000 and 48.5 per 100,000 , respectively). ${ }^{6}$ Utah had the lowest age-adjusted lung cancer incidence and mortality rates (28.1 per 100,000 and 20.4 per 100,000 , respectively). ${ }^{6}$

\section{Etiology of lung cancer}

A single etiologic agent, cigarette smoking, is by far the leading cause of lung cancer, and it accounts for approximately $90 \%$ of lung cancer cases in the US. ${ }^{7}$ The causal association of cigarette smoking with lung cancer is one of the most thoroughly documented causal relationships in biomedical literature. ${ }^{8 ; 9}$ Compared to never smokers, smokers have an approximately 20 times increased lung cancer risk. The risk of lung cancer among cigarette smokers increases with the duration of smoking and the number of cigarettes smoked per day. ${ }^{10}$ While trends in lung cancer occurrence closely reflect patterns of smoking, the rates of occurrence lag smoking rates by about 20 years. 
While the predominant cause of lung cancer is now well-known, there are other causes as well. They include exposure to radon, arsenic, asbestos, chromates, chloromethyl ethers, nickel, polycyclic aromatic hydrocarbons, and other carcinogenic agents. ${ }^{3}$ Outdoor air pollution, which includes combustion generated carcinogens, is also considered to contribute to lung cancer risk in an urban population. ${ }^{3}$ Some of these risk factors can also act in concert with smoking to synergistically increase risk of lung cancer.

\section{Prevention of lung cancer}

There are many interventions that might be considered as strategies for reducing lungspecific cancer risks including smoking prevention and cessation, lifestyle as well as dietary or nutritional changes, and effective screening of identified high-risk individuals among others. Of these strategies, only smoking prevention and cessation has been shown to reduce lung cancer risk. ${ }^{11}$ Research has shown a close association between national mortality rates and smoking. ${ }^{12}$ Prevention approaches that delay the age of onset of smoking in a population could have a substantial impact on the incidence of lung cancer by shortening the duration of smoking. Furthermore, smoking cessation has shown to reduce the risk of lung cancer, regardless of sex, and type of tobacco smoked. ${ }^{13}$

\section{Screening for lung cancer}

Similar to any other cancer, if lung cancer is diagnosed at an early stage, the treatment options and survival benefits are better compared to that of late stage cancer. 
Therefore, it makes sense to have screening tests that can increase the rate of detection at an early stage. Chest X-rays (CXR), sputum cytology and Low-Dose computed tomography (LDCT) are the commonly used non-invasive diagnostic tests for lung cancer screening. Prior studies assessing the utility of these non-invasive tests for lung cancer screening purposes in asymptomatic individuals have shown mixed results. ${ }^{14 ; 15}$

While, conventional CXR detect tumors about 1 to $2 \mathrm{~cm}$ (0.4 to 0.8 inches) in size, computed tomography (CT) is very sensitive, and is capable of routinely detecting nodules as small as 2 to $3 \mathrm{~mm}$ in size. Previous screening studies have shown that, screening increases the rate of detection of early-stage lung cancer, but it fails to reduce the number of late-stage lung cancers or the risk for dying from lung cancer. ${ }^{16-18}$ This is because screening detects a large number of small, slowly growing, less aggressive lung cancers that are unlikely to progress to a point that they cause clinical disease while missing cancers that advance rapidly and cause the majority of deaths from lung cancer. Currently, no clinical evidence-based guidelines support the use of any test for screening purposes in the general population. However, the evidence is changing, especially with results from the National Lung Screening Trial, ${ }^{14}$ and as new data become available, the guidelines may be updated. The National Lung Screening Trial was a randomized national trial involving more than 53,000 current and former heavy smokers ages 55 to 74 , which compared the effects of two screening procedures for lung cancer: low-dose helical CT; and CXR, on lung cancer mortality. This study was designed to have a $90 \%$ power to detect a mortality reduction of $20 \%$ by 2009 . The initial results show 20 percent fewer lung cancer deaths among trial participants 
screened with low-dose helical CT compared to those screened with CXR. In addition, deaths from all-causes (including lung cancer) were $7 \%$ lower among those who received the low-dose helical CT scans. In light of these findings, screening with lowdose spiral CT scans has been recommended for individuals at an increased risk of lung cancer by the American College of Chest Physicians (ACCP) and the American Society of Clinical Oncology (ASCO). ${ }^{19}$

\section{Diagnosis and staging of lung cancer}

A majority (90\%) of patients with lung cancer are symptomatic at presentation. The symptoms may be due to: (1) Primary tumor, example: cough, dyspnea, chest pain, and hemoptysis; (2) Intrathoracic spread of lung cancer, example: recurrent laryngeal nerve palsy, phenic nerve paralysis, and Horner syndrome; (3) Extrathoracic metastases, example: bone pain, and weight loss; and/or (4) Paraneoplastic syndromes related to malignant disease, example: hypercalcemia, and Cushing syndrome. The diagnosis is usually suspected following an abnormality on the chest radiograph. All patients suspected of lung cancer undergo a thorough medical history, physical examination, and standard laboratory tests, as a screen for metastatic disease.

The basis for staging lung cancer is the American Joint Committee on Cancer (AJCC), TNM (Tumor, Node, and Metastasis) system. ${ }^{20 ; 21}$ Correctly staging lung cancer is extremely important because the prognoses differ significantly by stage. Several noninvasive imaging studies are available to aid in identifying the disease, both within and outside of the chest. They include chest CT scanning, and whole-body positron emission tomography (PET) scanning. ${ }^{22}$ In cases where noninvasive radiographic 
staging is not reliable, invasive staging procedures are sometimes used to confirm the stage and diagnosis. These invasive staging tests include mediastinoscopy, thoracoscopy (video-assisted thoracoscopic surgery), transbronchial needle aspiration (TBNA), transthoracic needle aspiration (TTNA), and endoscopic ultrasound with fine needle aspiration (EUS-NA) ${ }^{23}$

\section{Treatment of lung cancer}

Lung cancer treatment options primarily depend on the type of cancer and the stage at diagnosis. The treatment options for early stage NSCLC (Stage I-III), include surgery, chemotherapy, radiation, or its combination. ${ }^{24}$ Surgical treatment options include lobectomy (removal of a lobe of the lung), segmentectomy (removal of an anatomic division of a particular lobe of the lung), pnemonectomy (removal of an entire lung), and wedge resection. Five year survival rates of approximately $40 \%$ are anticipated with standard surgical resection. ${ }^{25}$ Unfortunately, only a few NSCLC patients are diagnosed at an early stage, and approximately $70 \%$ of all NSCLS patients present with advanced stage III and IV disease. ${ }^{25}$ Treatment options for advanced stage NSCLC patients (Stage IV) are limited and include chemotherapy, radiation therapy or its combination for palliation of symptoms. ${ }^{24}$ The median survival times are typically 6 to 10 months and most patients die within 1 to 2 years of diagnosis. ${ }^{25}$

Small cell lung cancer without treatment has the most aggressive clinical course with median survival from diagnosis of only 2 to 4 months. ${ }^{26 ; 27}$ Approximately $30 \%$ of patients with SCLC present with limited-stage disease (Stage I-III) and their treatment options include chemotherapy and radiation therapy. ${ }^{26}$ Median survival of 16 to 24 
months and 5 -year survivals of $14 \%$ with current forms of treatment have been reported in this group. ${ }^{26}$ However, in SCLC patients with extensive-stage disease (Stage IV), median survival of only 6 to 12 months has been reported. ${ }^{26}$

Healthcare utilization and costs associated with lung cancer The economic burden of lung cancer in the US is significant. The National Institutes of Health estimates that approximately $\$ 10.3$ billion per year is spent in the US on lung cancer treatment alone. ${ }^{28}$ Compared to patients without cancer, patients with lung cancer have greater health care service utilization and costs for hospitalization, emergency room visits, outpatient office visits, radiology procedures, laboratory procedures and pharmacy-dispensed drugs. The main cost drivers found in one study were hospitalization (49.0\% of costs) and outpatient office visits $\left(35.2 \%\right.$ of costs) ${ }^{29}$ In the same study, monthly initial treatment phase costs $(\$ 11,496$ per patient) were higher than costs during the secondary treatment phase $(\$ 3,733)$ or terminal care phase $(\$ 9,399) .{ }^{29}$ Over the course of the 2-year study period, patients had total costs of $\$ 120,650$, compared with $\$ 45,953$ for those receiving initial treatment only. ${ }^{29}$ Strategies for increased prevention, reduced hospitalizations, and reduced treatment failure are much needed, which may help reduce both resource use and healthcare costs.

\section{Evidence Based Lung Cancer Care}

Significant improvements have been made during the past decade in treatment and survival after the diagnosis of cancer. ${ }^{30}$ Substantial disparities still exist in both cancer outcomes and the receipt of guideline-based cancer-related health care. ${ }^{31}$ Lack of 
timely and high quality cancer care is still a concern, ${ }^{32 ; 33}$ reflecting the extensively documented similar concern about the quality of US health care in general. ${ }^{34 ; 35} \operatorname{In} 1999$, the National Cancer Policy Board of the Institute of Medicine (IOM) released a report entitled, "Ensuring Quality Cancer Care", stating that many cancer patients might not be receiving the most effective care for their conditions. ${ }^{32}$ This might be attributable to variations in the use of appropriate standards of care and the resulting treatment variations. ${ }^{32}$

\section{Appropriateness of care}

To ensure uniformity of care, clinical guidelines, or statements of evidence for the management and treatment of lung cancer, have been issued by the American College of Chest Physicians (ACCP), the American Society for Clinical Oncology (ASCO), the National Cancer Institute ( $\mathrm{NCl}$ ), and others. ${ }^{36-40}$ Clinical practice guidelines are defined as "systematically developed statements to assist practitioner and patient decisions about appropriate health care for specific clinical circumstances." ${ }^{41}$ They are thought to be capable of improving quality, appropriateness, and cost-effectiveness of care. ${ }^{41}$

\section{Timeliness of care}

Timeliness of care is another important dimension of cancer care quality. As, lung cancer care requires complex coordination of services by different health care professionals, the traditional approach of referring patients for consultation with multiple specialists in a sequential fashion often results in care that is perceived as slow and poorly coordinated. More diagnostic and treatment options are now available in the 
outpatient settings resulting in fewer inpatient hospital stays. ${ }^{42}$ Clinical opinion-based guidelines have been published by the British Thoracic Society (BTS), the RAND Corporation, and the ACCP to establish standards for timely care for lung cancer patients. ${ }^{43-45}$

\section{Preventive care}

Clinical practice guidelines for preventive care in lung cancer have been published by ASCO, authors Biesalski et al, Cancer Guidance Group (CGG), College des Medecins du Quebec, National Cancer Institute (NCl), US Department of Health and Human Services (DHHS), and US Preventive Services Task Force. ${ }^{46-51}$ Smoking cessation is strongly encouraged among lung cancer patients in these guidelines, as it may reduce the rate of development of metachronous tumors. Continued smoking is also known to interfere with cancer treatment.

\section{Disparities in Lung Cancer Care and Health Outcomes}

Despite the availability of clinical practice guidelines, numerous studies of clinical practice patterns in US have documented variations in the management of lung cancer patients according to age, race or ethnicity, education, comorbidity, insurance and hospital type. ${ }^{52-58}$ Most of these studies include the elderly population aged 65 years and older. ${ }^{52-54 ; 56 ; 58}$ In their analysis of Surveillance, Epidemiology, and End Results (SEER)-Medicare linked dataset, Bach and colleagues $(1999)^{56}$ reported that lower survival rates among black patients with early-stage NSCLC, as compared to white patients is largely explained by lower rates of surgical treatment among blacks. 
Similarly, likelihood of undergoing surgical resection was also found lower among dually (Medicare-Medicaid) eligible patients with NSCLC compared to Medicare eligible patients. ${ }^{52}$ Wide variation in the utilization of palliative chemotherapy also exists among SEER-Medicare patients diagnosed with stage IV NSCLC. ${ }^{55}$ While overall use of recommended therapies for NSCLC is low in the elderly, large variations exist in the use of therapies according to age, race and ethnicity, and marital status. ${ }^{53}$

Extensive studies in European Union member countries have found delays in diagnosis and treatment of lung cancer than recommended in clinical opinion based guidelines. ${ }^{59-73}$ Five studies performed in the US have show mixed results. ${ }^{74-78}$ This included one large study from Hawaii, ${ }^{76}$ one small study from Massachusetts ${ }^{78}$ and three small studies conducted in Veterans Affairs (VA) facilities. ${ }^{74 ; 75 ; 77}$ In one of these studies, Dransfield and colleagues $(2006)^{75}$ found median time to resection among NSCLC patients (104 days) exceed the 56-day maximum recommended by BTS. In contrast, Riedel and colleagues $(2006)^{74}$ found less than expected median time to treatment initiation (22 days), while evaluating the benefits of multidisciplinary thoracic oncology clinics in a VA setting. In the study from Massachusetts, no differences in time to treatment were observed between Asian immigrants compared to non-Asians. ${ }^{78}$ Multidisciplinary clinics have been recommended in the literature to improve timeliness of care. ${ }^{45}$ However in the US, patient care coordination through a dedicated lung mass clinic or a multidisciplinary clinic has not shown any reduction in delays with either approach. ${ }^{74 ; 75}$ Even with timely care, Quarterman and colleagues $(2003)^{77}$ found no benefits in survival, making it unclear whether more timely care improves health outcomes. Delay in treatment also did not explain the observed higher mortality risk 
from NSCLC in the only large population based study from Hawaii. ${ }^{76}$ While no US study has identified the predictors of timely care, studies in other countries have found atypical symptoms, comorbid conditions, teaching hospital setting, receipt of curative (versus palliative) radiotherapy, initial referral to a non-respiratory physician, requirement for multiple diagnostic tests, and care received at more than one health care facility, to be associated with less timely care ${ }^{63 ; 66 ; 79-82}$ Household income, ${ }^{66 ; 80}$ gender, ${ }^{80}$ hospital volume ${ }^{80}$ rural residence ${ }^{80}$ and distance travelled to obtain care ${ }^{66}$ were not associated with timeliness in these studies. Mixed results were observed in studies that examined effect of age on timeliness of care. ${ }^{63 ; 79-81}$

Given the fact that smoking is common in patients with lung cancer, there is a profound impact of preventive care services such as smoking cessation counseling. Gritz and colleagues studied smoking behavior in 840 adults with stage I NSCLC who had participated in clinical trials. ${ }^{83}$ They found that at the time of diagnosis, of the $60 \%$ of the patients who were smokers only $40 \%$ had quit smoking after 2 years. ${ }^{83}$ Richardson et al found that the relative risk of developing a second lung cancer following curative-intent therapy for SCLC was lower for those who had stopped smoking. ${ }^{84}$ Tucker and colleagues found that continuing to smoke increased the risk of metachronous lung cancers in SCLC survivors. ${ }^{85}$

\section{Geographic Variation}

A significant reduction in lung cancer mortality can be achieved if patients receive timely and medically effective therapies. Unfortunately, many rural areas of the US are economically underdeveloped and medically underserved. ${ }^{86 ; 87}$ The patients in these 
regions carry a higher burden of lung cancer compared to their urban counterparts. ${ }^{88}$ These rural areas are also known to report a higher prevalence of lung cancer and a higher crude all-cause mortality rate. ${ }^{89}$ One such area is the Appalachian region, a population representing $8.1 \%$ of the total US population. ${ }^{90 ; 91}$ Forty-two percent of the Appalachian population live in rural areas, compared to $20 \%$ of the national population. ${ }^{91}$ The lung cancer death rate in rural Appalachia is higher than all of Appalachia, and it is significantly higher than the national lung cancer death rate. ${ }^{90}$ The observed lung cancer disparities in this rural population can be attributed to limited access to quality medical care facilities, less access to or utilization of early cancer detection programs, increased prevalence of behavioral risk factors like tobacco use and sedentary life style, obesity, radon exposure, and socioeconomic factors, such as low income and education. ${ }^{92-98}$ In addition to being medically underserved, this rural population also experiences variations in the quality, availability, and accessibility of services when compared to their urban counterparts. ${ }^{99}$

West Virginia is the only state situated entirely within the Appalachian region and is the third most rural state in the nation. Fifty of the 55 counties in the state are designated as medically underserved areas, and all or part of 40 counties in the state are classified as health professional shortage areas. ${ }^{100}$ During 2002-2006, the ageadjusted lung cancer incidence rate (WV: 481.5 per 100,000, US: 378.5 per 100,000), and mortality rate (WV: 390.6 per 100,000, US: 310.8 per 100,000) among the elderly were higher in the state in comparison to the rest of the country. ${ }^{101 ; 102}$ 


\section{Study Need}

I. Need to compare the appropriateness of lung cancer care and associated health outcomes among elderly in West Virginia and in the United States

While numerous studies have examined lung cancer treatment variations in the US, comprehensive evaluation of variations in clinical guideline based lung cancer care and its impact on health outcomes in the elderly, remains unknown. Furthermore, a majority of studies completed to-date have been conducted using the SEER-Medicare data, a dataset that represents only 17 cancer registries and states/regions, and which reflects a population that is more likely to reside in urban settings. ${ }^{103}$ Limited information is currently available with respect to the variation in cancer care among elderly diagnosed with lung cancer from rural settings and from non-SEER states. Population-based cancer research aimed at identifying such variation in cancer care and improving cancer outcomes in the rural and medically underserved elderly population is much needed. Such studies would also help to explain the observed geographic disparities in lung cancer mortality among elderly.

Chapter 2 in this study assesses the appropriateness of lung cancer care and associated health outcomes among elderly Medicare Fee-for-service (FFS) beneficiaries in WV, and in a representative US population. Appropriateness of care was determined using the comprehensive ACCP clinical practice guidelines for lung cancer care. ${ }^{37}$ West Virginia is representative of Appalachia and is similar to many other rural and medically underserved states. It therefore serves as an excellent laboratory for studying and addressing lung cancer disparities in a rural and medically underserved elderly population. As lung cancer is most common in the elderly, 
Medicare administrative claims data were used to determine health service utilization. Medicare is the federally funded program that provides health insurance for more than 47 million people, including nearly all persons age 65 years and older. Cancer registry data were also used to identify disease characteristics of lung cancer patients. This chapter provides a thorough evaluation of appropriateness of lung cancer care and its impact on health outcomes among the elderly in the WV and US populations. Specifically the objectives of this study include: (1) to compare treatment patterns among elderly with lung cancer in the WV-US populations; (2) to compare the proportion of elderly receiving minimally appropriate clinical guideline based lung cancer care in the WV-US populations; (3) to compare the factors associated with receipt of minimally appropriate clinical guideline based lung cancer care in the WV-US elderly populations; (4) to compare the survival benefits associated with receipt of minimally appropriate clinical guideline based lung cancer care in the WV-US elderly populations; and (5) to compare lung cancer mortality risk associated with non-receipt of minimally appropriate clinical guideline based lung cancer care, in the WV-US elderly populations.

II. Need to compare the timeliness of lung cancer care and associated health outcomes among elderly in West Virginia and in the United States Improving timeliness of lung cancer care is important, regardless of its effect on heath outcomes. Although prior studies have provided useful information concerning the timeliness of care in lung cancer patients, a majority of them have been conduced on European Union member countries. This limits the conclusion that one can make about lung cancer care in non-European Union healthcare settings. Studies performed in the 
US are also limited by small sample sizes, with the exception of the study from Hawaii that included more that 1000 patients. As lung cancer is most often diagnosed among the elderly, studies that describe timeliness of care in the US elderly population are required. Furthermore, given that many rural areas of the US are economically underdeveloped and medically underserved, studies that compare the timeliness of lung cancer care in such states within the US are required. Such studies would also help to explain the observed geographic disparities in lung cancer mortality among elderly.

Chapter 3 assesses the timeliness of lung cancer care and associated health outcomes among elderly Medicare FFS beneficiaries in WV, and in a representative US population. Timeliness of care was determined using the BTS, and the RAND Corporation clinical opinion-based guidelines for lung cancer care. ${ }^{44 ; 45}$ West Virginia was again chosen as a representative of other rural and medically underserved states. Medicare administrative claims data and cancer registry data were used to identify timeliness of lung cancer care in elderly patients. This chapter provides a thorough evaluation of timeliness of lung cancer care and its impact on health outcomes among elderly in the WV and US populations. Specifically, the objectives of this study include: (1) to compare delays in diagnosis and treatment among elderly with lung cancer in the WV-US populations; (2) to compare the proportion of elderly receiving timely lung cancer care based on clinical opinion-based guidelines in the WV-US populations; (3) to compare the factors associated with receipt of timely lung cancer care based on clinical opinion-based guidelines in the WV-US elderly populations; (4) to compare survival outcomes by receipt of timely lung cancer care based on clinical opinion-based guidelines in the WV-US elderly populations; and (5) to compare lung cancer mortality 
risk associated with non-receipt of timely lung cancer care based on clinical opinionbased guidelines in the WV-US elderly populations.

III. Need to assess patterns of receipt of tobacco-use cessation counseling services and the impact on health outcomes among elderly lung cancer patients with a history of tobacco use in West Virginia

Continued smoking following lung cancer diagnosis can interfere with cancer therapies, such as radiation therapy and chemotherapy; increase risk of infection due to surgery and decrease post-operative wound healing; and, increase the rate of development of metachronous tumors. Promoting smoking cessation following lung cancer diagnosis is much needed. Many insurance programs including Medicare, cover tobacco-use cessation counseling services to promote smoking cessation. Still a majority of patients continue to use tobacco following lung cancer diagnosis. Studies that identify patterns of receipt of tobacco-use cessation counseling service and the impact on health outcomes among elderly lung cancer patients are needed.

Chapter 4 in this study determines the patterns of receipt of tobacco-use cessation counseling services and the impact on health outcomes among elderly Medicare FFS beneficiaries with lung cancer and a history of tobacco use in WV. West Virginia was again chosen for this study, as it has the highest smoking prevalence rate $(26.8 \%)$ in the nation. ${ }^{104}$ Lung cancer incidence and mortality rates in WV are also higher than the US, and these rates are parallel to smoking prevalence rates within the state. ${ }^{101 ; 102}$ Therefore, West Virginia serves as an excellent laboratory for studying the patterns of receipt of tobacco-use cessation counseling services and the impact on 
health outcomes among elderly lung cancer patients with a history of tobacco use. Medicare administrative claims data and cancer registry data were used to identify receipt of tobacco-use cessation counseling services. Specifically, the objectives of this study include: (1) to determine the proportion of elderly lung cancer patients receiving tobacco-use cessation counseling services; (2) to determine the factors associated with receipt of tobacco-use cessation counseling services among elderly lung cancer patients; (3) to determine survival benefits associated with receipt of tobacco-use cessation counseling services among elderly lung cancer patients; and (4) to determine lung cancer mortality risk associated with non-receipt of tobacco-use cessation counseling services among elderly lung cancer patients.

\section{Significance of the study}

This study aims to provide in-depth information concerning patterns of lung cancer care and associated health outcomes among elderly Medicare FFS beneficiaries in the WV and US populations. First, appropriateness of lung cancer care is determined among elderly in the WV and US populations using ACCP evidence-based guidelines for diagnosis and management of lung cancer. These data enable us to understand the variation in receipt of minimal appropriate lung cancer care among the elderly. It also helps us understand the impact of receipt of minimal appropriate care on health outcomes. Second, the study identifies the delays in lung cancer care and the proportion of elderly that do receive timely lung cancer care based on BTS and RAND Corporation clinical opinion-based guidelines. It also helps us to understand the impact of delayed care on health outcomes. Finally, the study determines the patterns of 
receipt of tobacco-use cessation counseling service among elderly lung cancer patients with a history of tobacco use in WV. Overall, this study will help to fill critical gaps in clinical guidelines based lung cancer care and outcomes literature. Furthermore, the results from this study will help to explain the observed geographic disparities in lung cancer mortality among elderly in the WV and US populations. 


\section{Bibliography}

(1) American Cancer Society. Cancer Facts and Figures, 2012. Available at:http://www.cancer.org/acs/groups/content/@epidemiologysurveilance/docume nts/document/acspc-031941.pdf. Accessed on: January 15, 2013.

(2) U.S. National Institutes of Health. National Cancer Institute: SEER Cancer Statistics Review, 1973-2008. Available at: http://seer.cancer.gov/csr/1975_2009_pops09/index.html. Accessed on: January 15, 2013.

(3) Alberg AJ, Ford JG, Samet JM. Epidemiology of lung cancer: ACCP evidencebased clinical practice guidelines (2nd edition). Chest 2007; 132(3 Suppl):29S55 S.

(4) Greenlee RT, Hill-Harmon MB, Murray T et al. Cancer statistics, 2001. CA Cancer J Clin 2001; 51(1):15-36.

(5) Centers for Disease Control and Prevention. National Center for Health Statistics. National Vital Statistics Report. Deaths: Final Data for 2008. December 2011; 59(10). Available at: http://www.cdc.gov/nchs/data/nvsr/nvsr59/nvsr59_10.pdf. Accessed on: January 15, 2013.

(6) U.S. Cancer Statistics Working Group. United States Cancer Statistics: 19992009 Incidence and Mortality Web-based Report. Atlanta: U.S. Department of Health and Human Services, Centers for Disease Control and Prevention and National Cancer Institute; 2013. Available at: www.cdc.gov/uscs. Accessed on: January 15, 2013.

(7) Peto R, Lopez AD, Boreham J, et al. Mortality from smoking in developed countries 1950-2000: indrect estimates from national vital statistics. Oxford, UK: Oxford University Press, 1994.

(8) US Department of Health, and Human Services (US-DHHS). Reducing the health consequences of smoking: 25 years of progress; a report of the Surgeon General. Washington, DC: US Goverment Printing Office, 1989.

(9) Zaridze D,.Peto R Tobacco: a major international health hazard. Lyon, France: International Agency for Research on Cancer, 1986.

(10) Doll R, Peto R. Cigarette smoking and bronchial carcinoma: dose and time relationships among regular smokers and lifelong non-smokers. J Epidemiol Community Health 1978; 32(4):303-313.

(11) Dragnev KH, Stover D, Dmitrovsky E. Lung cancer prevention: the guidelines. Chest 2003; 123(1 Suppl):60S-71S. 
(12) Samet JM. Lung cancer. In: Greenwald P, Kramer BS, Weed DL, eds. Cancer prevention and control. New York, NY: Marcel Dekker, 995; 561-584.

(13) Kelley MJ, McCrory DC. Prevention of lung cancer: summary of published evidence. Chest 2003; 123(1 Suppl):50S-59S.

(14) Lung cancer trial results show mortality benefit with low-dose CT: Twenty percent fewer lung cancer deaths seen among those who were screened with low-dose spiral CT than with chest X-ray. Available at: http://www.cancer.gov/newscenter/pressreleases/2011/NLSTresultsRelease. Accessed on: January 20, 2013.

(15) Swensen SJ, Jett JR, Hartman TE et al. CT screening for lung cancer: five-year prospective experience. Radiology 2005; 235(1):259-265.

(16) Bach PB, Kelley MJ, Tate RC et al. Screening for lung cancer: a review of the current literature. Chest 2003; 123(1 Suppl):72S-82S.

(17) Kubik AK, Parkin DM, Zatloukal P. Czech Study on Lung Cancer Screening: post-trial follow-up of lung cancer deaths up to year 15 since enrollment. Cancer 2000; 89(11 Suppl):2363-2368.

(18) Marcus PM, Bergstralh EJ, Fagerstrom RM et al. Lung cancer mortality in the Mayo Lung Project: impact of extended follow-up. J Natl Cancer Inst 2000; 92(16):1308-1316.

(19) Bach PB, Mirkin JN, Oliver TK et al. Benefits and harms of CT screening for lung cancer: a systematic review. JAMA 2012; 307(22):2418-2429.

(20) Mountain CF. Revisions in the International System for Staging Lung Cancer. Chest 1997; 111(6):1710-1717.

(21) Mountain CF. A new international staging system for lung cancer. Chest 1986; 89(4 Suppl):225S-233S.

(22) Silvestri GA, Tanoue LT, Margolis ML et al. The noninvasive staging of non-small cell lung cancer: the guidelines. Chest 2003; 123(1 Suppl):147S-156S.

(23) Detterbeck FC, DeCamp MM, Jr., Kohman LJ et al. Lung cancer. Invasive staging: the guidelines. Chest 2003; 123(1 Suppl):167S-175S.

(24) National Cancer Institute: $P D Q \circledast$ Non-Small Cell Lung Cancer Treatment. Bethesda, MD: National Cancer Institute. Date last modified 11/05/2012. Available at: http://www.cancer.gov/cancertopics/pdq/treatment/non-small-celllung/healthprofessional. Accessed on January 19, 2013.

(25) Ihde DC, Minna JD. Non-small cell lung cancer. Part I: Biology, diagnosis, and staging. Curr Probl Cancer 1991; 15(2):61-104. 
(26) National Cancer Institute: PDQ® Small Cell Lung Cancer Treatment. Bethesda, MD: National Cancer Institute. Date last modified 1/20/2012. Available at: http://www.cancer.gov/cancertopics/pdq/treatment/small-celllung/healthprofessional. Accessed on January 19, 2013.

(27) National Cancer Institute: What you need to know about Lung Cancer [NIH Publication No. 07-1553]. Available at:

http://www.cancer.gov/cancertopics/wyntk/lung/page1. Accessed on: January 19, 2013.

(28) U.S. National Institutes of Health. National Cancer Institute. A Snapshot of Lung Cancer. October, 2012. Available at:

http://www.cancer.gov/researchandfunding/snapshots/pdf/Lung-Snapshot.pdf. Accessed on: January 15, 2013.

(29) Kutikova L, Bowman L, Chang S et al. The economic burden of lung cancer and the associated costs of treatment failure in the United States. Lung Cancer 2005; 50(2):143-154.

(30) Eden J, Sinone JV, eds. Assessing the Quality of Cancer Care: an Approach to Measurement in Georgia, Washington, DC: The National Academies Press; 2005.

(31) Harlan LC, Greene AL, Clegg LX et al. Insurance status and the use of guideline therapy in the treatment of selected cancers. J Clin Oncol 2005; 23(36):90799088.

(32) Hewitt M, Simone JV, eds. Ensuring the Quality of Cancer Care. Washington, DC: National Academy Press; 1999.

(33) Hewitt M, Simone JV, eds. Enhancing Data Systems to Improve the Quality of Cancer Care. Washington, DC: National Acadamy Press; 2000.

(34) McGlynn EA, Asch SM, Adams J et al. The quality of health care delivered to adults in the United States. N Engl J Med 2003; 348(26):2635-2645.

(35) Reid PP, Compton WD, Grossman JH, Fanjiang G, eds. Building a Better Delivery System: a New Engineering/Health Care Partnership. Washington, DC: The National Academies press; 2005.

(36) Pfister DG, Johnson DH, Azzoli CG et al. American Society of Clinical Oncology treatment of unresectable non-small-cell lung cancer guideline: update 2003. J Clin Oncol 2004; 22(2):330-353.

(37) Diagnosis and management of lung cancer: ACCP evidence-based guidelines. American College of Chest Physicians. Chest 2003; 123(1 Suppl):D-337S. 
(38) Clinical practice guidelines for the treatment of unresectable non-small-cell lung cancer. Adopted on May 16, 1997 by the American Society of Clinical Oncology. J Clin Oncol 1997; 15(8):2996-3018.

(39) National Comprehensive Cancer Network and American Cancer Society: Lung Cancer: Treatment Guidelines for Patients. Version 1, December 2001. Available at: http://www.nccn.org. Accessed on: January 15, 2013.

(40) National Cancer Institute: Physician Data Query Cancer Information Summaries. Available at: http://www.nci.nih.gov/cancerinfo/pdf/treatment/non-small-celllung/healthprofessional/. Accessed on: January 15, 2013.

(41) Institute of Medicine Committee to Advise the Public Health Service on Clinical Practice Guidelines. Clinial practice guidelines: directions for a new program. Field M, Lohr Kn, eds. Washington, DC: National Academy Press, 1990.

(42) Olsson JK, Schultz EM, Gould MK. Timeliness of care in patients with lung cancer: a systematic review. Thorax 2009; 64(9):749-756.

(43) Alberts WM, Bepler G, Hazelton T et al. Lung cancer. Practice organization. Chest 2003; 123(1 Suppl):332S-337S.

(44) Reifel, J. L. Lung cancer. Asch, S. M.; Kerr, E. A.; Hamilton, E. G.; Reifel, J. L., and McGlynn, E. A. Quality of care for oncologic condition and HIV: a review of the literature and quality indicators. RAND; 2000; pp. 133-71. Rec \#: 657. 2011.

(45) BTS recommendations to respiratory physicians for organising the care of patients with lung cancer. The Lung Cancer Working Party of the British Thoracic Society Standards of Care Committee. Thorax 1998; 53 Suppl 1:S1-S8.

(46) Cancer Guidence Group. Guidance on commissioning ancer services; improving outcomes in lung cancer: the manual. London, JK: National Health Service Executive, 1998.

(47) Colllege des medecins du Quebec. Clinical practice guidelines: smoking prevention and cessation; May 1999. Available at:

http://www.cmq.org/tabacang.pdf. Accessed on: August 16, 2012.

(48) National Cancer Institute. Lung cancer (PDQ): prevention; March 2001. Available at: http://www.cancer.gov/cancer_information/pdq. Accessed on: December 16,2012 .

(49) Fiore MC, Bailey WC, Cohen SJ, et al. Treating tobacco use and dependence: clinical practice guideline. Rockville, MD: US Department of Health and Human Services, Public Health Service, 2000. 
(50) US Preventive Services Task Force. Screening for lung cancer. In: Guide to clinical preventive services. 2nd ed. Baltimore, MD: Williams \& Wilkins, 1996; 135-139.

(51) Biesalski HK, Bueno de MB, Chesson A et al. Consensus statement on lung cancer. Lung Cancer Panel. Eur J Cancer Prev 1997; 6(4):316-322.

(52) Bradley CJ, Dahman B, Given CW. Treatment and survival differences in older Medicare patients with lung cancer as compared with those who are dually eligible for Medicare and Medicaid. J Clin Oncol 2008; 26(31):5067-5073.

(53) Potosky AL, Saxman S, Wallace RB et al. Population variations in the initial treatment of non-small-cell lung cancer. J Clin Oncol 2004; 22(16):3261-3268.

(54) Earle CC, Venditti LN, Neumann PJ et al. Who gets chemotherapy for metastatic lung cancer? Chest 2000; 117(5):1239-1246.

(55) Fry WA, Phillips JL, Menck HR. Ten-year survey of lung cancer treatment and survival in hospitals in the United States: a national cancer data base report. Cancer 1999; 86(9):1867-1876.

(56) Bach PB, Cramer LD, Warren JL et al. Racial differences in the treatment of early-stage lung cancer. N Engl J Med 1999; 341(16):1198-1205.

(57) Hillner BE, McDonald MK, Desch CE et al. A comparison of patterns of care of nonsmall cell lung carcinoma patients in a younger and Medigap commercially insured cohort. Cancer 1998; 83(9):1930-1937.

(58) Smith TJ, Penberthy L, Desch CE et al. Differences in initial treatment patterns and outcomes of lung cancer in the elderly. Lung Cancer 1995; 13(3):235-252.

(59) Leo F, Venissac N, Poudenx M et al. Multidisciplinary management of lung cancer: how to test its efficacy? J Thorac Oncol 2007; 2(1):69-72.

(60) Neal RD, Allgar VL, Ali N et al. Stage, survival and delays in lung, colorectal, prostate and ovarian cancer: comparison between diagnostic routes. $\mathrm{Br} \mathrm{J}$ Gen Pract 2007; 57(536):212-219.

(61) Devbhandari MP, Soon SY, Quennell P et al. UK waiting time targets in lung cancer treatment: are they achievable? Results of a prospective tracking study. J Cardiothorac Surg 2007; 2:5.

(62) Comber H, Cronin DP, Deady S et al. Delays in treatment in the cancer services: impact on cancer stage and survival. Ir Med J 2005; 98(8):238-239.

(63) Salomaa ER, Sallinen S, Hiekkanen H et al. Delays in the diagnosis and treatment of lung cancer. Chest 2005; 128(4):2282-2288. 
(64) Lewis NR, Le J, I, Baldwin DR. Under utilisation of the 2-week wait initiative for lung cancer by primary care and its effect on the urgent referral pathway. $\mathrm{Br} \mathrm{J}$ Cancer 2005; 93(8):905-908.

(65) Lee J, Marchbank A, Goldstraw P. Implementation of the British Thoracic Society recommendations for organising the care of patients with lung cancer: the surgeon's perspective. Ann R Coll Surg Engl 2002; 84(5):304-308.

(66) Campbell NC, Elliott AM, Sharp L et al. Impact of deprivation and rural residence on treatment of colorectal and lung cancer. Br J Cancer 2002; 87(6):585-590.

(67) Aragoneses FG, Moreno N, Leon P et al. Influence of delays on survival in the surgical treatment of bronchogenic carcinoma. Lung Cancer 2002; 36(1):59-63.

(68) Melling PP, Hatfield AC, Muers MF et al. Lung cancer referral patterns in the former Yorkshire region of the UK. Br J Cancer 2002; 86(1):36-42.

(69) Koyi H, Hillerdal G, Branden E. Patient's and doctors' delays in the diagnosis of chest tumors. Lung Cancer 2002; 35(1):53-57.

(70) Bozcuk H, Martin C. Does treatment delay affect survival in non-small cell lung cancer? A retrospective analysis from a single UK centre. Lung Cancer 2001; 34(2):243-252.

(71) Spurgeon P, Barwell F, Kerr D. Waiting times for cancer patients in England after general practitioners' referrals: retrospective national survey. BMJ 2000; 320(7238):838-839.

(72) Kesson E, Bucknall CE, McAlpine LG et al. Lung cancer--management and outcome in Glasgow, 1991-92. Br J Cancer 1998; 78(10):1391-1395.

(73) Christensen ED, Harvald T, Jendresen $\mathrm{M}$ et al. The impact of delayed diagnosis of lung cancer on the stage at the time of operation. Eur J Cardiothorac Surg $1997 ; 12(6): 880-884$.

(74) Riedel RF, Wang X, McCormack M et al. Impact of a multidisciplinary thoracic oncology clinic on the timeliness of care. J Thorac Oncol 2006; 1(7):692-696.

(75) Dransfield MT, Lock BJ, Garver RI, Jr. Improving the lung cancer resection rate in the US Department of Veterans Affairs Health System. Clin Lung Cancer 2006; 7(4):268-272.

(76) Liu DM, Kwee SA. Demographic, treatment, and survival patterns for Native Hawaiians with lung cancer treated at a community medical center from 1995 to 2001. Pac Health Dialog 2004; 11(2):139-145. 
(77) Quarterman RL, McMillan A, Ratcliffe MB et al. Effect of preoperative delay on prognosis for patients with early stage non-small cell lung cancer. $J$ Thorac Cardiovasc Surg 2003; 125(1):108-113.

(78) Finlay GA, Joseph B, Rodrigues CR et al. Advanced presentation of lung cancer in Asian immigrants: a case-control study. Chest 2002; 122(6):1938-1943.

(79) Bardell T, Belliveau $P$, Kong $W$ et al. Waiting times for cancer surgery in Ontario: 1984-2000. Clin Oncol (R Coll Radiol ) 2006; 18(5):401-409.

(80) Simunovic M, Theriault ME, Paszat L et al. Using administrative databases to measure waiting times for patients undergoing major cancer surgery in Ontario, 1993-2000. Can J Surg 2005; 48(2):137-142.

(81) Johnston GM, MacGarvie VL, Elliott $D$ et al. Radiotherapy wait times for patients with a diagnosis of invasive cancer, 1992-2000. Clin Invest Med 2004; 27(3):142156.

(82) Ringbaek T, Borgeskov S, Lange $\mathrm{P}$ et al. Diagnostic and therapeutic process and prognosis in suspected lung cancer. Scand Cardiovasc J 1999; 33(6):337-343.

(83) Gritz ER, Nisenbaum R, Elashoff RE et al. Smoking behavior following diagnosis in patients with stage I non-small cell lung cancer. Cancer Causes Control 1991; 2(2):105-112.

(84) Richardson GE, Tucker MA, Venzon DJ et al. Smoking cessation after successful treatment of small-cell lung cancer is associated with fewer smoking-related second primary cancers. Ann Intern Med 1993; 119(5):383-390.

(85) Tucker MA, Murray N, Shaw EG et al. Second primary cancers related to smoking and treatment of small-cell lung cancer. Lung Cancer Working Cadre. J Natl Cancer Inst 1997; 89(23):1782-1788.

(86) Behringer, B. (1994). Health care services in Appalachia. In: Couto, R. A., Simpson, N. K., and Harris, G. (eds.), Sowing Seeds in the Mountains, Community-based Coalitions for Cancer Prevention and Control. NIH Publication No. 94-3779:62-80. Bethesda, MD: NIH, National Cancer Institute.

(87) Newell-Withrow C. A glance at Appalachia. J Cult Divers 1997; 4(4):129-131.

(88) Monroe AC, Ricketts TC, Savitz LA. Cancer in rural versus urban populations: a review. J Rural Health 1992; 8(3):212-220.

(89) Ricketts, T. C. (Ed.) 1999. Rural health in the United States. New York, NY: Oxford University Press.

(90) Cancer death rates--Appalachia, 1994-1998. MMWR Morb Mortal Wkly Rep 2002; 51(24):527-529. 
(91) ARC (Appalachian Regional Commission) (2011).The Appalachian region. Available at: http://www.arc.gov/index.do?nodeld=2. Accessed on: August 24, 2012.

(92) State-specific prevalence and trends in adult cigarette smoking--United States, 1998-2007. MMWR Morb Mortal Wkly Rep 2009; 58(9):221-226.

(93) Casto BC, Sharma S, Fisher JL et al. Oral cancer in Appalachia. J Health Care Poor Underserved 2009; 20(1):274-285.

(94) Wingo PA, Howe HL, Thun MJ et al. A national framework for cancer surveillance in the United States. Cancer Causes Control 2005; 16(2):151-170.

(95) Silverstein MD, Nietert PJ, Ye X et al. Access to care and stage at diagnosis for patients with lung cancer and esophageal cancer: analysis of the Savannah River Region Information System cancer registry data. South Med J 2002; 95(8):900-908.

(96) Hall HI, Uhler RJ, Coughlin SS et al. Breast and cervical cancer screening among Appalachian women. Cancer Epidemiol Biomarkers Prev 2002; 11(1):137-142.

(97) Casey MM, Thiede CK, Klingner JM. Are rural residents less likely to obtain recommended preventive healthcare services? Am J Prev Med 2001; 21(3):182188.

(98) Wright JS, Champagne F, Dever GE et al. A comparative analysis of rural and urban mortality in Georgia, 1979. Am J Prev Med 1985; 1(1):22-29.

(99) Amey $\mathrm{CH}$, Miller MK, Albrecht SL. The role of race and residence in determining stage at diagnosis of breast cancer. J Rural Health 1997; 13(2):99-108.

(100) West Virginia Health Care Authority (WVHCA) West Virginia State Health Plan. 2010. Available at: http://www.hcawv.org/PolicyPlan/shpBmat/shpProPiper.pdf. Accessed on: September 17, 2011.

(101) United States Cancer Statistics: 1999-2006 Incidence, WONDER On-line Database. United States Department of Health and Human Services, Centers for Disease Control and Prevention and National Cancer Institute; 2010. Available at http://wonder.cdc.gov/cancer-v2006.html. Accessed on: January 15, 2013.

(102) United States Cancer Statistics: 1999-2006 Mortality, WONDER On-line Database. United States Department of Health and Human Services, Centers for Disease Control and Prevention; 2010. Available at: http://wonder.cdc.gov/CancerMort-v2006.html. Accessed on: January 15, 2013. 
(103) Warren JL, Klabunde CN, Schrag D et al. Overview of the SEER-Medicare data: content, research applications, and generalizability to the United States elderly population. Med Care 2002; 40(8 Suppl):IV-18.

(104) Vital signs: current cigarette smoking among adults aged $>/=18$ years--United States, 2005-2010. MMWR Morb Mortal Wkly Rep 2011; 60(35):1207-1212. 
CHAPTER 2 


\section{CHAPTER 2:}

APPROPRIATENESS OF LUNG CANCER CARE AND ASSOCIATED HEALTH

OUTCOMES AMONG ELDERLY MEDICARE FEE-FOR-SERVICE BENEFICIARIES IN WEST VIRGINIA AND IN THE UNITED STATES

\section{Introduction}

In the United States (US), lung cancer is the leading cause of cancer deaths in both men and women. ${ }^{1 ; 2}$ It causes more deaths than the next three most common cancers combined (colon, breast, and prostate). ${ }^{1-3}$ The elderly carry a disproportionate burden of lung cancer, since approximately $81 \%$ of those living with lung cancer are 60 years of age or older. ${ }^{2}$ This pattern is expected to persist as the estimated number of elderly in the U.S. doubles to nearly 70 million by 2030 .

Although lung cancer in the elderly is associated with a poor prognosis, several treatment strategies can cure, or at least prolong survival. These treatment options primarily depend on the type of lung cancer and the stage at diagnosis. Non-small cell lung cancer (NSCLC) is the most common type of lung cancer, and it makes up about $80 \%$ of all lung cancer cases. ${ }^{4}$ The treatment options for early stage NSCLC (Stages IIII), include surgery, chemotherapy, radiation, or its combination. ${ }^{5}$ Five year survival rates of approximately $40 \%$ are anticipated with standard surgical resection. ${ }^{6}$ Treatment options for individuals with advanced stage NSCLC (Stage IV) are limited and include chemotherapy, radiation therapy, or its combination for palliation of symptoms. ${ }^{5}$ The median survival times are typically 6 to 10 months and most individuals die within 1 to 2 years of diagnosis. ${ }^{6}$ Compared to NSCLC, small cell lung 
cancer (SCLC) grows and spreads more quickly, and without treatment has the most aggressive clinical course with median survival time from diagnosis of only 2 to 4 months. ${ }^{7 ; 8}$ Approximately $30 \%$ of individuals with SCLC present with limited-stage disease (Stages I-III) and their treatment options include chemotherapy and radiation therapy. ${ }^{8}$ Median survival time of 16 to 24 months and 5 -year survivals of $14 \%$ with current forms of treatment have been reported in this group. ${ }^{8}$ However, in individuals with extensive-stage SCLC (Stage IV), median survival time of only 6 to 12 months has been reported. ${ }^{8}$

A significant reduction in lung cancer mortality can be achieved if the elderly receive timely and medically effective therapies. To that end, specific strategies for the management and treatment of lung cancer have been recommended in clinical guidelines by the American College of Chest Physicians (ACCP), the American Society for Clinical Oncology (ASCO), the National Cancer Institute (NCI), and others. ${ }^{9-13}$ These clinical guidelines ensure uniformity of care, and are thought to be capable of improving quality, appropriateness, and cost-effectiveness of care. ${ }^{14}$ However, numerous studies of clinical practice patterns in the US have documented variations in the management of individuals with lung cancer according to age, race or ethnicity, education, comorbidity, insurance and hospital type. ${ }^{15-21}$ In one study, lower rates of surgical treatment among elderly black individuals with early-stage NSCLC, as compared to white individuals, largely explained the survival difference by race. ${ }^{19}$ In another study, the likelihood of undergoing surgical resection among elderly with NSCLC was found to be lower among dually (Medicare-Medicaid) eligible individuals compared to Medicare eligible individuals. ${ }^{15}$ Besides treatment with curative intent, 
wide variation in the utilization of palliative chemotherapy also exists among individuals diagnosed with stage IV NSCLC. ${ }^{18}$ Lack of high quality cancer care remains a concern, and it is attributable to variations in the use of appropriate standards of care. ${ }^{22-24}$

While variations in lung cancer management and outcomes exist across the nation, it is a cause for major concern in the rural areas. Many rural areas of the US are economically underdeveloped and medically underserved. ${ }^{25 ; 26}$ The elderly in these regions carry a higher burden of lung cancer compared to their urban counterparts. ${ }^{27}$ These rural areas are also known to report a higher prevalence of lung cancer and a higher crude all-cause mortality rate among the elderly. ${ }^{28 ; 29}$ One such area is the Appalachian region, a population representing $8.1 \%$ of the total US population. ${ }^{29}$ West Virginia (WV) is the only state situated entirely within the Appalachian region and is the third most rural state in the nation. ${ }^{29}$ Fifty of the 55 counties in the state are designated as medically underserved areas, and all or part of 40 counties in the state are classified as health professional shortage areas. ${ }^{30}$ During 2002-2006, the age-adjusted lung cancer incidence rate (WV: 481.5 per 100,000, US: 378.5 per 100,000), and mortality rate (WV: 390.6 per 100,000, US: 310.8 per 100,000) among the elderly were higher in the state in comparison to rest of the country. ${ }^{31 ; 32}$ Interestingly, the proportional difference in age-adjusted lung cancer mortality rates among the elderly from $\mathrm{WV}$ and the US was lower than the difference in age-adjusted lung cancer incidence rates. This might suggest better survival outcomes among elderly lung cancer patients in WV as compared to the US; however, such a hypothesis remains unexplored. The observed lung cancer disparities in the rural population can be attributed to limited access to quality medical care facilities; less access to, or utilization, of early cancer detection 
programs; increased prevalence of behavioral risk factors, such as tobacco use and sedentary life style, and socioeconomic factors, such as low income and education. ${ }^{33-39}$ In addition to being medically underserved, the rural population may also experience variations in the quality, availability, and accessibility of services when compared to urban counterparts. ${ }^{40}$

While numerous studies have examined lung cancer treatment variations in the US, comprehensive evaluation of variations in clinical guideline based lung cancer care, and its impact on health outcomes in the elderly remains unknown. Furthermore, comparison of geographical variations in clinical guideline based lung cancer care and associated health outcomes among the elderly from a diverse region like WV with those in the US is much needed. Such studies would help to explain the observed regional disparities in lung cancer mortality among the elderly. To this end, the main focus of this study is to investigate and compare the appropriateness of lung cancer care based on clinical guidelines among the elderly in WV, and in a representative US population. Specifically the objectives of this study include: (1) to compare treatment patterns among elderly with lung cancer in the WV-US populations; (2) to compare the proportion of elderly receiving minimally appropriate clinical guideline based lung cancer care in the WV-US populations; (3) to compare the factors associated with receipt of minimally appropriate clinical guideline based lung cancer care in the WV-US elderly populations; (4) to compare the survival benefits associated with receipt of minimally appropriate clinical guideline based lung cancer care in the WV-US elderly populations; and (5) to compare lung cancer mortality risk associated with non-receipt of minimally appropriate clinical guideline based lung cancer care, in the WV-US elderly populations. 


\section{Methods}

\section{Data sources}

This retrospective study was conducted using cancer registry linked Medicare data files for the years 2002 through 2007. Cancer registry data files provided clinical, demographic, cause of death, and initial treatment information for elderly individuals with lung cancer in selected geographic regions. The Medicare administrative data files provided the health service claims information for care provided by physicians, inpatient hospital stays, hospital outpatient clinics, home health care agencies, skilled nursing facilities, and hospice programs.

Specifically, the Surveillance, Epidemiology, and End Results (SEER) - Medicare linked data files were purchased from the National Cancer Institute, and were used to estimate the appropriateness of lung cancer care based on clinical guidelines in the elderly US population. Data from the SEER program are representative of US cancer incidence and mortality, as they contain information from 20 population-based cancer registries covering approximately 28 percent of the US population. ${ }^{41}$

To estimate the appropriateness of lung cancer care based on clinical guidelines in the elderly WV population, we used West Virginia Cancer Registry (WVCR) Medicare linked data files. The WVCR-Medicare linked data files are similar in structure to the SEER-Medicare linked data files, and represent data from the West Virginia Cancer Registry, which does not participate in the SEER program. Details on the creation of WVCR-Medicare linked data files can be found elsewhere. ${ }^{42}$ 


\section{Study populations}

We initially identified all Medicare Fee-for-service (FFS) beneficiaries aged 66 years and older, with incident lung cancer (Stages I-IV) diagnosis, between July 1, 2003 and December 31, 2006, from the SEER-Medicare linked data files (hereafter referred to as 'US population'), and the WVCR-Medicare linked data files (hereafter referred to as 'WV population'), separately. Lung cancer diagnosis was identified among individuals in the cancer registry files using the International Classification of Diseases for Oncology (ICD-O) codes (C34.0, C34.1, C34.2, C34.3, C34.8, C34.9, and C33.9). Lung cancer stage was identified using American Joint Committee on Cancer (AJCC), Tumor Node Metastasis (TNM), $3^{\text {rd }}$ edition stage (for 2003 diagnosis) and $6^{\text {th }}$ edition stage (for 20042006 diagnosis). ${ }^{43 ; 4}$ While Medicare eligibility starts at age 65 , we only included beneficiaries aged 66 years and older at the time of diagnosis, so that we would have a full year of Medicare claims before lung cancer diagnosis for assessing comorbidity. We then excluded individuals with multiple primary cancer diagnosis or whose diagnosis was made only at the time of death (death certificate review/autopsy diagnosis). We also excluded beneficiaries who were enrolled in a Medicare managed care plan or who had non-continuous Medicare Part A and Part B enrollment, in the year prior to diagnosis, and during the year following diagnosis. This is because their Medicare files would not have complete treatment information. The remaining cohorts of continuously enrolled elderly Medicare FFS beneficiaries in WV and the US population (study cohorts) were then used to compare treatment patterns, to compare the proportion of beneficiaries receiving minimally appropriate clinical guideline based lung cancer care, 
and to compare the factors associated with receipt of minimally appropriate clinical guideline based lung cancer care.

Given the limited years of data available for follow up in our data sources, we further subset the above study cohorts for survival analysis. Specifically, from the study cohorts we selected beneficiaries with lung cancer diagnosis between July 1, 2003 and December 31, 2004, and then followed them for three years following the incident lung cancer diagnosis to determine lung cancer specific mortality. These subsets of study cohorts in WV and the US population were then used to compare survival benefits associated with receipt of minimally appropriate clinical guideline based lung cancer care, and to compare lung cancer mortality risk associated with non-receipt of minimally appropriate clinical guideline based lung cancer care.

\section{Assessing receipt of clinical guideline based lung cancer care}

Continuously enrolled elderly Medicare FFS beneficiaries in WV and in the US population were followed for one year after an incident lung cancer diagnosis to determine receipt of minimally appropriate clinical guideline based lung cancer care (hereafter referred to as 'minimally appropriate care'). Minimally appropriate care was defined using the ACCP evidence-based guidelines for diagnosis and management of lung cancer, published in January, 2003. ${ }^{10}$ We choose ACCP evidence-based guidelines, as they are the most comprehensive of all published clinical guidelines. ${ }^{9-13}$ Figure 2.1 shows the algorithm adapted from the ACCP guidelines, and used to determine receipt of minimally appropriate care. Lung cancer specific treatments and procedures were identified from the Medicare claim data files using appropriate 
International Classification of Diseases (ICD-9) diagnosis and procedure codes, Healthcare Common Procedure Coding System (HCPCS) codes, Current Procedural Terminology (CPT) codes and revenue center codes (Appendix 1). Considering the poor quality of life following curative treatment among some individuals with stage IV lung cancer, clinical guidelines recommend 'no curative treatment' for such individuals, except for palliation of symptoms. We therefore excluded beneficiaries with stage IV lung cancer from our analysis, except for separately reporting the proportion of beneficiaries receiving minimally appropriate care with curative intent.

\section{Dependent variables}

The primary outcome of interest was receipt of minimally appropriate clinical guideline based lung cancer care, which was categorized as (a) minimally appropriate care or (b) inappropriate care. Treatment patterns were categorized as 'surgery only', 'radiation only', 'chemotherapy only', 'combination treatment', or 'no treatment'. Combination treatment included any combination of surgery, radiation, and chemotherapy. Survival time in days was calculated for each beneficiary from the time of incident lung cancer diagnosis to date of death or the three year follow-up cutoff date, which ever came first. To estimate lung cancer specific survival, beneficiaries who were not found to be deceased by the cutoff date, or who died due to causes other than lung cancer were censored at that time and considered to be alive. We measured lung cancer specific survival instead of overall survival, as we wanted to determine the association between minimally appropriate clinical guideline based lung cancer care and survival. 
While exact date of lung cancer diagnosis was available in the WVCR-Medicare linked data files to calculate survival time, the SEER-Medicare linked data files only contained the month and year of diagnosis. Hence to approximate the date of lung cancer diagnosis in the US population, we used the earliest Medicare claim date, which had a lung cancer diagnosis code, and which was in the month of lung cancer diagnosis. This approximation is appropriate given the high level of agreement (nearly $90 \%$ ) within one month of diagnosis between the SEER diagnosis date and the first Medicare claim date with a cancer diagnosis. ${ }^{45}$ In cases where beneficiaries had no Medicare claims with a lung cancer diagnosis code, earliest date from any claim in the month of cancer diagnosis was used as the date of diagnosis. Finally, among beneficiaries with no Medicare claim in the month of diagnosis, the date of diagnosis was approximated as the $15^{\text {th }}$ day of the diagnosis month. Date of death was identified from Medicare enrollment records.

\section{Independent variables}

The main independent variables were lung cancer type and stage, age at diagnosis, gender, race, urban-rural residence, Charlson comorbidity index score, and census tract level measures of education and income. These variables were considered in our analysis because of their prognostic significance. Lung cancer type was categorized based on cell histology. Beneficiaries with ICD-O histology codes $8000-8040$ or 8046 9989 were categorized as NSCLC, and those with codes 8041-8045 were categorized as SCLC. Lung cancer stage was categorized based on AJCC TNM staging

system. ${ }^{43 ; 44}$ Age at diagnosis was categorized as 66-69 years, 70-74 years, 75-79 
years, and 80 years and older. Given that WV population is predominantly White, race was classified as White and others. Based on Rural-Urban Continuum codes developed by the US Department of Agriculture (USDA), urban-rural residence was categorized as Metro, Urban, or Rural. Charlson comorbidity index score was calculated using diagnosis and procedure codes reported in Medicare inpatient claims from the year prior to incident lung cancer diagnosis. ${ }^{46-48}$ Comorbidities related to cancer were excluded from the index score. The Charlson comorbidity index score was used to categorize comorbidity into three groups: 0,1 and 2 or more, with a higher score indicating a greater burden of comorbid illness.

Given the lack of individual socioeconomic status measures in our data sources, we used as proxy, the year 2000 US Census tract level measures of college education and income. ${ }^{49}$ Specifically, we used the percentage of individuals in the census tract with some college education as a proxy measure for education, and categorized it based on tercile distribution (using WV population) as $0 \%-0.10 \%, 0.11 \%-0.20 \%$, and $0.21 \%$ or greater. Similarly, we used median household income at the census tract level as a proxy measure of income, and categorized it based on tertile distribution (using WV population) as $\$ 0-25,000, \$ 25,000-50,000$, and $\$ 50,001$ or more.

\section{Data Analysis}

The Pearson chi-square test was used to determine unadjusted associations between categorical variables of interest. Three hierarchical generalized logistic models were constructed with PROC GLIMMIX procedure in SAS $9.2^{50}$ to assess the association between independent variables and the receipt of minimally appropriate care. In each 
model, the estimated probability of a beneficiary receiving minimally appropriate care conditioned on a set of predictor variables was modeled. First and second models included beneficiaries from the WV and US populations, respectively. The third model was constructed to determine population variation in likelihood of beneficiaries receiving minimally appropriate care, and therefore included beneficiaries from both populations combined. The hierarchical model was chosen, as individual measures of socioeconomic status were not available in our data sources, and we relied on census tract level measures of education and income. This was done by treating census tract as a random effect to account for potential correlation among beneficiaries within the same county. Odds ratios, $95 \%$ confidence intervals, and two-sided p-values were calculated for each predictor.

Non-parametric estimates of the survivor function, by receipt of minimally appropriate care, were calculated for each population using the Kaplan-Meier method. The log-rank test was used to assess the statistical significance of the differences between the survival curves. Three-year survival estimates were also computed by receipt of minimally appropriate care within each population. Stratified analysis was performed by lung cancer type and stage within each population.

Three multivariate Cox proportional hazards models were constructed to estimate lung cancer mortality risk associated with non-receipt of minimally appropriate care. First and second model included beneficiaries from the WV and US populations, respectively. The third model was constructed to determine population variation in lung cancer mortality risk, and therefore included beneficiaries from both populations combined. To evaluate the proportional hazards assumption, we plotted smoothed 
Schoenfeld residuals against time and found no evidence of a systematic deviation from proportional hazards in any model. Variance in all Cox models were adjusted to account for patient clustering at the census tract level by use of the robust inference of

Lin and Wei. ${ }^{51}$ Adjusted hazard ratios, 95\% confidence intervals and their two-sided pvalues were calculated for each predictor.

All data were analyzed using the SAS Version 9.2 (SAS Institute, Cary, NC) statistical software package. ${ }^{50}$ Results were considered to be statistically significant when $p \leq 0.05$. The study was approved by the West Virginia Institutional Review Board, and is in full compliance with federal, state, and institutional regulations and guidelines.

\section{Results}

Study population characteristics

Based on study inclusion and exclusion criteria, we identified 1,689 beneficiaries in WV population, and 42,323 beneficiaries in the US population. Table 2.1 shows the distribution of clinical and sociodemographic characteristics of these beneficiaries by type of lung cancer. Compared to beneficiaries with NSCLC in the US population, beneficiaries with NSCLC in WV population were younger, male, white, resided in nonmetro areas, had higher comorbidity score, and were diagnosed at earlier stages ( $p \leq$ 0.05). Similarly, compared to beneficiaries with SCLC in the US population, beneficiaries with SCLC in WV population were of white race, resided in non-metro areas, and were diagnosed at earlier stages $(p \leq 0.05)$. In both populations, 
beneficiaries with SCLC were diagnosed at late stages, compared to beneficiaries with NSCLC $(p \leq 0.05)$. In the US population, compared to beneficiaries with SCLC, beneficiaries with NSCLC were older, male, resided in metro areas, and had lower comorbidity scores $(p \leq 0.05)$.

\section{Treatment patterns}

Table 2.2 shows the descriptive characteristics by type of treatment among beneficiaries in the WV and US populations. Overall, proportion of beneficiaries receiving no treatment was lower in the WV population, as compared to the US population $(26.8 \%$ vs. $33.4 \%)(p \leq 0.05)$. Significant population variation in treatment patterns were observed by lung cancer type, stage, age, gender, race, urban-rural residence, comorbidity score, and by year of diagnosis $(p \leq 0.05)$. The proportion of beneficiaries receiving treatment as 'surgery alone', 'radiation alone', or 'combination treatment' was higher in WV population, compared to the US population $(p \leq 0.05)$. However, proportion of beneficiaries receiving treatment as 'chemotherapy alone' was lower in the WV population, compared to the US population $(p \leq 0.05)$. In both populations, the proportion of beneficiaries receiving treatment as 'surgery alone' or 'radiation alone' was higher among beneficiaries with NSCLC, compared to beneficiaries with SCLC $(p \leq 0.05)$. Similarly, the proportion of beneficiaries receiving treatment as 'surgery alone' was also higher among those with early stage disease, compared to those with late stage disease in both populations $(p \leq 0.05)$. Within the two populations, variations in treatment patterns were also observed by age, gender, urban-rural residence, and comorbidity score $(p \leq 0.05)$. Significant variation in 
treatment patterns by race and by year of diagnosis were only observed among beneficiaries in the US population $(p \leq 0.05)$.

Receipt of minimally appropriate care

Table 2.3 shows the descriptive characteristics of beneficiaries by receipt of minimally appropriate care in the WV and US populations. Overall, the proportion of beneficiaries receiving minimally appropriate care was $46.5 \%$ in WV population, and $44.7 \%$ in the US population. However, this population variation in overall receipt of minimally appropriate care was not significant. Significant population variations in receipt of minimally appropriate care were observed only among female beneficiaries. Specifically, the proportion of female beneficiaries receiving minimally appropriate care was higher in WV population as compared to the US population $(51.2 \%$ vs. $44.8 \%)(p \leq 0.05)$. Within the WV population, receipt of minimally appropriate care was also higher among female beneficiaries as compared to male beneficiaries $(p \leq 0.05)$. In both populations, compared to beneficiaries receiving inappropriate care, beneficiaries receiving minimally appropriate care were of young age $(p \leq 0.05)$. Variations in receipt of minimally appropriate care by race, urban-rural residence, comorbidity score, and year of diagnosis were only observed among beneficiaries in the US population $(p \leq 0.05)$.

Table 2.4 shows the proportion of beneficiaries receiving minimally appropriate care by lung cancer type and stage in the WV and US populations. The proportion of beneficiaries with NSCLC receiving minimally appropriate care was slightly higher in WV population, than in the US population ( $47.2 \%$ vs. $44.3 \%)$. However, the proportion 
of beneficiaries with SCLC, receiving minimally appropriate care was lower in the WV population, than in the US population $(40.0 \%$ vs. $48.0 \%)$.

Among beneficiaries with stage IV lung cancer, the overall proportion of beneficiaries receiving minimally appropriate care with curative intent was $24.2 \%$ in the WV population, and $21.6 \%$ in the US population. Among beneficiaries with NSCLC (Stage IV), this proportion was $17.8 \%$ in WV population and $16.3 \%$ in the US population. Similarly, among beneficiaries with SCLC (Stage IV) this proportion was $47.7 \%$ in the WV population and $45.7 \%$ in the US population.

Factors associated with receipt of minimally appropriate care Controlling for all sociodemographic variables, age remained a strong predictor of receipt of minimally appropriate care in all models (Table 2.5). Compared to beneficiaries aged 80 years and older, beneficiaries aged 66 to 69 years were more than twice likely to receive minimally appropriate care, and these odds gradually decreased with increase in age. Gender was only significant in model 1 (WV population), with males $27 \%$ less likely to receive minimally appropriate care as compared to females. Race, comorbidity score, and census tract level measure of income, were the other significant predictors of receipt of minimally appropriate care in model 2 (US population) and model 3 (Combined population). Specifically, beneficiaries of non-white race were $21 \%$ less likely to receive minimally appropriate care as compared to whites. The likelihood of receipt of minimally appropriate care was also higher among beneficiaries with low comorbidity score as compared to those with high comorbidity score. Finally, the likelihood of receipt of minimally appropriate care 
decreased with decrease in median household income. Census tract level measure of education and urban-rural residence were not statistically significant in any model. After controlling for all sociodemographic variables, population variation in likelihood of beneficiaries receiving minimally appropriate care was not significant.

Survival benefits associated with receipt of minimally appropriate care

Figure 2.2 compares the three year Kaplan-Meier survival curves by receipt of minimally appropriate care in the WV and US populations. In both populations, the three year survival rates and median survival times were significantly greater for beneficiaries receiving minimally appropriate care as compared to beneficiaries receiving inappropriate care $(p \leq 0.05)$. Specifically, with receipt of minimally appropriate care the three year median survival time exceeded by 433 days in WV population, and by 487 days in the US population $(p \leq 0.05)$. Compared to the US population, the median survival times by receipt of minimally appropriate care were significantly greater among beneficiaries in WV population $(p \leq 0.05)$. However, the three year survival rates among beneficiaries receiving minimally appropriate care were lower in WV population as compared to the US population $(p \leq 0.05)$.

Table 2.6 shows the three year survival rates and median survival times among beneficiaries receiving minimally appropriate care by lung cancer type and stage, in the WV and US populations. In WV population, survival benefits associated with receipt of minimally appropriate care were significant only among beneficiaries with SCLC (Stages I-III) ( $p \leq 0.05)$. However, in the US population, survival benefits associated with receipt of minimally appropriate care were significant for all beneficiaries except for 
beneficiaries with SCLC (stage I or stage II) $(p \leq 0.05)$. Significant population variations in survival among beneficiaries receiving either minimally appropriate care or inappropriate care were also observed by lung cancer type and stage $(p \leq 0.05)$.

Lung cancer mortality risk associated with non-receipt of minimally appropriate care In all Cox proportional hazards models, the adjusted lung cancer mortality risk was significantly higher among beneficiaries not receiving minimally appropriate care, relative to those who did receive minimally appropriate care (Table 2.7). Specifically, lung cancer mortality risk among beneficiaries not receiving minimally appropriate care increased by $60 \%$ in WV population, by $91 \%$ in the US population, and by $90 \%$ in the combined population $(p \leq 0.05)$. In all models, NSCLC diagnosis and early stage disease were the only other factors independently associated with lower lung cancer specific mortality $(p \leq 0.05)$. In model 1 (WV population), less education was the only other factor significantly associated with higher lung cancer specific mortality ( $\leq \leq 0.05)$. Older age, male sex, White race, higher comorbidity score, and lower income were the only other factors significantly associated with higher lung cancer specific mortality in model 2 (US population) and model 3 (Combined population). After controlling for all clinical and sociodemographic variables and for appropriateness of care, population variation in lung cancer mortality risk was not significant.

\section{Discussion}

Compared to other types of cancer, lung cancer diagnosis in the elderly is usually associated with poor prognosis. This burden is especially higher among elderly residing 
in rural and medically underserved regions of the US. ${ }^{25-27}$ Appropriate use of treatment options, as recommended in evidence-based clinical guidelines, has the potential to cure the disease, or prolong survival in this population. Prior studies have found variation in receipt of recommended lung cancer care according to age, race, comorbidity, and hospital type. ${ }^{15-21}$ However, these studies mainly represented NSCLC individuals from non-rural populations. In this study, using cancer registry linked Medicare administrative data files, we compare geographic variations in clinical guideline based lung cancer care and associated health outcomes among elderly in a representative rural and medically underserved state population, with a representative US population.

Overall, treatment patterns varied significantly among beneficiaries with lung cancer in the WV and US populations. Despite availability of various treatment options to treat the disease, many beneficiaries did not receive any treatment in either population. Among those beneficiaries who did receive treatment, other than chemotherapy alone, the proportions were higher among beneficiaries in the WV population, as compared to the US population. Similar population variation in treatment patterns was also seen by lung cancer type and stage. These observed population variations in treatment patterns may be related to differences in disease severity, comorbid illness burden, physician judgment, and/or individual preferences.

Minimally appropriate care was only received by less than half of all beneficiaries in each population. More female beneficiaries in the $\mathrm{WV}$ population received minimally appropriate care, as compared to that in the US population. Controlling for other factors, increasing age at diagnosis was associated with a decline in receipt of 
minimally appropriate care in both populations. This finding is similar to that reported in prior studies, and may be due to physician treatment choice, and/or individual treatment preferences. ${ }^{16 ; 1720 ; 21}$ Compared to younger individuals, some physicians may be conservative in their choice of curative treatment for the elderly given its impact on patient morbidity and quality of life. Gender disparities in receipt of minimally appropriate care were observed only in WV population, with males less likely to receive minimally appropriate care. Racial differences in receipt of minimally appropriate care were observed only in the US population, with non-white beneficiaries having less likelihood of receipt of minimally appropriate care than white beneficiaries. These racial differences are similar to that reported in prior studies. ${ }^{16 ; 19}$ Similar to results found in prior studies, comorbidity was inversely associated with receipt of minimally appropriate care in the US population. ${ }^{16}$ This may be due to less aggressive treatment approach by physicians in elderly with higher comorbidities, or due to individual preference to avoid aggressive treatments in favor of better quality of life. Increasing poverty was associated with decrease in likelihood of receipt of minimally appropriate care only in the US population. Compared to the US population, the WV population is much poorer, and that may explain the non-significance of income on receipt of minimally appropriate care among beneficiaries in the WV population. Urban-rural residence and education had no impact on receipt of minimally appropriate care in either population. After controlling for all sociodemographic variables, likelihood of receipt of minimally appropriate care among beneficiaries in the $\mathrm{WV}$ and US populations were not significantly different. 
Receipt of minimally appropriate care by beneficiaries was associated with longer survival times in both populations. Although beneficiaries receiving minimally appropriate care in the WV population had greater median survival times, compared to the US population, their three year survival rates were significantly lower. Survival benefits associated with receipt of minimally appropriate care also varied by lung cancer type and stage among beneficiaries in both the populations. In both populations, we found the adjusted lung cancer mortality risk significantly higher among beneficiaries not receiving minimally appropriate care than those who did receive such care. However, the magnitude of risk associated with non-receipt of minimally appropriate care was lower in the WV population, than in the US population. These findings highlight the fact that significant survival benefits can be achieved in beneficiaries, if they receive minimally appropriate care. Early stage disease and NSCLC diagnosis were the only other factors independently associated with lower lung cancer mortality risk in both populations. This is true given that the treatment management for beneficiaries is easier among those with early stage disease compared to late stage disease, and is also easier among those with NSCLC diagnosis compared to SCLC diagnoses. Lung cancer mortality risk varied significantly by census tract measure of education, only in the WV population, as risk increased with less education. Variation in lung cancer mortality risk by age, sex, race, comorbidity score, and income were only observed in the US population. After controlling for the variability associated with receipt of minimally appropriate care and all sociodemographic variables, lung cancer mortality risk was no different among beneficiaries in the WV and US populations. 
Although treatment patterns varied between the two populations, significant population variation in receipt of minimally appropriate care and associated lung cancer mortality risk were not observed in this study. These findings are contrary to what would be expected given that the WV population is more rural and medically underserved, and has higher lung cancer mortality rates as compared to the US population. The finding suggests that observed geographic differences in lung cancer mortality may not be associated with variation in receipt of minimally appropriate care among elderly beneficiaries with an incident diagnosis of lung cancer. Furthermore, higher lung cancer incidence in the WV population, as compared to the US population, may partly explain the disparities seen in lung cancer mortality among these populations. Future cancer prevention efforts directed towards promoting smoking cessation are much needed in the rural WV population, where the smoking prevalence rates are the highest in the nation. In the long run, these cancer prevention efforts can help to reduce the incidence of lung cancer in this rural population, which in turn can help to reduce the geographic disparities in lung cancer mortality.

The findings from this study are subject to several limitations. Although we used cancer registry linked claims data, an inherent limitation of using administrative claims data for epidemiologic studies is the possibility of misclassification as a result of coding errors. ${ }^{52 ; 53}$ However, claims data have been evaluated for their utility as a source of epidemiologic or health services information in cancer patients. ${ }^{52-56}$ Increasing the use of these types of data to assess the quality of cancer care has also been identified as a priority by the Institute of Medicine..$^{57}$ Studies using claims data are usually population based and have the potential to address a number of priority questions regarding the 
quality of cancer care and health care disparities. These population based studies provide valuable information for future planning and prioritization of health programs that improve cancer outcomes. Therefore, there is increasing interest in analyzing large health claims databases to assess treatment and outcomes for cancer. ${ }^{52 ; 53 ; 57}$

The results of this study are generalizable only to the elderly Medicare FFS population aged 66 years and older, as encounter data for Medicare recipients enrolled in the managed care plan were not available for this study. There was a small increase in percentage of Medicare recipients enrolled in managed care during the study years in both populations; in 2007 it was $~ 16 \%$ in WV population and $\sim 19 \%$ in the US population. ${ }^{58}$ Information on care received by the Medicare recipients outside of the Medicare system, or through non-Medicare providers, was also not available in the claims data for our study. However, Medicare is the largest and most comprehensive insurance provider for the elderly in the United States. Racial disparities in cancer outcomes could not be ascertained in this study, as the populations were predominantly White.

One of the inclusion criteria for cohort selection in this study was continuous enrollment in Medicare Part A and B during the study period. This resulted in the noninclusion of individuals with non-continuous enrollment and the loss of individuals who were enrolled intermittently. We acknowledge that various clinical guidelines have been published for lung cancer diagnosis and management, each with recommendations that are more or less the same. ${ }^{9-13}$ For the purpose of this study, we chose ACCP guidelines for lung cancer management and outcomes, as it is the most comprehensive of all available guidelines. ${ }^{10}$ The algorithm we adapted from these guidelines to identify 
minimally appropriate care takes into account the limitations in our data sources. Specifically, information on various lung function test results and lung performance scores were not available in our data source, and were not considered in our analysis. However, these indicators of lung performance are most crucial only in planning for chemotherapy in NSCLC stage IV individuals who we excluded from our analysis. Our estimates of proportion of beneficiaries receiving minimally appropriate care may be biased slightly upward as we included patients who received minimally appropriate care and additional unproven therapies. We also acknowledge that our definition of receipt of minimally appropriate care may be too narrow, and that given the heterogeneity of patients seen by physicians, receipt of no therapy may still be considered as appropriate care. None the less, our definition of receipt of minimally appropriate care provides a conceptual framework to assess and compare patterns of care that were prevalent during the years 2002 through 2007. Because of limited data availability at the time of study, we were unable to conduct a long-term (5-10 year) follow-up to assess the health outcomes associated with receipt of minimally appropriate care. Individual-level socioeconomic measures of educational attainment, marital status, and family income were also unavailable for this study. However, aggregate measures of socioeconomic status at the census tract level from 2000 decennial census data were used as a proxy. Finally, our definition of minimally appropriate versus inappropriate care is limited to the data recorded in the claims such as the presence or absence of ICD-9 diagnosis and procedure codes, HCPCS procedure codes, CPT procedure codes and revenue center codes. Future studies can overcome the barriers seen in this study by collecting data on physician behaviors and patient preferences on treatment choices. 
This study is the first of its kind to compare geographic variations in clinical guideline based lung cancer care and associated health outcomes among elderly Medicare FFS beneficiaries. Although lung cancer diagnostic and management services are covered under the Medicare program, underutilization of these services among recipients in the Medicare FFS population is a concern. Results of this study also emphasize the need to address disparities in receipt of minimally appropriate care among recipients in the Medicare FFS population. Reducing observed treatment variations according to individual characteristics can help to improve the use of clinical guideline based treatments in the elderly and that in turn would improve health outcomes. Furthermore, increased lung cancer risk and incidence among the elderly from economically underdeveloped and medically underserved regions, such as WV, may be the reason behind observed geographical disparities in lung cancer mortality. Promoting smoking cessation among individuals residing in such rural areas has the potential to reduce observed geographic disparities in lung cancer mortality. 
Figure 2.1. Algorithm adapted from American College of Chest Physicians (ACCP) evidence-based guidelines for diagnosis and management of lung cancer published in January, 2003, and used to determine receipt of minimally appropriate clinical guideline based lung cancer care.

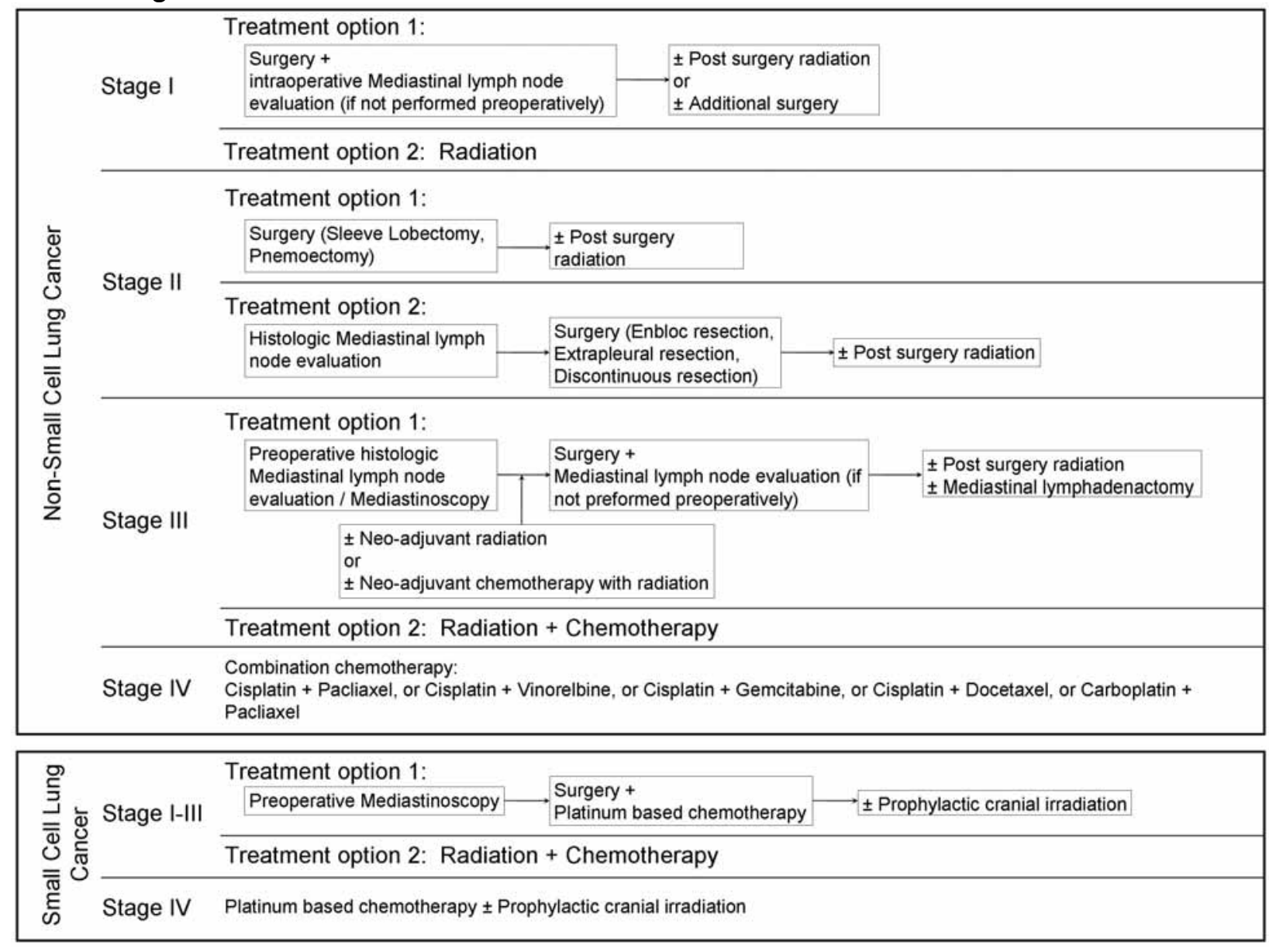


Figure 2.2. Kaplan-Meier survival estimates with $95 \%$ confidence limits by receipt of minimally appropriate clinical guideline based lung cancer care among continuously enrolled Medicare Fee-for-service beneficiaries with incident diagnosis of lung cancer (Stages I-III) in West Virginia and in the United States, July 2003 through December 2004. Curves (unadjusted) show cause-specific mortality.

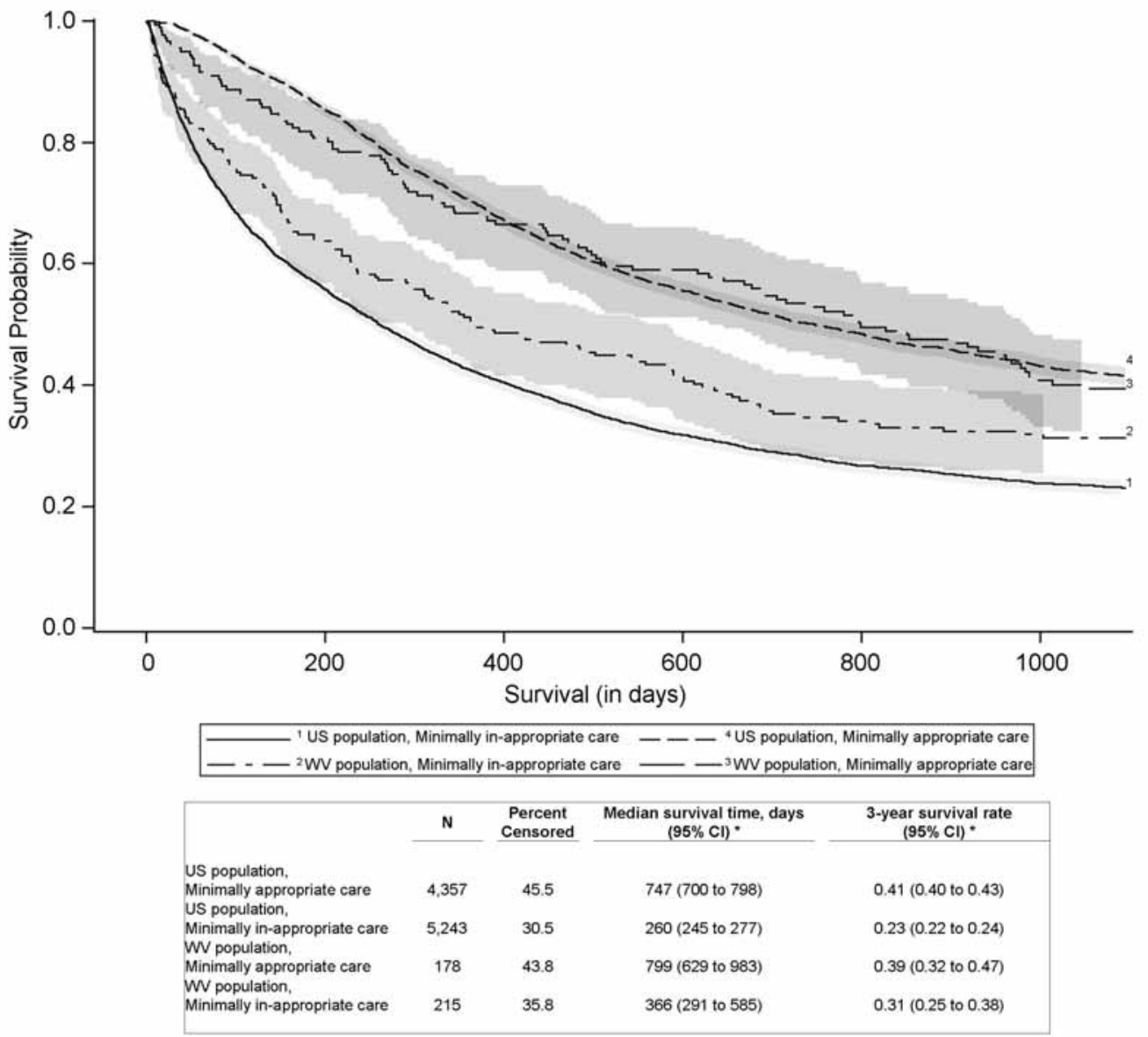

WV $=$ West Virginia population, US = United States population represented by the Surveillance, Epidemiology and End Results

(SEER) population, $\mathrm{Cl}=$ confidence interval.

Survival times and rates were obtained from Kaplan-Meier survival estimates.

Minimally appropriate care determined using American College of Chest Physicians (ACCP) evidence-based guidelines for diagnosis and management of lung cancer published in January, 2003.

Log-rank test $(p \leq 0.05)$ comparing differences in survival by receipt of minimally appropriate care, among beneficiaries within US population.

Log-rank test $(p \leq 0.05)$ comparing differences in survival by receipt of minimally appropriate care, among beneficiaries within WV population.

Log-rank test $(p \leq 0.05)$ comparing population differences in survival among beneficiaries receiving minimally appropriate care.

Log-rank test $(p \leq 0.05)$ comparing population differences in survival among beneficiaries receiving inappropriate care.

Source: West Virginia Cancer Registry - Medicare linked data files, 2002-2007, Surveillance, Epidemiology and End Results Medicare linked data files, 2002-2007. 
Table 2.1. Descriptive characteristics of continuously enrolled Medicare Fee-for-service beneficiaries with incident diagnosis of lung cancer in West Virginia and in the United States, July 2003 through December 2006.

\begin{tabular}{|c|c|c|c|c|}
\hline \multirow{3}{*}{ Characteristics } & \multicolumn{4}{|c|}{ Proportion (\%) } \\
\hline & \multicolumn{2}{|c|}{ NSCLC } & \multicolumn{2}{|c|}{ SCLC } \\
\hline & WV & US & WV & US \\
\hline Overall, n (\%) & $\begin{array}{l}1,444 \\
(85.5)\end{array}$ & $\begin{array}{c}36,417 \\
(86.0)\end{array}$ & $\begin{array}{c}245 \\
(14.5)\end{array}$ & $\begin{array}{l}5,906 \\
(14.0)\end{array}$ \\
\hline
\end{tabular}

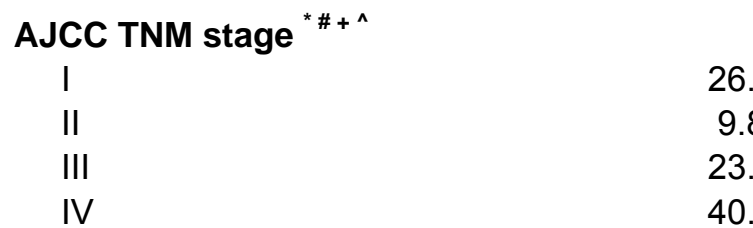

Age (years) *^ 66-69

$70-74$

75-79

80 or more

\section{Gender $^{* \wedge}$ \\ Male \\ Female}

$$
\begin{array}{r}
\text { Race }{ }^{*} \wedge \\
\text { Other } \\
\text { White }
\end{array}
$$
Urban-rural residence *^^
Metro
Urban
Rural

\section{Comorbidity, Charlson score *^}

0

1

2 or more

\section{Year of diagnosis *^ \\ 2003 (July-Dec) \\ 2004 \\ 2005}

2006

\section{6}

4.7

28.4

46.2

19.2

25.8

25.9

29.1

21.5

58.2

41.8

2.2

97.8

54.8

39.5

5.6

26.5

29.9

43.6

11.4

28.9

29.4

30.2
51.9

48.1

13.3

86.7

83.1

14.9

2.0

31.7

28.5

39.8

15.3

28.3

28.4

28.0
6.9

4.5

25.3

63.3

5.1

2.2

29.8

62.9
24.9

30.6

23.7

20.8

51.8

48.2

47.4

52.6

0.8

99.2

9.2

90.8

80.2

17.2

2.6

$\begin{array}{cc}32.2 & 17.2 \\ 7.8 & 2.6\end{array}$

WV = West Virginia population, US = United States population represented by the Surveillance, Epidemiology and End Results (SEER) population, NSCLC = Non-Small Cell Lung Cancer, SCLC $=$ Small Cell Lung Cancer, AJCC = American Joint Committee on Cancer, TNM = Tumor Node Metastasis.

* Chi-square test $(p \leq 0.05)$ measuring association between beneficiary characteristics and population type, among beneficiaries with non-small cell lung cancer. 
\# Chi-square test $(p \leq 0.05)$ measuring association between beneficiary characteristics and population type, among beneficiaries with small cell lung cancer.

+ Chi-square test $(p \leq 0.05)$ measuring association between beneficiary characteristics and cancer type, among beneficiaries in West Virginia population.

^ Chi-square test $(p \leq 0.05)$ measuring association between beneficiary characteristics and cancer type, among beneficiaries in United States population.

Source: West Virginia Cancer Registry - Medicare linked data files, 2002-2007, Surveillance, Epidemiology and End Results Medicare linked data files, 2002-2007. 
Table 2.2. Descriptive characteristics by type of treatment among continuously enrolled Medicare Fee-for-service beneficiaries with incident diagnosis of lung cancer in West Virginia and in the United States, July 2003 through December 2006.

\begin{tabular}{|c|c|c|c|c|c|c|c|c|c|c|}
\hline \multirow{3}{*}{ Characteristics } & \multicolumn{10}{|c|}{ Proportion (\%) ${ }^{\#}$} \\
\hline & \multicolumn{2}{|c|}{ No Treatment } & \multicolumn{2}{|c|}{ Surgery Only } & \multicolumn{2}{|c|}{ Radiation Only } & \multicolumn{2}{|c|}{$\begin{array}{c}\text { Chemotherapy } \\
\text { Only }\end{array}$} & \multicolumn{2}{|c|}{$\begin{array}{l}\text { Combination } \\
\text { Treatment }\end{array}$} \\
\hline & WV & US & WV & US & WV & US & WV & US & WV & US \\
\hline Overall, n (\%) & $\begin{array}{c}453 \\
(26.8)\end{array}$ & $\begin{array}{l}14,137 \\
(33.4)\end{array}$ & $\begin{array}{c}228 \\
(13.5)\end{array}$ & $\begin{array}{c}4,172 \\
(9.9)\end{array}$ & $\begin{array}{c}321 \\
(19.0)\end{array}$ & $\begin{array}{l}6,730 \\
(15.9)\end{array}$ & $\begin{array}{c}176 \\
(10.4)\end{array}$ & $\begin{array}{l}5,461 \\
(12.9)\end{array}$ & $\begin{array}{c}511 \\
(30.3)\end{array}$ & $\begin{array}{l}11,832 \\
(27.9)\end{array}$ \\
\hline \multicolumn{11}{|l|}{ Cancer type $^{+\wedge}$} \\
\hline NSCLC ${ }^{*}$ & 26.7 & 34.1 & 15.7 & 11.4 & 20.6 & 17.1 & 8.4 & 11.2 & 28.6 & 26.2 \\
\hline SCLC & 27.8 & 28.9 & 0.4 & 0.5 & 9.4 & 8.4 & 22.5 & 23.6 & 40.0 & 38.7 \\
\hline \multicolumn{11}{|c|}{ AJCC TNM stage $^{+\wedge}$} \\
\hline I & 17.5 & 23.7 & 43.2 & 41.0 & 11.4 & 12.7 & 3.0 & 3.6 & 24.9 & 19.0 \\
\hline II & 19.6 & 17.0 & 22.2 & 19.7 & 12.4 & 10.7 & 2.6 & 4.9 & 43.1 & 47.8 \\
\hline III & 25.9 & 32.5 & 3.5 & 3.5 & 18.3 & 14.5 & 11.8 & 13.1 & 40.5 & 36.5 \\
\hline IV & 34.0 & 39.1 & 0.7 & 0.8 & 25.0 & 18.4 & 15.4 & 17.1 & 25.0 & 24.5 \\
\hline \multicolumn{11}{|l|}{ Age (years) ${ }^{+\wedge}$} \\
\hline $66-69$ * & 20.6 & 23.0 & 14.0 & 9.8 & 13.0 & 12.9 & 10.4 & 13.8 & 42.0 & 40.5 \\
\hline $70-74$ & 21.8 & 26.1 & 14.6 & 10.4 & 18.4 & 14.7 & 11.0 & 13.7 & 34.2 & 35.0 \\
\hline $75-79$ & 27.9 & 32.5 & 14.1 & 11.3 & 21.2 & 15.9 & 10.4 & 13.9 & 26.5 & 26.5 \\
\hline 80 or more ${ }^{*}$ & 39.2 & 48.5 & 10.8 & 8.1 & 23.8 & 19.2 & 9.7 & 10.6 & 16.6 & 13.7 \\
\hline \multicolumn{11}{|l|}{ Gender $^{+\wedge}$} \\
\hline Male * & 29.6 & 33.4 & 12.4 & 8.8 & 18.3 & 15.9 & 9.8 & 13.0 & 29.9 & 28.8 \\
\hline Female $^{*}$ & 23.1 & 33.4 & 15.0 & 11.0 & 19.9 & 15.9 & 11.2 & 12.8 & 30.7 & 27.0 \\
\hline
\end{tabular}




\begin{tabular}{|c|c|c|c|c|c|c|c|c|c|c|}
\hline Other & 44.1 & 37.9 & 11.8 & 7.0 & 11.8 & 17.6 & 14.7 & 12.4 & 17.7 & 25.1 \\
\hline White * & 26.5 & 32.7 & 13.5 & 10.3 & 19.2 & 15.7 & 10.3 & 13.0 & 30.5 & 28.3 \\
\hline \multicolumn{11}{|c|}{$\begin{array}{l}\text { ban-rural } \\
\text { sidence }^{+\wedge}\end{array}$} \\
\hline Metro * & 27.6 & 32.9 & 13.4 & 10.1 & 20.7 & 16.1 & 8.4 & 13.1 & 29.9 & 27.8 \\
\hline Urban & 26.8 & 36.2 & 14.2 & 8.7 & 17.1 & 15.1 & 12.2 & 11.6 & 29.8 & 28.5 \\
\hline Rural & 20.0 & 34.2 & 10.0 & 8.2 & 16.0 & 14.8 & 18.0 & 13.6 & 36.0 & 29.2 \\
\hline
\end{tabular}

\section{Comorbidity,}

\section{Charlson score ${ }^{+}$}

\begin{tabular}{|c|c|c|c|c|c|c|c|c|c|c|}
\hline 0 & 31.3 & 33.1 & 10.3 & 7.9 & 17.9 & 14.9 & 10.9 & 13.2 & 29.5 & 31.0 \\
\hline $1^{*}$ & 21.6 & 29.4 & 15.7 & 11.2 & 18.8 & 15.6 & 10.1 & 13.2 & 33.7 & 30.6 \\
\hline 2 or more * & 27.6 & 36.6 & 14.0 & 10.4 & 19.8 & 16.9 & 10.3 & 12.5 & 28.3 & 23.6 \\
\hline $\begin{array}{l}\text { ar of diagn } \\
2003 \text { (July- }\end{array}$ & & & & & & & & & & \\
\hline Dec) & 25.8 & 33.6 & 15.7 & 9.4 & 19.7 & 15.2 & 11.1 & 13.3 & 27.8 & 28.5 \\
\hline $2004^{*}$ & 24.9 & 32.2 & 14.5 & 9.5 & 17.8 & 14.5 & 10.0 & 13.4 & 32.9 & 30.5 \\
\hline $2005^{*}$ & 27.4 & 33.2 & 12.9 & 9.7 & 16.9 & 15.0 & 11.1 & 13.5 & 31.8 & 28.6 \\
\hline $2006^{*}$ & 28.6 & 34.8 & 12.3 & 10.6 & 22.0 & 18.7 & 9.9 & 11.6 & 27.2 & 24.4 \\
\hline
\end{tabular}

WV = West Virginia population, US = United States population represented by the Surveillance, Epidemiology and End Results (SEER) population, NSCLC = Non-Small Cell Lung

Cancer, SCLC = Small Cell Lung Cancer, AJCC = American Joint Committee on Cancer, TNM = Tumor Node Metastasis.

* Proportions reported are row percentages of beneficiaries receiving particular treatment within WV or the US population.

* Chi-square test $(p \leq 0.05)$, measuring association between type of treatment and population type, among beneficiaries within each row category.

+ Chi-square test $(p \leq 0.05)$ measuring association between beneficiary characteristics and type of treatment, among beneficiaries in West Virginia population.

Chi-square test $(\mathrm{p} \leq 0.05)$ measuring association between beneficiary characteristics and type of treatment, among beneficiaries in United States population.

Source: West Virginia Cancer Registry - Medicare linked data files, 2002-2007, Surveillance, Epidemiology and End Results - Medicare linked data files, $2002-2007$. 
Table 2.3. Descriptive characteristics by receipt of minimally appropriate clinical guideline based lung cancer care among continuously enrolled Medicare Fee-forservice beneficiaries with incident diagnosis of lung cancer (Stages I-III) in West Virginia and in the United States, July 2003 through December 2006.

\begin{tabular}{|c|c|c|c|c|c|c|c|c|}
\hline \multirow{3}{*}{ Characteristics } & \multicolumn{4}{|c|}{ Minimally Appropriate Care } & \multicolumn{4}{|c|}{ Inappropriate Care } \\
\hline & \multicolumn{2}{|c|}{ WV } & \multicolumn{2}{|c|}{ US } & \multicolumn{2}{|c|}{ WV } & \multicolumn{2}{|c|}{ US } \\
\hline & No. & $\%^{\#}$ & No. & $\%^{\#}$ & No. & $\%^{\#}$ & No. & $\%^{\#}$ \\
\hline Overall & 445 & 46.5 & 9,736 & 44.7 & 511 & 53.5 & 12,048 & 55.3 \\
\hline \multicolumn{9}{|l|}{ Age (years) ${ }^{+\wedge}$} \\
\hline $66-69$ & 118 & 51.8 & 2,325 & 55.7 & 110 & 48.2 & 1,849 & 44.3 \\
\hline $70-74$ & 159 & 53.9 & 2,899 & 50.4 & 136 & 46.1 & 2,851 & 49.6 \\
\hline $75-79$ & 112 & 45.0 & 2,576 & 45.0 & 137 & 55.0 & 3,152 & 55.0 \\
\hline 80 or more & 56 & 30.4 & 1,936 & 31.6 & 128 & 69.6 & 4,196 & 68.4 \\
\hline \multicolumn{9}{|l|}{ Gender $^{+}$} \\
\hline Male & 231 & 42.9 & 4,930 & 44.6 & 307 & 57.1 & 6,130 & 55.4 \\
\hline Female * & 214 & 51.2 & 4,806 & 44.8 & 204 & 48.8 & 5,918 & 55.2 \\
\hline \multicolumn{9}{|l|}{ Race $^{\wedge}$} \\
\hline Other & 7 & 38.9 & 1,090 & 39.7 & 11 & 61.1 & 1,654 & 60.3 \\
\hline White & 438 & 46.7 & 8,646 & 45.4 & 500 & 53.3 & 10,394 & 54.6 \\
\hline
\end{tabular}

\section{Urban-rural residence $^{\wedge}$}

$\begin{array}{lcccccccc}\text { Metro } & 254 & 46.8 & 8,101 & 45.3 & 289 & 53.2 & 9,793 & 54.7 \\ \text { Urban } & 170 & 47.2 & 1,446 & 42.0 & 190 & 52.8 & 1,995 & 58.0 \\ \text { Rural } & 21 & 39.6 & 189 & 42.1 & 32 & 60.4 & 260 & 57.9\end{array}$

\section{Comorbidity,} Charlson score

$\begin{array}{lllllllll}0 & 103 & 45.0 & 2,820 & 46.0 & 126 & 55.0 & 3,314 & 54.0 \\ 1 & 139 & 49.3 & 3,040 & 48.2 & 143 & 50.7 & 3,265 & 51.8 \\ 2 \text { or more } & 203 & 45.6 & 3,876 & 41.5 & 242 & 54.4 & 5,469 & 58.5\end{array}$

\section{Year of diagnosis}

\begin{tabular}{|c|c|c|c|c|c|c|c|c|}
\hline 2003 (July-Dec) & 43 & 43.9 & 1,511 & 42.5 & 55 & 56.1 & 2,046 & 57.5 \\
\hline 2004 & 135 & 45.8 & 2,846 & 46.5 & 160 & 54.2 & 3,274 & 53.5 \\
\hline 2005 & 136 & 48.2 & 2,788 & 45.5 & 146 & 51.8 & 3,344 & 54.5 \\
\hline 2006 & 131 & 46.6 & 2,591 & 43.4 & 150 & 53.4 & 3,384 & 56.6 \\
\hline $\begin{array}{l}\text { West Virginia popul } \\
\text { EER) population. } \\
\text { inimally appropriate ca } \\
\text { agnosis and managem } \\
\text { oportions reported are } \\
\text { the US population. } \\
\text { i-square test }(p \leq 0.05 \\
\text { neficiaries within each }\end{array}$ & & & ulation re & & & Epidem & and End & \\
\hline
\end{tabular}


+ Chi-square test $(p \leq 0.05)$ measuring association between beneficiary characteristics and receipt of minimally appropriate care, among beneficiaries in West Virginia population.

Chi-square test $(p \leq 0.05)$ measuring association between beneficiary characteristics and receipt of minimally appropriate care, among beneficiaries in United States population.

Source: West Virginia Cancer Registry - Medicare linked data files, 2002-2007, Surveillance, Epidemiology and End Results Medicare linked data files, 2002-2007. 
Table 2.4. Minimally appropriate clinical guideline based lung cancer care by cancer type and stage, among continuously enrolled Medicare Fee-for-service beneficiaries with incident diagnosis of lung cancer (Stages I-III) in West Virginia and in the United States, July 2003 through December 2006.

\begin{tabular}{|c|c|c|c|c|c|c|c|c|}
\hline \multirow{3}{*}{ Characteristics } & \multicolumn{4}{|c|}{ Minimally Appropriate Care ${ }^{\sim}$} & \multicolumn{4}{|c|}{ Inappropriate Care } \\
\hline & \multicolumn{2}{|c|}{ WV } & \multicolumn{2}{|c|}{ US } & \multicolumn{2}{|c|}{ WV } & \multicolumn{2}{|c|}{ US } \\
\hline & No. & $\%{ }^{\#}$ & No. & $\%{ }^{\#}$ & No. & $\%^{\#}$ & No. & $\%{ }^{\#}$ \\
\hline \multicolumn{9}{|l|}{ NSCLC } \\
\hline Stage I & 209 & 53.9 & 4,188 & 55.7 & 179 & 46.1 & 3,332 & 44.3 \\
\hline Stage II & 67 & 47.2 & 844 & 49.1 & 75 & 52.8 & 876 & 50.9 \\
\hline Stage III & 133 & 39.6 & 3,653 & 35.3 & 203 & 60.4 & 6,701 & 64.7 \\
\hline Stages I-III & 409 & 47.2 & 8,685 & 44.3 & 457 & 52.8 & 10,909 & 55.7 \\
\hline \multicolumn{9}{|l|}{ SCLC } \\
\hline Stage I & 6 & 35.3 & 130 & 43.2 & 11 & 64.7 & 171 & 56.8 \\
\hline Stage II & 2 & 18.2 & 59 & 45.7 & 9 & 81.8 & 70 & 54.3 \\
\hline Stage III & 28 & 45.2 & 862 & 49.0 & 34 & 54.8 & 898 & 51.0 \\
\hline Stages I-III & 36 & 40.0 & 1,051 & 48.0 & 54 & 60.0 & 1,139 & 52.0 \\
\hline \multicolumn{9}{|c|}{$\begin{array}{l}\text { WV = West Virginia population, US = United States population represented by the Surveillance, Epidemiology and End Results } \\
\text { (SEER) population. } \\
\text { Minimally appropriate care determined using American College of Chest Physicians (ACCP) evidence-based guidelines for } \\
\text { diagnosis and management of lung cancer published in January, } 2003 \text {. } \\
\text { Proportions reported are row percentages of beneficiaries receiving minimally appropriate care, or inappropriate care, within WV } \\
\text { or the US population. } \\
\text { Stages based on American Joint Committee on Cancer (AJCC), Tumor Node Metastasis (TNM) staging system. } \\
\text { Source: West Virginia Cancer Registry - Medicare linked data files, 2002-2007, Surveillance, Epidemiology and End Results - } \\
\text { Medicare linked data files, 2002-2007. }\end{array}$} \\
\hline
\end{tabular}


Table 2.5. Factors associated with receipt of minimally appropriate clinical guideline based lung cancer care among continuously enrolled Medicare Fee-for-service beneficiaries with incident diagnosis of lung cancer (Stages I-III) in West Virginia and in the United States, July 2003 through December 2006.

\begin{tabular}{|c|c|c|c|}
\hline & \multicolumn{3}{|c|}{ Odds Ratio (95\% Confidence Interval) } \\
\hline & Model 1: WV & Model 2: US & Model 3: WV + US \\
\hline Intercept (p-value) & 0.09 & 0.15 & 0.11 \\
\hline \multicolumn{4}{|l|}{ Population } \\
\hline WV & NA & NA & 0.94 (0.78 to 1.13$)$ \\
\hline US & NA & NA & 1 (Ref) \\
\hline \multicolumn{4}{|l|}{ Age (years) } \\
\hline 66-69 & $2.50^{* * *}(1.65$ to 3.79$)$ & $2.66^{\star * \star}$ (2.44 to 2.89$)$ & $2.65^{\star \star *}$ (2.44 to 2.87 ) \\
\hline $70-74$ & $2.68^{* * *}(1.81$ to 3.98$)$ & $2.13^{* * *}(1.97$ to 2.31$)$ & $2.16^{* * *}(2.00$ to 2.33$)$ \\
\hline $75-79$ & $1.84^{* *}(1.22$ to 2.77$)$ & $1.79^{* * *}(1.66$ to 1.93$)$ & $1.79^{* * *}(1.66$ to 1.93$)$ \\
\hline 80 or more & 1 (Ref) & 1 (Ref) & 1 (Ref) \\
\hline \multicolumn{4}{|l|}{ Gender } \\
\hline Male & $0.73^{*}(0.56$ to 0.95$)$ & 0.97 (0.92 to 1.03$)$ & $0.96(0.91$ to 1.01$)$ \\
\hline Female & 1 (Ref) & 1 (Ref) & 1 (Ref) \\
\hline \multicolumn{4}{|l|}{ Race } \\
\hline Other & $0.77(0.25$ to 2.34$)$ & $0.79^{* * *}(0.72$ to 0.86$)$ & $0.79^{* * *}(0.72$ to 0.86$)$ \\
\hline White & 1 (Ref) & 1 (Ref) & 1 (Ref) \\
\hline \multicolumn{4}{|l|}{$\begin{array}{l}\text { Urban-rural } \\
\text { residence }\end{array}$} \\
\hline Metro & 1.50 (0.82 to 2.77$)$ & $1.11(0.90$ to 1.38$)$ & $1.15(0.94$ to 1.40$)$ \\
\hline Urban & 1.44 (0.78 to 2.66$)$ & 0.99 (0.79 to 1.22$)$ & $1.03(0.84$ to 1.26$)$ \\
\hline Rural & 1 (Ref) & 1 (Ref) & 1 (Ref) \\
\hline \multicolumn{4}{|l|}{$\begin{array}{l}\text { Comorbidity, } \\
\text { Charlson } \\
\text { score }\end{array}$} \\
\hline 0 & 0.95 (0.68 to 1.32$)$ & $1.14^{* * *}(1.06$ to 1.21$)$ & $1.13^{* * *}(1.06$ to 1.20$)$ \\
\hline 1 & 1.14 (0.83 to 1.55$)$ & $1.27^{* * *}(1.18$ to 1.35$)$ & $1.26^{\star \star *}$ (1.18 to 1.34$)$ \\
\hline 2 or more & 1 (Ref) & 1 (Ref) & 1 (Ref) \\
\hline \multicolumn{4}{|l|}{$\begin{array}{l}\text { Percentage } \\
\text { with some } \\
\text { college } \\
\text { education (\%) ^ }\end{array}$} \\
\hline $0.0-0.10$ & 0.34 (0.09 to 1.31$)$ & $1.00(0.02$ to 45.32$)$ & $0.52(0.01$ to 0.60$)$ \\
\hline $0.11-0.20$ & $1.20(0.90$ to 1.59$)$ & $1.09(0.05$ to 8.79$)$ & $1.25(0.22$ to 7.16$)$ \\
\hline $\begin{array}{l}0.21 \text { or } \\
\text { more }\end{array}$ & 1 (Ref) & 1 (Ref) & 1 (Ref) \\
\hline
\end{tabular}


Median

household

income (\$)

\begin{tabular}{lccc}
$0-25,000$ & $1.53(0.64$ to 3.66$)$ & $0.75^{\star * *}(0.67$ to 0.84$)$ & $0.76^{* * *}(0.68$ to 0.85$)$ \\
$25,001-50,000$ & $1.58(0.70$ to 3.59$)$ & $0.85^{* *}(0.77$ to 0.94$)$ & $0.86^{* *}(0.78$ to 0.95$)$ \\
$\begin{array}{l}50,001 \text { or } \\
\text { more }\end{array}$ & 1 (Ref) & 1 (Ref) & 1 (Ref) \\
\hline
\end{tabular}

WV = West Virginia population, US = United States population represented by the Surveillance, Epidemiology and End Results (SEER) population, Ref = reference category, NA = Not Applicable.

* Estimates are statistically significant $(p \leq 0.05)$.

*** Estimates are statistically significant $(p \leq 0.01)$

Estimates are statistically significant $(p \leq 0.001)$.

'Census tract level measures of beneficiaries socioeconomic status.

Minimally appropriate care determined using American College of Chest Physicians (ACCP) evidence-based guidelines for diagnosis and management of lung cancer published in January, 2003.

Model 1: WV population $(N=956)$, Fit Statistics: -2 restricted log pseudo-likelihood $=4110.26$, Covariance parameter estimates: Intercept $=$ county, estimate $=0.33$, standard error $=0.001$.

Model 2: US population $(N=21,784)$, Fit Statistics: -2 restricted log pseudo-likelihood $=93427.13$, Covariance parameter estimates: Intercept $=$ county, estimate $=0.56$, standard error $=0.011$.

Model 3: Combined WV + US population $(\mathrm{N}=22,740)$, Fit Statistics: -2 restricted log pseudo-likelihood $=97505.27$, Covariance parameter estimates: Intercept $=$ county, estimate $=0.05$, standard error $=0.011$.

Source: West Virginia Cancer Registry - Medicare linked data files, 2002-2007, Surveillance, Epidemiology and End Results Medicare linked data files, 2002-2007. 
Table 2.6. Three-year median survival time and survival rate by cancer type and stage, and by receipt of minimally appropriate clinical guideline based lung cancer care, among continuously enrolled Medicare Fee-for-service beneficiaries with incident diagnosis of lung cancer (Stages I-III) in West Virginia and in the United States, July 2003 through December 2004.

\begin{tabular}{|c|c|c|c|c|c|c|c|c|}
\hline & \multicolumn{4}{|c|}{ Minimally Appropriate Care } & \multicolumn{4}{|c|}{ Inappropriate Care } \\
\hline & \multicolumn{2}{|c|}{$\begin{array}{l}\text { Median survival time, days } \\
\qquad(95 \% \mathrm{Cl}) \text { * }\end{array}$} & \multicolumn{2}{|c|}{$\begin{array}{l}\text { 3-year survival rate } \\
(95 \% \mathrm{Cl}) \text { * }\end{array}$} & \multicolumn{2}{|c|}{$\begin{array}{l}\text { Median survival time, days } \\
(95 \% \mathrm{Cl}) \text { * }\end{array}$} & \multicolumn{2}{|c|}{$\begin{array}{l}\text { 3-year survival rate } \\
(95 \% \mathrm{Cl}) \text { * }\end{array}$} \\
\hline & WV & US & WV & US & WV & US & WV & US \\
\hline \multicolumn{9}{|l|}{ NSCLC } \\
\hline $\mathrm{I}^{\#}$ & $\begin{array}{c}983 \\
\left(797 \text { to } N A^{\wedge}\right)\end{array}$ & - & $\begin{array}{c}0.46 \\
(0.34 \text { to } 0.57)\end{array}$ & $\begin{array}{c}0.62 \\
(0.60 \text { to } 0.65)\end{array}$ & - & - & $\begin{array}{c}0.60 \\
(0.49 \text { to } 0.70)\end{array}$ & $\begin{array}{c}0.55 \\
(0.53 \text { to } 0.58)\end{array}$ \\
\hline II \# & - & - & $\begin{array}{c}0.51 \\
(0.30 \text { to } 0.68)\end{array}$ & $\begin{array}{c}0.54 \\
(0.48 \text { to } 0.59)\end{array}$ & $\begin{array}{c}493 \\
\text { (299 to } 643)\end{array}$ & $\begin{array}{c}384 \\
(328 \text { to } 459)\end{array}$ & $\begin{array}{c}0.17 \\
(0.05 \text { to } 0.34)\end{array}$ & $\begin{array}{c}0.20 \\
(0.16 \text { to } 0.25)\end{array}$ \\
\hline 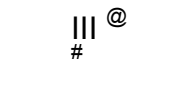 & $\begin{array}{c}493 \\
(293 \text { to } 705)\end{array}$ & $\begin{array}{c}439 \\
(412 \text { to } 475)\end{array}$ & $\begin{array}{c}0.28 \\
(0.16 \text { to } 0.41)\end{array}$ & $\begin{array}{c}0.25 \\
(0.23 \text { to } 0.27)\end{array}$ & $\begin{array}{c}188 \\
(119 \text { to } 256)\end{array}$ & $\begin{array}{c}146 \\
(135 \text { to } 164)\end{array}$ & $\begin{array}{c}0.12 \\
(0.05 \text { to } 0.21)\end{array}$ & $\begin{array}{c}0.09 \\
(0.08 \text { to } 0.11)\end{array}$ \\
\hline I-III $\$$ @\# & $\begin{array}{c}851 \\
\text { (677 to } 992)\end{array}$ & $\begin{array}{c}835 \\
\text { (781 to } 912)\end{array}$ & $\begin{array}{c}0.41 \\
(0.33 \text { to } 0.48)\end{array}$ & $\begin{array}{c}0.44 \\
(0.43 \text { to } 0.46)\end{array}$ & $\begin{array}{c}493 \\
(341 \text { to } 643)\end{array}$ & $\begin{array}{c}283 \\
\text { (265 to } 301)\end{array}$ & $\begin{array}{c}0.35 \\
(0.28 \text { to } 0.42)\end{array}$ & $\begin{array}{c}0.25 \\
(0.24 \text { to } 0.26)\end{array}$ \\
\hline \multicolumn{9}{|l|}{ SCLC } \\
\hline 1 & $\begin{array}{c}449 \\
\left(300 \text { to } \mathrm{NA}^{\wedge}\right)\end{array}$ & $\begin{array}{c}585 \\
(464 \text { to } 701)\end{array}$ & 0 & $\begin{array}{c}0.28 \\
(0.18 \text { to } 0.39)\end{array}$ & $\begin{array}{c}211 \\
\text { (71 to } 366)\end{array}$ & $\begin{array}{c}324 \\
(204 \text { to } 474)\end{array}$ & 0 & $\begin{array}{c}0.16 \\
(0.09 \text { to } 0.26)\end{array}$ \\
\hline II & $\begin{array}{c}490 \\
\text { (21 to } 958)\end{array}$ & $\begin{array}{c}423 \\
(276 \text { to } 618)\end{array}$ & 0 & $\begin{array}{c}0.14 \\
(0.04 \text { to } 0.31)\end{array}$ & $\begin{array}{c}150 \\
\text { (3 to } 552)\end{array}$ & $\begin{array}{c}276 \\
\text { (99 to } 498)\end{array}$ & 0 & $\begin{array}{c}0.06 \\
(0.00 \text { to } 0.25)\end{array}$ \\
\hline $\mathbb{\#}_{111}^{@}$ & $\begin{array}{c}281 \\
\left(171 \text { to } N A^{\wedge}\right)\end{array}$ & $\begin{array}{c}448 \\
(405 \text { to } 491)\end{array}$ & $\begin{array}{c}0.32 \\
(0.09 \text { to } 0.59)\end{array}$ & $\begin{array}{c}0.18 \\
(0.14 \text { to } 0.22)\end{array}$ & $\begin{array}{c}85 \\
\text { (6 to } 219)\end{array}$ & $\begin{array}{c}109 \\
\text { (92 to } 133)\end{array}$ & 0 & $\begin{array}{c}0.02 \\
(0.01 \text { to } 0.05)\end{array}$ \\
\hline 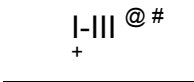 & $\begin{array}{c}345 \\
\left(263 \text { to } N A^{\wedge}\right)\end{array}$ & $\begin{array}{c}457 \\
\text { (428 to } 509)\end{array}$ & $\begin{array}{c}0.27 \\
(0.07 \text { to } 0.51)\end{array}$ & $\begin{array}{c}0.19 \\
(0.16 \text { to } 0.23)\end{array}$ & $\begin{array}{c}150 \\
(16 \text { to } 219)\end{array}$ & $\begin{array}{c}135 \\
(109 \text { to } 160)\end{array}$ & 0 & $\begin{array}{c}0.05 \\
(0.03 \text { to } 0.07)\end{array}$ \\
\hline \multicolumn{9}{|c|}{ 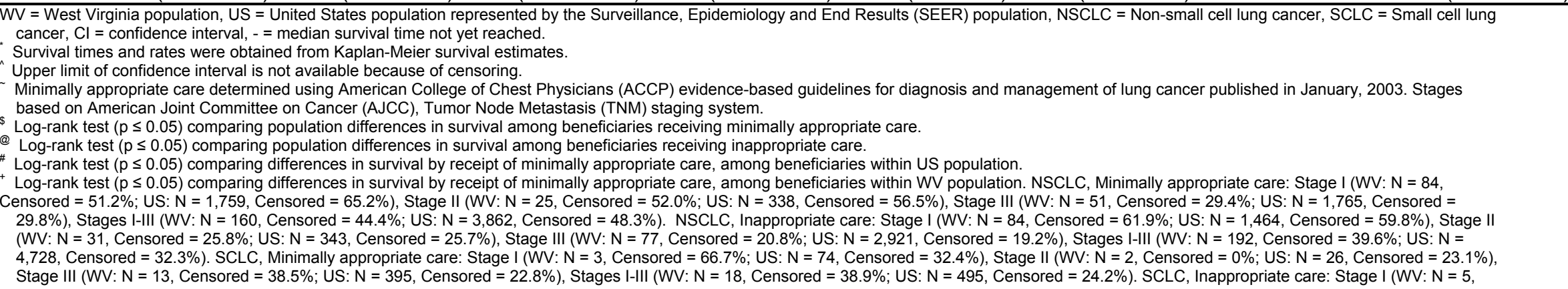 } \\
\hline
\end{tabular}


Censored $=0 \%$; US: $N=80$, Censored $=25.0 \%$ ), Stage II (WV: $N=4$, Censored $=25.0 \%$; US: $N=26$, Censored $=23.1 \%)$, Stage III (WV: $N=14$, Censored $=0 \%$; US: $N=409$, Censored $=12.0 \%$ ), Stages I-III (WV: $\mathrm{N}=23$, Censored $=4.3 \%$; US: $\mathrm{N}=515, \%$ censored $=14.6 \%$ ).

Source: West Virginia Cancer Registry - Medicare linked data files, 2002-2007, Surveillance, Epidemiology and End Results - Medicare linked data files, 2002-2007. 
Table 2.7. Lung cancer mortality risk associated with non-receipt of minimally appropriate clinical guideline based lung cancer care, among continuously enrolled Medicare Fee-for-service beneficiaries with incident diagnosis of lung cancer (Stages IIII) in West Virginia and in the United States, July 2003 through December 2004.

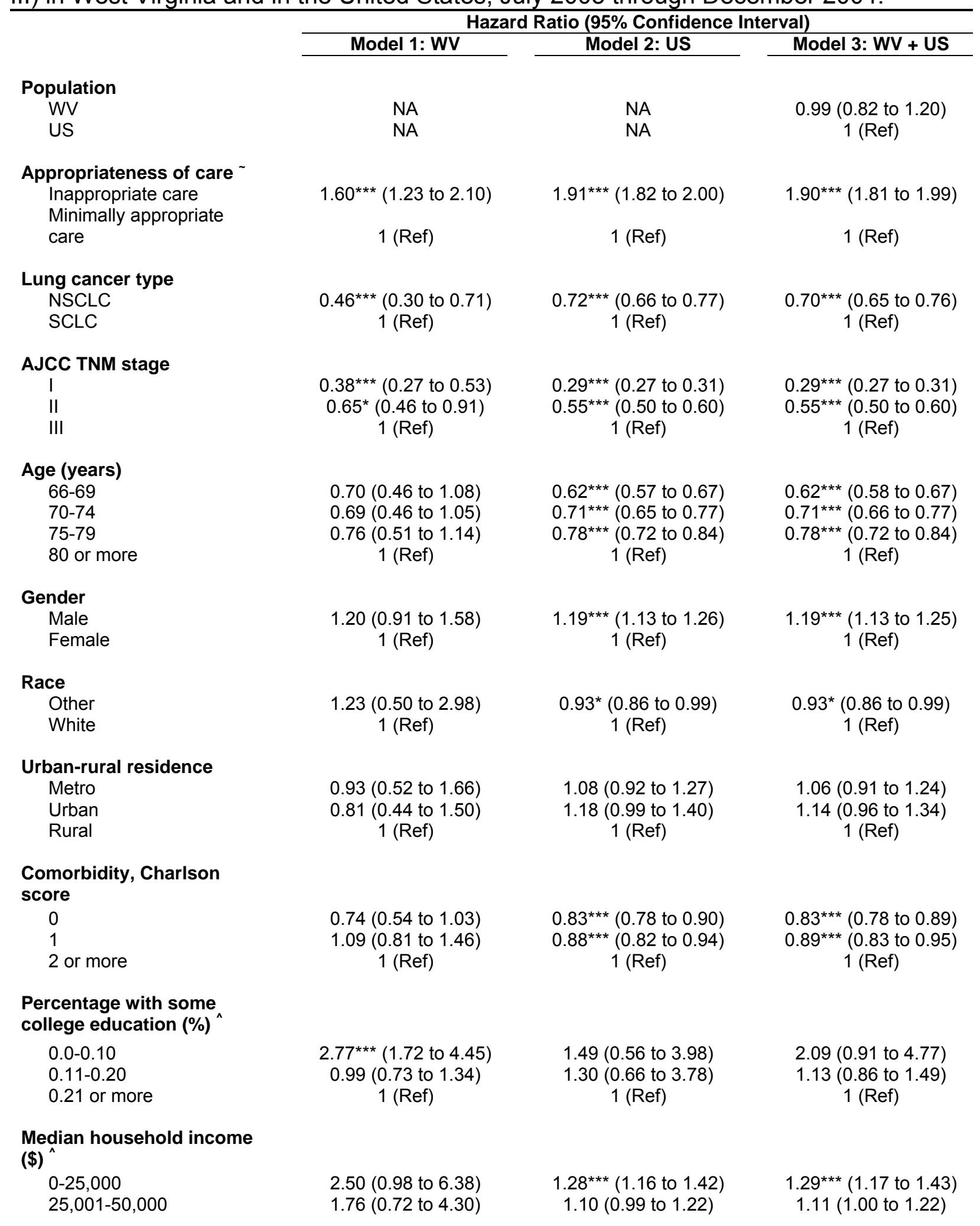


WV = West Virginia population, US = United States population represented by the Surveillance, Epidemiology and End Results (SEER) population, NSCLC = Non-Small Cell Lung Cancer, SCLC $=$ Small Cell Lung Cancer, AJCC = American Joint Committee on Cancer, TNM = Tumor Node Metastasis, Ref = reference category, NA = Not Applicable.

${ }^{\wedge}$ Census tract level measures of beneficiaries socioeconomic status.

*Estimates are statistically significant $(p \leq 0.05)$.

Estimates are statistically significant $(p \leq 0.01)$

Estimates are statistically significant $(p \leq 0.001)$.

- Minimally appropriate care determined using American College of Chest Physicians (ACCP) evidence-based guidelines for diagnosis and management of lung cancer published in January, 2003.

Model 1: WV population $(\mathrm{N}=393)$, Fit Statistics: -2 log likelihood $=2613.12$ (without covariates) and 2521.42 (with covariates), Global null hypothesis: Likelihood ratio chi-square test $=91.70(p \leq 0.05)$.

Model 2: US population $(N=9,677)$, Fit Statistics: -2 log likelihood $=103906.66$ (without covariates) and 100941.84 (with covariates), Global null hypothesis: Likelihood ratio chi-square test $=2964.82(p \leq 0.05)$.

Model 3: Combined WV + US population ( $N=10,070)$, Fit Statistics: -2 log likelihood $=108543.65$ (without covariates) and 105501.06 (with covariates), Global null hypothesis: Likelihood ratio chi-square test $=3042.59$ ( $p \leq 0.05$ ).

Source: West Virginia Cancer Registry - Medicare linked data files, 2002-2007, Surveillance, Epidemiology and End Results Medicare linked data files, 2002-2007. 


\section{Bibliography}

(1) American Cancer Society. Cancer Facts and Figures, 2012. Available at:http://www.cancer.org/acs/groups/content/@epidemiologysurveilance/docume nts/document/acspc-031941.pdf. Accessed on: January 15, 2013.

(2) U.S. National Institutes of Health. National Cancer Institute: SEER Cancer Statistics Review, 1973-2008. Available at: http://seer.cancer.gov/csr/1975_2009_pops09/index.html. Accessed on: January 15, 2013.

(3) Greenlee RT, Hill-Harmon MB, Murray T et al. Cancer statistics, 2001. CA Cancer J Clin 2001; 51(1):15-36.

(4) Alberg AJ, Ford JG, Samet JM. Epidemiology of lung cancer: ACCP evidencebased clinical practice guidelines (2nd edition). Chest 2007; 132(3 Suppl):29S55 S.

(5) National Cancer Institute: PDQ® Non-Small Cell Lung Cancer Treatment. Bethesda, MD: National Cancer Institute. Date last modified 11/05/2012. Available at: http://www.cancer.gov/cancertopics/pdq/treatment/non-small-celllung/healthprofessional. Accessed on January 19, 2013.

(6) Ihde DC, Minna JD. Non-small cell lung cancer. Part I: Biology, diagnosis, and staging. Curr Probl Cancer 1991; 15(2):61-104.

(7) National Cancer Institute: What you need to know about Lung Cancer [NIH Publication No. 07-1553]. Available at:

http://www.cancer.gov/cancertopics/wyntk/lung/page1. Accessed on: January 19, 2013.

(8) National Cancer Institute: $P D Q \circledast$ Small Cell Lung Cancer Treatment. Bethesda, MD: National Cancer Institute. Date last modified 1/20/2012. Available at: http://www.cancer.gov/cancertopics/pdq/treatment/small-celllung/healthprofessional. Accessed on January 19, 2013.

(9) Pfister DG, Johnson DH, Azzoli CG et al. American Society of Clinical Oncology treatment of unresectable non-small-cell lung cancer guideline: update 2003. J Clin Oncol 2004; 22(2):330-353.

(10) Diagnosis and management of lung cancer: ACCP evidence-based guidelines. American College of Chest Physicians. Chest 2003; 123(1 Suppl):D-337S.

(11) Clinical practice guidelines for the treatment of unresectable non-small-cell lung cancer. Adopted on May 16, 1997 by the American Society of Clinical Oncology. J Clin Oncol 1997; 15(8):2996-3018. 
(12) National Comprehensive Cancer Network and American Cancer Society: Lung Cancer: Treatment Guidelines for Patients. Version 1, December 2001. Available at: http://www.nccn.org. Accessed on: January 15, 2013.

(13) National Cancer Institute: Physician Data Query Cancer Information Summaries. Available at: http://www.nci.nih.gov/cancerinfo/pdf/treatment/non-small-celllung/healthprofessional/. Accessed on: January 15, 2013.

(14) Institute of Medicine Committee to Advise the Public Health Service on Clinical Practice Guidelines. Clinial practice guidelines: directions for a new program. Field M, Lohr Kn, eds. Washington, DC: National Academy Press, 1990.

(15) Bradley CJ, Dahman B, Given CW. Treatment and survival differences in older Medicare patients with lung cancer as compared with those who are dually eligible for Medicare and Medicaid. J Clin Oncol 2008; 26(31):5067-5073.

(16) Potosky AL, Saxman S, Wallace RB et al. Population variations in the initial treatment of non-small-cell lung cancer. J Clin Oncol 2004; 22(16):3261-3268.

(17) Earle CC, Venditti LN, Neumann PJ et al. Who gets chemotherapy for metastatic lung cancer? Chest 2000; 117(5):1239-1246.

(18) Fry WA, Phillips JL, Menck HR. Ten-year survey of lung cancer treatment and survival in hospitals in the United States: a national cancer data base report. Cancer 1999; 86(9):1867-1876.

(19) Bach PB, Cramer LD, Warren JL et al. Racial differences in the treatment of early-stage lung cancer. N Engl J Med 1999; 341(16):1198-1205.

(20) Hillner BE, McDonald MK, Desch CE et al. A comparison of patterns of care of nonsmall cell lung carcinoma patients in a younger and Medigap commercially insured cohort. Cancer 1998; 83(9):1930-1937.

(21) Smith TJ, Penberthy L, Desch CE et al. Differences in initial treatment patterns and outcomes of lung cancer in the elderly. Lung Cancer 1995; 13(3):235-252.

(22) Harlan LC, Greene AL, Clegg LX et al. Insurance status and the use of guideline therapy in the treatment of selected cancers. J Clin Oncol 2005; 23(36):90799088.

(23) Hewitt M, Simone JV, eds. Ensuring the Quality of Cancer Care. Washington, DC: National Academy Press; 1999.

(24) Hewitt M, Simone JV, eds. Enhancing Data Systems to Improve the Quality of Cancer Care. Washington, DC: National Acadamy Press; 2000.

(25) Behringer, B. (1994). Health care services in Appalachia. In: Couto, R. A., Simpson, N. K., and Harris, G. (eds.), Sowing Seeds in the Mountains, 
Community-based Coalitions for Cancer Prevention and Control. NIH Publication No. 94-3779:62-80. Bethesda, MD: NIH, National Cancer Institute.

(26) Newell-Withrow C. A glance at Appalachia. J Cult Divers 1997; 4(4):129-131.

(27) Monroe AC, Ricketts TC, Savitz LA. Cancer in rural versus urban populations: a review. J Rural Health 1992; 8(3):212-220.

(28) Ricketts, T. C. (Ed.) 1999. Rural health in the United States. New York, NY: Oxford University Press.

(29) Cancer death rates--Appalachia, 1994-1998. MMWR Morb Mortal Wkly Rep 2002; 51(24):527-529.

(30) West Virginia Health Care Authority (WVHCA) West Virginia State Health Plan. 2010. Available at: http://www.hcawv.org/PolicyPlan/shpBmat/shpProPiper.pdf. Accessed on: September 17, 2011.

(31) United States Cancer Statistics: 1999-2006 Incidence, WONDER On-line Database. United States Department of Health and Human Services, Centers for Disease Control and Prevention and National Cancer Institute; 2010. Available at http://wonder.cdc.gov/cancer-v2006.html. Accessed on: January 15, 2013.

(32) United States Cancer Statistics: 1999-2006 Mortality, WONDER On-line Database. United States Department of Health and Human Services, Centers for Disease Control and Prevention; 2010. Available at: http://wonder.cdc.gov/CancerMort-v2006.html. Accessed on: January 15, 2013.

(33) State-specific prevalence and trends in adult cigarette smoking--United States, 1998-2007. MMWR Morb Mortal Wkly Rep 2009; 58(9):221-226.

(34) Casto BC, Sharma S, Fisher JL et al. Oral cancer in Appalachia. J Health Care Poor Underserved 2009; 20(1):274-285.

(35) Wingo PA, Howe HL, Thun MJ et al. A national framework for cancer surveillance in the United States. Cancer Causes Control 2005; 16(2):151-170.

(36) Silverstein MD, Nietert PJ, Ye X et al. Access to care and stage at diagnosis for patients with lung cancer and esophageal cancer: analysis of the Savannah River Region Information System cancer registry data. South Med J 2002; 95(8):900-908.

(37) Hall HI, Uhler RJ, Coughlin SS et al. Breast and cervical cancer screening among Appalachian women. Cancer Epidemiol Biomarkers Prev 2002; 11(1):137-142. 
(38) Casey MM, Thiede CK, Klingner JM. Are rural residents less likely to obtain recommended preventive healthcare services? Am J Prev Med 2001; 21(3):182188.

(39) Wright JS, Champagne F, Dever GE et al. A comparative analysis of rural and urban mortality in Georgia, 1979. Am J Prev Med 1985; 1(1):22-29.

(40) Amey $\mathrm{CH}$, Miller MK, Albrecht SL. The role of race and residence in determining stage at diagnosis of breast cancer. J Rural Health 1997; 13(2):99-108.

(41) Warren JL, Klabunde CN, Schrag D et al. Overview of the SEER-Medicare data: content, research applications, and generalizability to the United States elderly population. Med Care 2002; 40(8 Suppl):IV-18.

(42) Nadpara PA, Madhavan SS. Linking Medicare, Medicaid, and Cancer Registry data to study the burden of cancers in West Virginia. Medicare Medicaid Res Rev 2012; 2(4):E1-E25.

(43) Mountain CF. A new international staging system for lung cancer. Chest 1986; 89(4 Suppl):225S-233S.

(44) Mountain CF. Revisions in the International System for Staging Lung Cancer. Chest 1997; 111(6):1710-1717.

(45) Agreement Between the SEER \& Medicare Claims Regarding the Month of Diagnosis. Available at: http://healthservices.cancer.gov/seermedicare/considerations/date.html. Accessed on: January 15, 2013.

(46) Charlson ME, Pompei P, Ales KL et al. A new method of classifying prognostic comorbidity in longitudinal studies: development and validation. J Chronic Dis 1987; 40(5):373-383.

(47) Deyo RA, Cherkin DC, Ciol MA. Adapting a clinical comorbidity index for use with ICD-9-CM administrative databases. J Clin Epidemiol 1992; 45(6):613-619.

(48) Romano PS, Roos LL, Jollis JG. Adapting a clinical comorbidity index for use with ICD-9-CM administrative data: differing perspectives. J Clin Epidemiol 1993; 46(10):1075-1079.

(49) US Census Bureau. 2000 Census of Population and Housing, Summary File 3: Washington, DC: US Census Bureau; 2002. Available at: http://www.census.gov/census2000/sumfile3.html. Accessed on : October 15, 2011.

(50) SAS Institute Inc. SAS 9.1.3 Help and Documentation. SAS Institute Inc., Cary, NC; 2000-2004. 
(51) Lin DY, Wei LJ. The robust inference for the Cox Proportional Hazards Model. J Am Stat Assoc 1989; 84(408):1074-1078.

(52) Potosky AL, Riley GF, Lubitz JD et al. Potential for cancer related health services research using a linked Medicare-tumor registry database. Med Care 1993; 31(8):732-748.

(53) Doebbeling BN, Wyant DK, McCoy KD et al. Linked insurance-tumor registry database for health services research. Med Care 1999; 37(11):1105-1115.

(54) Cooper GS, Yuan Z, Stange KC et al. The sensitivity of Medicare claims data for case ascertainment of six common cancers. Med Care 1999; 37(5):436-444.

(55) Du X, Freeman JL, Warren JL et al. Accuracy and completeness of Medicare claims data for surgical treatment of breast cancer. Med Care 2000; 38(7):719727.

(56) Brooks JM, Chrischilles E, Scott S et al. Information gained from linking SEER Cancer Registry Data to state-level hospital discharge abstracts. Surveillance, Epidemiology, and End Results. Med Care 2000; 38(11):1131-1140.

(57) Hewitt M, Simone JV. Enhancing Data Systems to Improve the Quality of Cancer Care. Washington, DC: National Academies Press; 2000.

(58) The Kaiser Family Foundation. Medicare and Medicare Advantage enrollment. Available at:

http://www.statehealthfacts.org/comparecat.jsp?cat=6\&rgn=6\&rgn=1. Accessed on : January 15, 2013. 
CHAPTER 3 


\section{CHAPTER 3:}

TIMELINESS OF LUNG CANCER CARE AND ASSOCIATED HEALTH OUTCOMES AMONG ELDERLY MEDICARE FEE-FOR-SERVICE BENEFICIARIES IN WEST VIRGINIA AND IN THE UNITED STATES

\section{Introduction}

Lung cancer is the most common cause of cancer death among elderly in the United States (US). ${ }^{1}$ Despite significant advances in treatment options, prognosis associated with lung cancer diagnosis remains poor, with five year survival of approximately $10 \%$. Cancer stage at diagnosis is the most important factor for survival among patients with lung cancer. If diagnosed at an early stage, standard surgical resection can result in five year survival rates of approximately $40 \%$ among patients with non-small cell lung cancer (NSCLC). ${ }^{2}$ Among patients diagnosed with early stage small cell lung cancer (SCLC), five-year survival rates of approximately $14 \%$ can be achieved with

chemotherapy and radiation therapy. ${ }^{3}$ Unfortunately, most lung cancers are found too late to cure, and the median survival times among those patients is typically 6 to 12 months. ${ }^{2 ; 3}$

Delays in lung cancer diagnosis can be attributed to patient's delay in seeking medical services, and/or physician delay in diagnosis. These delays may primarily result from lack of routine lung cancer screening tests for the general public. Furthermore, delayed diagnosis may also occur as lung cancer patients present with symptoms such as cough and dyspnoea, which are very common in general practice. 
Reducing diagnostic delays may increase the proportion of early stage cancers, and improve survival.

Elderly carry a disproportionate burden of lung cancer, since approximately $81 \%$ of those living with lung cancer are 60 years of age or older. ${ }^{1}$ Therefore, significant reduction in lung cancer mortality can also be achieved if the elderly receive timely and medically effective therapies following diagnosis. As lung cancer care requires complex coordination of services by a medical or surgical specialist, the traditional approach of referring patients for consultation with multiple specialists in a sequential fashion often results in care that is perceived slow. To establish standards for timely lung cancer care, clinical opinion-based guidelines have been published by the British Thoracic Society (BTS), the RAND Corporation, and by the American College of Chest Physicians (ACCP). ${ }^{4-6}$ However, extensive studies in European Union member countries have found delays in time to diagnosis and treatment of lung cancer than recommended in clinical opinion-based guidelines. ${ }^{7-21} \mathrm{~A}$ few studies performed in the US have shown mixed results. ${ }^{22-28}$ Dransfield and colleagues (2006) found median time to resection among NSCLC patients (104 days) exceed the 56-day maximum recommended by BTS. ${ }^{23}$ Similarly, Gould and colleagues (2008) found time to treatment among NSCLC patients often longer than recommended. ${ }^{28}$ On the contrary, Riedel and colleagues (2006) found less than expected median time to treatment initiation (22 days), while evaluating the benefits of multidisciplinary thoracic oncology clinics in a Veterans Affairs setting. ${ }^{22}$ In another study from Massachusetts, no differences in time to treatment were observed between Asian immigrants compared to non-Asians. ${ }^{26}$ While multidisciplinary clinics have been recommended in the literature 
to improve timeliness of care, patient care coordination through a dedicated lung mass clinic or a multidisciplinary clinic have not shown any reduction in delays in the US. ${ }^{4 ; 22 ; 23}$

Various factors have been associated with less timely care, and they include atypical symptoms, comorbid conditions, teaching hospital setting, receipt of curative (versus palliative) radiotherapy, initial referral to a non-respiratory physician, requirement for multiple diagnostic tests, and care received at more than one health care facility. ${ }^{11 ; 14 ; 29-32}$ However, gender, ${ }^{30}$ household income, ${ }^{14 ; 30}$ hospital volume,${ }^{30}$ rural residence, ${ }^{30}$ and distance travelled to obtain care ${ }^{14}$ have not been associated with timeliness of lung cancer care. Mixed results were observed in studies that examined effect of age on timeliness of lung cancer care..$^{11 ; 29-31}$

While timely lung cancer care is important, its impact on health outcomes remains unclear. Three studies from non-US countries reported poorer survival among patients with delayed diagnosis and treatment. ${ }^{33-35}$ However, four other studies from non-US countries found better median survival among patients that received less timely care.$^{8 ; 10 ; 36 ; 37}$ Similarly in the US, while two studies found no benefits in survival following timely care, only one study found survival benefits among patients with a solitary pulmonary nodule, making it unclear whether or not more timely care improves health outcomes. ${ }^{25 ; 27 ; 28}$ Delay in treatment also failed to explain the observed higher mortality risk from NSCLC in the only large population based study from Hawaii. ${ }^{24}$ Improving timeliness of lung cancer care is important regardless of its effect on health outcomes. It is particularly important for patients residing in rural areas of the US. Many rural areas of the US are economically underdeveloped and medically underserved, ${ }^{38 ; 39}$ and the elderly in these regions carry a higher burden of lung cancer 
compared to their urban counterparts. ${ }^{40}$ These rural areas are also known to report a higher prevalence of lung cancer and a higher crude all-cause mortality rate among the elderly. ${ }^{41 ; 42}$ One such area is the Appalachian region, a population representing $8.1 \%$ of the total US population. ${ }^{42}$ West Virginia (WV) is the only state situated entirely within the Appalachian region and is the third most rural state in the nation. ${ }^{42}$ Fifty of the 55 counties in the state are designated as medically underserved areas, and all or part of 40 counties in the state are classified as health professional shortage areas. ${ }^{43}$ During 2002-2006, the age-adjusted lung cancer incidence rate (WV: 481.5 per 100,000, US: 378.5 per 100,000$)$, and mortality rate (WV: 390.6 per 100,000 , US: 310.8 per 100,000 ) among the elderly were higher in the state in comparison to rest of the country. ${ }^{44 ; 45}$ Interestingly, the proportional difference in age-adjusted lung cancer mortality rates among the elderly from WV and the US was lower than the difference in age-adjusted lung cancer incidence rates. This might suggest better survival outcomes among elderly lung cancer patients in WV as compared to the US; however, such a hypothesis remains unexplored. The observed lung cancer disparities in the rural population can be attributed to limited access to quality medical care facilities, less access to or utilization of early cancer detection programs, increased prevalence of behavioral risk factors like tobacco use and sedentary life style, and socioeconomic factors, such as low income and education. ${ }^{46-52}$ In addition to being medically underserved, the rural population may also experiences variations in the quality, availability, and accessibility of services when compared to their urban counterparts. ${ }^{53}$

While numerous studies have examined timeliness of lung cancer care, a majority of them have been conduced in European Union healthcare settings. ${ }^{7-21}$ Few 
studies performed in the US were either limited to small sample sizes, restricted to NSCLC patients, included both elderly and non-elderly patients, focused on specific demographic subgroups, performed within specific health care settings, or failed to examine health outcomes associated with timely care. ${ }^{22-28 ; 54}$ As elderly carry a disproportionate burden of lung cancer in the US, studies that examine timeliness of lung cancer care, based on clinical opinion-based guidelines, and the associated health outcomes in the elderly are much needed. ${ }^{1}$ Furthermore, comparison of variations in timeliness of lung cancer care based on clinical opinion-based guidelines, and the associated health outcomes among the elderly from a diverse region like WV with those in the US may help to explain the observed geographical disparities in lung cancer mortality. To this end, the main focus of this study is to investigate and compare the timeliness of lung cancer care based on clinical opinion-based guidelines, among the elderly in WV, and in a representative US population. Specifically the objectives of this study include: (1) to compare delays in diagnosis and treatment among elderly with lung cancer in the WV-US populations; (2) to compare the proportion of elderly receiving timely lung cancer care based on clinical opinion-based guidelines in the WV-US populations; (3) to compare the factors associated with receipt of timely lung cancer care based on clinical opinion-based guidelines in the WV-US elderly populations; (4) to compare survival outcomes by receipt of timely lung cancer care based on clinical opinion-based guidelines in the WV-US elderly populations; and (5) to compare lung cancer mortality risk associated with non-receipt of timely lung cancer care based on clinical opinion-based guidelines in the WV-US elderly populations. 


\section{Methods}

\section{Data sources}

This retrospective study was conducted using cancer registry linked Medicare data files for the years 2002 through 2007. While the cancer registry data files provide clinical, demographic, cause of death, and initial treatment information for elderly individuals with lung cancer in selected geographic regions, the Medicare administrative data files provided the health service claims information for care provided by physicians, inpatient hospital stays, hospital outpatient clinics, home health care agencies, skilled nursing facilities, and hospice programs.

Specifically, the Surveillance, Epidemiology, and End Results (SEER) - Medicare linked data files were purchased from the National Cancer Institute, and were used to estimate the timeliness of lung cancer care based on clinical opinion-based guidelines in the elderly US population. The data from SEER program are representative of the US cancer incidence and mortality as they contain information from 20 populationbased cancer registries covering approximately 28 percent of the US population. ${ }^{55}$

To estimate the timeliness of lung cancer care based on clinical opinion-based guidelines in the elderly WV population, we used West Virginia Cancer Registry (WVCR) - Medicare linked data files. The WVCR-Medicare linked data files are similar in structure to the SEER-Medicare linked data files and represent data from the West Virginia Cancer Registry, which does not participate in the SEER program. Details on the creation of WVCR-Medicare linked data files can be found elsewhere. ${ }^{56}$ 


\section{Study populations}

We initially identified all Medicare Fee-for-service (FFS) beneficiaries, aged 66 years and older with incident lung cancer (Stages I-IV) diagnosis during the years 2003 through 2006 from the SEER-Medicare linked data files (hereafter referred to as 'US population') and the WVCR-Medicare linked data files (hereafter referred to as 'WV population'), separately. Lung cancer diagnosis was identified among individuals in the cancer registry files using International Classification of Diseases for Oncology (ICD-O) codes (C34.0, C34.1, C34.2, C34.3, C34.8, C34.9, and C33.9). Lung cancer stage was identified using American Joint Committee on Cancer (AJCC), Tumor Node Metastasis (TNM), $3^{\text {rd }}$ edition stage (for 2003 diagnosis) and $6^{\text {th }}$ edition stage (for 2004-2006

diagnosis). ${ }^{57 ; 58}$ While Medicare eligibility starts at age 65 , we only included beneficiaries aged 66 years and older at the time of diagnosis so that we would have a full year of Medicare claims before lung cancer diagnosis for assessing comorbidity. We then excluded individuals with multiple primary cancer diagnosis or whose diagnosis was made only at the time of death (death certificate review/autopsy diagnosis). We also excluded beneficiaries who were enrolled in Medicare managed care plan or who had non-continuous Medicare Part A and Part B enrollment in the year prior to diagnosis and during the year following diagnosis. This is because their Medicare files would not have complete treatment information. The remaining cohorts of continuously enrolled elderly Medicare FFS beneficiaries in the WV and US populations (study cohorts) were then used to compare delays in diagnosis and treatment. To compare the proportion of beneficiaries receiving timely lung cancer care, based on clinical opinion-based guidelines, and to compare the factors associated with receipt of timely 
lung cancer care, we subset the study cohorts to include only those beneficiaries that received any treatment during the year following diagnosis.

Given the limited years of data available for follow-up in our data sources, we further subset the above study cohorts for survival analysis. Specifically, we selected beneficiaries with lung cancer diagnosis during the years 2003 and 2004 in the study cohorts, and who received any treatment during the year following the diagnosis. We then followed these beneficiaries for three years after the incident lung cancer diagnosis to determine lung cancer specific mortality. These subsets of study cohorts were then used to compare survival outcomes by receipt of timely lung cancer care and to compare lung cancer mortality risk associated with non-receipt of timely lung cancer care.

\section{Assessing delays in diagnosis and treatment}

Continuously enrolled elderly Medicare FFS beneficiaries in the WV and US populations were followed during the year prior to the incident lung cancer diagnosis to determine delays in diagnosis. The delays in diagnosis were categorized as 'symptom to chest $\mathrm{x}$ ray' delay, 'chest x-ray to specialist visit' delay, specialist delay, and referral delay. Given the retrospective nature of our data sources, we estimated the occurrence of earliest lung cancer symptoms by identifying the date of the earliest Medicare claim, which had an International Classification of Diseases (ICD-9) code associated with symptoms of primary tumor (cough, weight loss, dyspnea, chest pain, hemoptysis, bone pain, clubbing, fever, weakness, superior vena cava obstruction, dysphagia, wheezing and stridor), symptoms of intrathoracic spread (recurrent laryngeal nerve palsy, pancost 
tumor/superior sulcus tumor, horner syndrome), symptoms of extrathoracic metastases (headache, nausealvomiting, seizures, confusion, personality change, musculoskeletal pain, syncope, lympadenopathylenlargement of lymph nodes, hoarseness, hepatomegaly, papilledema), or paraneoplastic syndromes (Appendix 3.1). The 'symptom to chest $\mathrm{x}$-ray' delay was then defined as the time from the earliest Medicare claim date, which had an ICD-9 code associated with lung cancer symptom, until the date of first Medicare claim for a chest x-ray. The 'chest x-ray to specialist visit' delay was defined as the time from the first Medicare claim for a chest x-ray until the date of first Medicare claim on which the service provider was a specialist, such as respiratory/chest physician, pulmonologist, oncologist, cardiologist, or thoracic/cardiac/regular surgeon. The specialist delay was defined as the time from the Medicare claim for the first specialist appointment until the date of cancer diagnosis. Among beneficiaries that were referred to the specialist, referral delay was defined as the time from the last Medicare claim associated with services provided by the referring physician, until the date of first Medicare claim on which the service provider was the referred specialist. The overall delay in diagnosis was defined as the time from the earliest Medicare claim date, which had an ICD-9 code associated with lung cancer symptom, until the date of cancer diagnosis. Delays in diagnosis were identified only among those beneficiaries who had Medicare claims associated with events of interest necessary to calculate the type of delay.

Continuously enrolled elderly Medicare FFS beneficiaries in the WV and US populations were followed for one year following incident lung cancer diagnosis to determine delays in treatment. Specifically, treatment delay was defined as the time 
from cancer diagnosis until the date of first Medicare claim for surgery, radiation, or chemotherapy. Lung cancer specific treatments and procedures were identified from the Medicare claim data files using appropriate ICD-9 diagnosis and procedure codes, Healthcare Common Procedure Coding System (HCPCS) codes, Current Procedural Terminology (CPT) codes and revenue center codes (Appendix 3.1).

Assessing receipt of timely lung cancer care based on clinical opinion-based guidelines Timeliness of lung cancer care based on clinical opinion-based guidelines (hereafter referred to as 'timely care') was determined among continuously enrolled elderly Medicare FFS beneficiaries who received treatment during the year following an incident lung cancer diagnosis in the WV and US populations. Timely care was defined using clinical opinion-based guidelines published by the BTS, and the RAND Corporation. ${ }^{4 ; 5}$ The British Thoracic Society recommends duration between first consultation with respiratory physician and surgery to be no more than eight weeks, between physician referral to see a clinical oncologist and start of radiotherapy to be no more than seven weeks, and between physician referral to see an oncologist and start of chemotherapy to be no more than four weeks, approximately. ${ }^{4}$ On the other hand, the RAND Corporation recommends that any planned treatment should be offered within six weeks of the diagnosis date. ${ }^{5}$ To incorporate recommendations from both guidelines, we defined timely care by selecting the maximum duration allowed under either guideline for a given type of treatment. Specifically, initial treatment was considered timely if the duration between diagnosis date and treatment date was no 
more than eight weeks for surgery, seven weeks for radiotherapy, and six weeks for chemotherapy.

\section{Dependent variables}

The primary outcome of interest was receipt of timely lung cancer care based on clinical opinion-based guidelines, which was categorized as (a) timely care, or (b) non-timely care. Survival time in days was calculated for each beneficiary from the time of incident lung cancer diagnosis to date of death or the three year follow-up cutoff date, which ever came first. To estimate lung cancer specific survival, beneficiaries who were not found to be deceased by the cutoff date, or who died due to causes other than lung cancer were censored at that time and considered to be alive. We measured lung cancer specific survival, instead of overall survival, as we wanted to determine the association between receipt of timely lung cancer care based on clinical opinion-based guidelines and survival.

While exact date of lung cancer diagnosis was available in the WVCR-Medicare linked data files to calculate survival time, the SEER-Medicare linked data files only contained the month and year of diagnosis. Hence, to approximate the date of lung cancer diagnosis in the US population, we used the earliest Medicare claim date, which had a lung cancer diagnosis code, and which was in the month of lung cancer diagnosis. This approximation is appropriate given the high level of agreement (nearly $90 \%$ ) within one month of diagnosis between the SEER diagnosis date and the first Medicare claim date with a cancer diagnosis. ${ }^{59}$ In cases were beneficiaries had no Medicare claims with a lung cancer diagnosis code, earliest date from any claim in the 
month of cancer diagnosis was used as the date of diagnosis. Finally, in beneficiaries with no Medicare claim in the month of diagnosis, the date of diagnosis was approximated as the $15^{\text {th }}$ day of the diagnosis month. Date of death was identified from Medicare enrollment records.

\section{Independent variables}

The main independent variables were lung cancer type and stage, age at diagnosis, gender, race, urban-rural residence, Charlson comorbidity index score, and census tract level measures of education and income. These variables were considered in our analysis because of their prognostic significance. Lung cancer type was categorized based on cell histology. Beneficiaries with ICD-O histology codes $8000-8040$ or 8046 9989 were categorized as NSCLC, and those with codes 8041-8045 were categorized as SCLC. Lung cancer stage was categorized based on AJCC TNM staging system. ${ }^{57 ; 58}$ Age at diagnosis was categorized as 66-69 years, 70-74 years, 75-79 years, and 80 years and older. Given that WV population is predominantly White, race was classified as White and others. Based on Rural-Urban Continuum codes developed by the US Department of Agriculture (USDA), urban-rural residence was categorized as Metro, Urban, and Rural. Charlson comorbidity index score was calculated using diagnosis and procedure codes reported in Medicare inpatient claims from the year prior to incident lung cancer diagnosis. ${ }^{60-62}$ Comorbidities related to cancer were excluded from the index score. The Charlson comorbidity index score was used to categorize comorbidity into three groups: 0,1 and 2 or more, with a higher score indicating a greater burden of comorbid illness. 
Given the lack of individual socioeconomic status measures in our data sources, we used as proxy the year 2000 US Census tract level measures of college education

and income. ${ }^{63}$ Specifically, we used the percentage of individuals in the census tract with some college education as a proxy measure for education, and categorized it based on tertile distribution (using WV population) as $0 \%-0.10 \%, 0.11 \%-0.20 \%$, and $0.21 \%$ or greater. Similarly, we used median household income at the census tract level as a proxy measure of income and categorized it based on tertile distribution (using the WV population) as $\$ 0-25,000, \$ 25,000-50,000$, and $\$ 50,001$ or more.

\section{Data Analysis}

The Pearson chi-square test was used to determine unadjusted associations between categorical variables of interest. Median delays (with $25 \%$ and $75 \%$ interquartiles) in diagnosis and treatment were calculated for each population. Non-parametric tests were used to compare delays, as the distribution was not normal. The Mann-Whitney test was used for pair wise comparison of delays, and the Kruskal-Wallis test was used for analyses involving multiple groups.

Three hierarchical generalized logistic models were constructed with PROC GLIMMIX procedure in SAS $9.2^{64}$ to assess the association between independent variables and the receipt of timely care. In each model, the estimated probability of a beneficiary receiving timely care conditioned on a set of predictor variables was modeled. First and second model included beneficiaries from the WV and US populations, respectively. The third model was constructed to determine population variation in likelihood of beneficiaries receiving timely care, and therefore included 
beneficiaries from both populations combined. The hierarchical model was chosen as individual measures of socioeconomic status were not available in our data sources, and since we relied on census tract level measures of education and income. This was done by treating census tract as a random effect to account for potential correlation among beneficiaries within the same county. Odds ratios, 95\% confidence intervals, and two-sided p-values were calculated for each predictor.

Non-parametric estimates of the survivor function by receipt of timely care were calculated for each population using the Kaplan-Meier method. The log-rank test was used to assess the statistical significance of the differences in survival outcomes. Three-year survival estimates were also computed by receipt of timely care within each population. Stratified analysis was performed by lung cancer type and stage within each population.

Three multivariate Cox proportional hazards models were constructed to estimate lung cancer mortality risk associated with non-receipt of timely care. First and second model included beneficiaries from the WV and US populations, respectively. The third model was constructed to determine population variation in lung cancer mortality risk, and therefore included beneficiaries from both populations combined. To evaluate the proportional hazards assumption, we plotted smoothed Schoenfeld residuals against time and found no evidence of a systematic deviation from proportional hazards in any model. Variance in all Cox models were adjusted to account for patient clustering at the census tract level by use of the robust inference of Lin and Wei. ${ }^{65}$ Stratified analysis was performed by lung cancer type and stage within 
each population. Adjusted hazard ratios, $95 \%$ confidence intervals, and their two-sided p-values were calculated for each predictor.

All data were analyzed using the SAS Version 9.2 (SAS Institute, Cary, NC) statistical software package. ${ }^{64}$ Results were considered to be statistically significant when $p \leq 0.05$. This study was approved by the West Virginia Institutional Review Board, and is in full compliance with federal, state, and institutional regulations and guidelines.

\section{Results}

Study population characteristics

Based on study inclusion and exclusion criteria, we identified 1,924 beneficiaries in WV population, and 48,850 beneficiaries in the US population. Table 3.1 shows the distribution of clinical and sociodemographic characteristics of these beneficiaries by type of lung cancer. Compared to beneficiaries with NSCLC in the US population, beneficiaries with NSCLC in WV population were younger, male, white, resided in nonmetro areas, had higher comorbidity score, and were diagnosed at earlier stages ( $p \leq$ 0.05). Similarly, compared to beneficiaries with SCLC in the US population, beneficiaries with SCLC in WV population were of white race, resided in non-metro areas, and were diagnosed at earlier stages $(p \leq 0.05)$. In both populations, beneficiaries with SCLC were diagnosed at late stages, compared to beneficiaries with NSCLC $(p \leq 0.05)$. In the US population, compared to beneficiaries with SCLC, 
beneficiaries with NSCLC were older, male, of non-white race, resided in metro areas, and had lower comorbidity scores $(p \leq 0.05)$.

\section{Delays in diagnosis and treatment}

Table 3.2 shows the earliest lung cancer symptoms reported among beneficiaries in the WV and US populations. In both population, common symptoms of primary tumor included chest pain, cough, weakness, and dyspnea. Table 3.3 shows the delays in diagnosis and treatment among beneficiaries in the WV and US populations. Median delay from symptom to diagnosis was approximately six months in each population. Diagnosis to treatment interval was less than a month on average, and was shorter among beneficiaries in the WV population as compared to the US population $(p \leq 0.05)$. Compared to beneficiaries in the US population, beneficiaries in the WV population had shorter referral delay, specialist delay, 'diagnosis to surgery' delay, and 'diagnosis to chemotherapy' delay $(p \leq 0.05)$. However, 'chest $x$-ray to specialist visit' delay was longer among beneficiaries in WV population as compared to the US population ( $p \leq$ $0.05)$.

Table 3.4 shows the delays in diagnosis and treatment in relation to clinical characteristics among beneficiaries in the WV and US populations. Longer delay in symptom to diagnosis was observed among female beneficiaries and among beneficiaries residing in urban areas in the $\mathrm{WV}$ population as compared to the US population $(p \leq 0.05)$. However, beneficiaries with no comorbid illness had shorter 'symptom to diagnosis' delay in the WV population, as compared to the US population $(p \leq 0.05)$. Significant population variation in diagnosis to treatment interval was 
observed by lung cancer type, stage, age, gender, race, urban-rural residence, and by comorbidity score. In all comparisons, the diagnosis to treatment interval was shorter among beneficiaries in WV population than in the US population $(p \leq 0.05)$. Within the two populations, beneficiaries with longer symptom to diagnosis delay were old aged, male sex, had higher comorbidity score, and were diagnosed at early stages $(p \leq 0.05)$. Significant variation in symptom to diagnosis delay by lung cancer type, race and urbanrural residence were only observed among beneficiaries in the US population $(p \leq 0.05)$. Longer diagnosis to treatment interval was observed among beneficiaries with NSCLC, and who were diagnosed at earlier stages, in both populations $(p \leq 0.05)$. Significant variation in diagnosis to treatment interval by age, race and comorbidity score were only observed among beneficiaries in the US population $(p \leq 0.05)$.

\section{Receipt of timely care}

In both populations, the proportion of beneficiaries receiving timely care was highest among those receiving radiation as initial therapy (WV: $80.1 \%$; US: 80.3\%). Among beneficiaries receiving chemotherapy as initial treatment, the proportion was higher in the WV population than in the US population $(79.6 \%$ vs. $74.6 \%)$. However, the proportion was lower among beneficiaries receiving surgery as initial treatment in WV population than in the US population $(75.9 \%$ vs. $76.8 \%)$.

Table 3.5 shows the descriptive characteristics of beneficiaries by receipt of timely care in the WV and US populations. Overall, the proportion of beneficiaries receiving timely care was $78.7 \%$ in the WV population and $77.5 \%$ in the US population. However, this population variation in overall receipt of timely care was not significant. 
Significant population variation in receipt of timely care was observed only among beneficiaries diagnosed in the year 2004. Specifically, the proportion of beneficiaries diagnosed in the year 2004 receiving timely care was higher in the WV population as compared to the US population ( $83.2 \%$ vs. $78.7 \%)(p \leq 0.05)$. In both populations, compared to beneficiaries receiving non-timely care, beneficiaries receiving timely care had SCLC and were diagnosed at late stage $(p \leq 0.05)$. Variations in receipt of timely care by age, race, urban-rural residence, comorbidity score, and year of diagnosis were only observed among beneficiaries in the US population $(p \leq 0.05)$.

\section{Factors associated with receipt of timely care}

Controlling for all sociodemographic variables, lung cancer type and stage remained strong predictors of receipt of timely care in all three models (Table 3.6). Specifically, compared to beneficiaries with late stage diagnosis, beneficiaries diagnosed at early stage were less likely to receive timely care and these odds gradually increased with increase in stage at diagnosis $(p \leq 0.05)$. Beneficiaries with NSCLC were also less likely to receive timely care as compared to beneficiaries with SCLC $(p \leq 0.05)$. While no other factor significantly predicted receipt of timely care in model 1 (WV population), age, race, comorbidity score, and census tract level measure of income significantly predicted receipt of timely care in model 2 (US population) and model 3 (Combined population). Compared to beneficiaries aged 80 years and older, beneficiaries aged 66 to 69 years were $10 \%$ more likely to receive timely care $(p \leq 0.05)$. Beneficiaries of nonwhite race were $21 \%$ less likely to receive timely care as compared to whites $(p \leq 0.05)$. The likelihood of receipt of timely care was also higher among beneficiaries with low 
comorbidity score compared to those with high comorbidity score $(p \leq 0.05)$. Finally, the likelihood of receipt of timely care decreased with decrease in median household income $(p \leq 0.05)$. Gender, urban-rural residence, and census tract level measure of education were not statistically significant in any model. After controlling for all sociodemographic variables, population variation in likelihood of beneficiaries receiving timely care was not significant.

\section{Survival outcomes by receipt of timely care}

Table 3.7 shows the three year survival rates and median survival times by receipt of timely care and by lung cancer type, among beneficiaries in the WV and US populations. Overall, timely care was associated with poorer survival outcomes only among beneficiaries in the US population ( $p \leq 0.05)$. In stratified analysis by lung cancer type, similar results were observed among beneficiaries in the US population ( $p$ $\leq 0.05)$. However, in the WV population timely care was associated with poorer survival outcomes only among beneficiaries with SCLC $(p \leq 0.05)$. Among those beneficiaries receiving non-timely care, survival outcomes were also poorer in the WV population as compared to the US population $(p \leq 0.05)$. Among beneficiaries receiving timely care, survival outcomes were better in the WV population as compared to the US population $(p \leq 0.05)$. Significant population variations in survival by receipt of timely care were also observed among beneficiaries in the stratified analysis by cancer type.

Figure 3.1 compares the three year Kaplan-Meier survival curves by cancer stage and by receipt of timely care in the WV and US populations. In both populations, among beneficiaries with early stage disease (stage I or stage II) better survival 
outcomes with receipt of timely care were observed, but were not significant. However, timely care was associated with significantly poorer survival outcomes among beneficiaries with stage IV disease in the WV population, and among those with stage III/IV disease in the US population. Significant population variation in survival outcomes by receipt of timely care were also observed among beneficiaries with late stage disease (stage III or stage IV), and were generally poorer in the WV population as compared to the US population.

\section{Lung cancer mortality risk associated with non-receipt of timely care}

In all Cox proportional hazards models, the adjusted lung cancer mortality risk was significantly lower among beneficiaries not receiving timely care, relative to those who did receive timely care (Table 3.8). Specifically, lung cancer mortality risk among beneficiaries not receiving timely care decreased by $25 \%$ in the WV population, by $32 \%$ in the US population, and by $31 \%$ in the combined population $(p \leq 0.05)$. In all models, NSCLC diagnosis, early stage disease, and young age were the only other factors independently associated with lower lung cancer specific mortality $(p \leq 0.05)$. While no other factor was independently associated with lung cancer specific mortality in model 1 (WV population), male sex, higher comorbidity score, less education and low income, were significantly associated with higher lung cancer specific mortality in model 2 (US population) and model 3 (Combined population). After controlling for all clinical and sociodemographic variables, and for timeliness of care, population variation in lung cancer mortality risk was significantly higher among beneficiaries in the WV population as compared to the US population. 
In stratified analysis by lung cancer type, receipt of non-timely care was associated with lower lung cancer specific mortality within each population $(p \leq 0.05)$ (Table 3.9). However, in stratified analysis by cancer stage, similar results were observed only among beneficiaries with stage IV disease in the WV population and among those with stage III/IV disease in the US population $(p \leq 0.05)$.

\section{Discussion}

Compared to other types of cancer, lung cancer diagnosis in the elderly is usually associated with poor prognosis. This burden is especially higher among elderly residing in rural and medically underserved regions of the US. ${ }^{38-40}$ Reducing delays in diagnosis and treatment of lung cancer have the potential to prolong survival in this population. In this study, using cancer registry-linked Medicare administrative data files, we compared geographic variations in timeliness of lung cancer care and associated health outcomes among elderly in a representative rural and medically underserved state population, and in a representative US population.

Overall, delays in diagnosis and treatment ranged widely and also varied significantly among beneficiaries with lung cancer in the WV and US populations. The median delay from symptom to diagnosis was more than six months in either population. Such delays may occur, as several invasive procedures may be needed to establish the diagnosis. These delays could be minimized if all investigations are planned during the initial visit to a physician. Compared to the US population, 'chest $x$ ray to specialist visit' delay was longer among beneficiaries in the WV population. This may have resulted from shortage of qualified health professionals in the medically 
underserved state. Longer 'symptom to diagnosis' delay was also observed among female beneficiaries and among beneficiaries residing in urban areas in the WV population, as compared to the US population. Diagnosis to treatment intervals were similar to that reported in a prior study by Riedel and colleagues, and were shorter among beneficiaries in the WV population as compared to the US population. ${ }^{22}$ In either population, surgically treated patients had longer delays than those treated nonsurgically, a difference that is likely to reflect the extra time needed to refer patents to thoracic surgeon for additional treatment consideration. A multidisciplinary team approach involving both surgeons and oncologist in the care process, may help to minimize such delay. ${ }^{6}$ Population variations in diagnosis and treatment delay were also observed by clinical characteristics, and may be related to differences in disease severity, comorbid illness burden, physician and/or individual treatment preferences.

Timely care was received by most beneficiaries in each population and was highest among those receiving radiotherapy. Contrary to what we expected, the proportion of beneficiaries receiving timely care did not vary between the two populations. Controlling for other factors, beneficiaries with NSCLC disease, as compared to SCLC disease, and those with early stage diagnosis as compared to late stage diagnosis, were less likely to receive timely care in both populations. This finding is likely as patients with limited disease may have to wait significantly longer for treatment than those with advanced disease. ${ }^{6}$ The finding also indicates that severity of disease at presentation may influence the speed of the medical decision-making process. Differences in receipt of timely care by age, race, comorbidity, and census tract level measure of income were only observed in the US population. Contrary to 
results from a prior study, increasing age was inversely associated with receipt of timely care in the US population. ${ }^{29}$ This may occur as compared to younger individuals some physicians may be conservative in their choice of aggressive treatment for the elderly, given its impact on patient morbidity and quality of life. Similar to results found in prior studies, comorbidity was inversely associated with receipt of timely care in the US population. ${ }^{30 ; 36}$ This may be due to less aggressive treatment approach by physicians in elderly with higher comorbidities, or due to individual preference to avoid aggressive treatments in favor of better quality of life. Increasing poverty was associated with a decrease in likelihood of receipt of timely care in the US population. Compared to the US population, the WV population is poorer and that may explain the non-significance of income on receipt of timely care among beneficiaries in the WV population. Similar to results found in a prior study, gender, urban-rural residence, and education were not associated with receipt of timely care in either population. ${ }^{30}$ After controlling for all sociodemographic variables, likelihood of receipt of timely care among beneficiaries in the WV and US populations were not significantly different.

This study is one of the few that have assessed the influence of timely lung cancer care on survival outcomes. Contrary to what would be expected, the results of this study indicate that non-timely care is not associated with poorer prognosis in lung cancer. This results corroborate findings from earlier studies. $8 ; 10 ; 24 ; 36 ; 37$ Survival outcomes associated with receipt of timely care varied by lung cancer type and stage among beneficiaries in both the populations. Similar to findings from prior studies, the association between shorter delay and poorer outcomes was most pronounced in patients with advanced stage disease in both populations. ${ }^{37}$ Compared to the US 
population, survival outcomes were poorer among beneficiaries receiving non-timely care and among those with late stage disease in the WV population. In both populations, we found the adjusted lung cancer mortality risk significantly lower among beneficiaries not receiving timely care than those who did receive such care. However, the magnitude of risk associated with non-receipt of timely care was higher in the WV population than in the US population. Young age, early stage disease, and NSCLC diagnosis were the only other factors independently associated with lower lung cancer mortality risk in both populations. This is true given that the treatment management for beneficiaries is easier among those with early stage disease compared to late stage disease, and is also easier also among those with NSCLC diagnosis compared to SCLC diagnoses. Variations in lung cancer mortality risk by sex, comorbidity score, education and income were only observed in the US population. In stratified analysis, by cancer type and stage, we again found the adjusted lung cancer mortality risk significantly lower among beneficiaries not receiving timely care than those who did receive such care, and the results were most pronounced in patients with advanced stage disease. After controlling for the variability associated with receipt of timely care and all sociodemographic variables, lung cancer mortality risk was significantly higher among beneficiaries in WV population as compared to the US population. This finding highlights the need to address underlying geographic disparities in lung cancer risk.

Based on mathematical models of lung cancer growth, it takes 10-15 years from appearance of the first cancer cell to the possibility of detecting lung cancer by conventional chest x-ray. ${ }^{66}$ Given this slow growth, it seems unlikely that the prognosis is changed by delay in diagnosis or treatment, and the results from this study agree to 
that theory. However, the tumor volume expands exponentially, and it can turn from being potentially curable to incurable over a period of 1 month. ${ }^{67}$ Timely care may therefore be beneficial in patients with tumors with aggressive phenotypes.

Nonetheless, delays in diagnosis and treatment should be avoided, as it may increase psychological stress in patients. ${ }^{68}$

Although delays in diagnosis and treatment varied between the two populations, significant population variation in receipt of timely care was not observed in this study. These findings are contrary to what would be expected given that the WV population is more rural and medically underserved, and has a higher lung cancer mortality rate, as compared to the US population. The finding suggests that observed geographic differences in lung cancer mortality may not be associated with variation in receipt of timely care among elderly beneficiaries with an incident diagnosis of lung cancer. However, population variation in lung cancer mortality risk was observed in this study. This may have resulted from higher lung cancer incidence in WV population, as compared to the US population. Higher incidence may also partly explain the disparities seen in lung cancer mortality among these populations. Future cancer prevention efforts directed towards promoting smoking cessation are much needed in rural WV population, where the smoking prevalence rates are the highest in the nation. ${ }^{69}$ In the long run, these cancer prevention efforts can help reduce the incidence of lung cancer in this rural population which in turn can help reduce the geographic disparities in lung cancer mortality.

The findings from this study are subject to several limitations. Although we used cancer registry linked claims data, an inherent limitation of using administrative claims 
data for epidemiologic studies is the possibility of misclassification as a result of coding errors. ${ }^{70 ; 71}$ However, claims data have been evaluated for their utility as a source of epidemiologic or health services information in cancer patients. ${ }^{70-74}$ Increasing the use of these types of data to assess the quality of cancer care has also been identified as a priority by the Institute of Medicine.$^{75}$ Studies using claims data are usually population based and have the potential to address a number of priority questions regarding the quality of cancer care and health care disparities. These population-based studies provide valuable information for future planning and prioritization of health programs that improve cancer outcomes. Therefore, there is an increasing interest in analyzing large health claims databases to assess treatment and outcomes for cancer..$^{70 ; 71 ; 75}$

The results of this study are generalizable only to the elderly Medicare FFS population aged 66 years and older, as encounter data for Medicare recipients enrolled in the managed care plan were not available for this study. There was a small increase in the percentage of Medicare recipients enrolled in managed care during the study years in both populations; in 2007 it was $\sim 16 \%$ in WV population and $\sim 19 \%$ in the US population. ${ }^{76}$ Information on care received by the Medicare recipients outside of the Medicare system or through non-Medicare providers was also not available in the claims data for our study. However, Medicare is the largest and most comprehensive insurance provider to the elderly in the US. Racial disparities in cancer outcomes could not be ascertained in this study as the populations were predominantly White.

One of the inclusion criteria for cohort selection in this study was continuous enrollment in Medicare Part A and B during the study period. This resulted in the noninclusion of individuals with non-continuous enrollment and the loss of individuals who 
were enrolled intermittently. Given the limitations in our data sources, the delays in diagnosis and treatment were defined appropriately using claim dates, and may not be exact. Retrospective review of health services usage to estimate date of earliest lung cancer symptoms was limited to the year prior to diagnosis since findings from prior research have shown delays in symptom to diagnosis to be less than a year. ${ }^{77}$ Our estimates of 'symptom to diagnosis' delay may be biased, as beneficiaries in whom earliest symptom date could not be identified were excluded from our analysis. These beneficiaries may have either had no health services usage or may have had no Medicare claim with an ICD-9 code associated with lung cancer symptom in the year prior to diagnosis. It is less likely that we missed any reported lung cancer symptom as the list of symptoms searched for in this study was comprehensive, and was derived from ACCP guidelines for management and treatment of lung cancer (Appendix 3.1). ${ }^{78}$ Overall, date of earliest lung cancer symptom was identified in $88 \%$ of beneficiaries in WV population, and in $90 \%$ of beneficiaries in the US population. Our estimates of 'symptom to diagnosis' delay may also be biased, as the earliest symptom identified may have been unrelated to lung cancer. We acknowledge that our definition of timely care may be too narrow, and that given the heterogeneity of patients seen by physicians, receipt of non-timely care or no care may still be considered appropriate. Furthermore, given the limitations in our data sources we could not determine whether delays in lung cancer diagnosis and treatment were attributable to patient's delay in seeking medical services. None the less, our definition of timely care provides a conceptual framework to assess and compare patterns of care that were prevalent during the years 2002 through 2007. Because of limited data availability at the time of 
study, we were unable to conduct a long-term (5-10 years) follow-up to assess the health outcomes associated with receipt of timely care. Individual level socioeconomic measures of educational attainment, marital status, and family income were also unavailable for this study. However aggregate measures of socioeconomic status at the census tract level from 2000 decennial census data were used as a proxy. Finally, our definition of timely versus non-timely care is limited to the data recorded in the claims such as the presence or absence of ICD-9 diagnosis and procedure codes, HCPCS procedure codes, CPT procedure codes and revenue center codes. Future studies can overcome the barriers seen in this study by collecting data on physician behaviors and patient preferences on treatment choices.

This study is the first of its kind to compare geographic variations in timely lung cancer care based on clinical opinion-based guidelines and associated health outcomes among elderly Medicare FFS beneficiaries. Although lung cancer diagnostic and management services are covered under Medicare program, delays in diagnosis and treatment among recipients in the Medicare FFS population are a concern. Increasing patient awareness of lung cancer symptoms and better coordination of care among providers may help to reduce the delays in diagnosis and treatment. Results of this study also emphasize the need to address disparities in receipt of timely care among recipients in the Medicare FFS population. Although longer delay in treatment is not associated with poorer prognosis, delayed care may increase the risk of disease progression and psychological stress in patients. Finally, increased lung cancer risk and incidence among the elderly from economically underdeveloped and medically underserved regions, such as WV, may be the reason behind observed geographical 
disparities in lung cancer mortality. Promoting smoking cessation among individuals residing in such rural areas has the potential to reduce observed geographic disparities in lung cancer mortality. 
Figure 3.1. Kaplan-Meier survival curves by cancer stage, and by receipt of timely lung cancer care, based on clinical opinion-based guidelines, among continuously enrolled Medicare Fee-for-service beneficiaries with incident diagnosis of lung cancer in West Virginia and in the United States from 2003 through 2004. Curves (unadjusted) show cause-specific mortality.
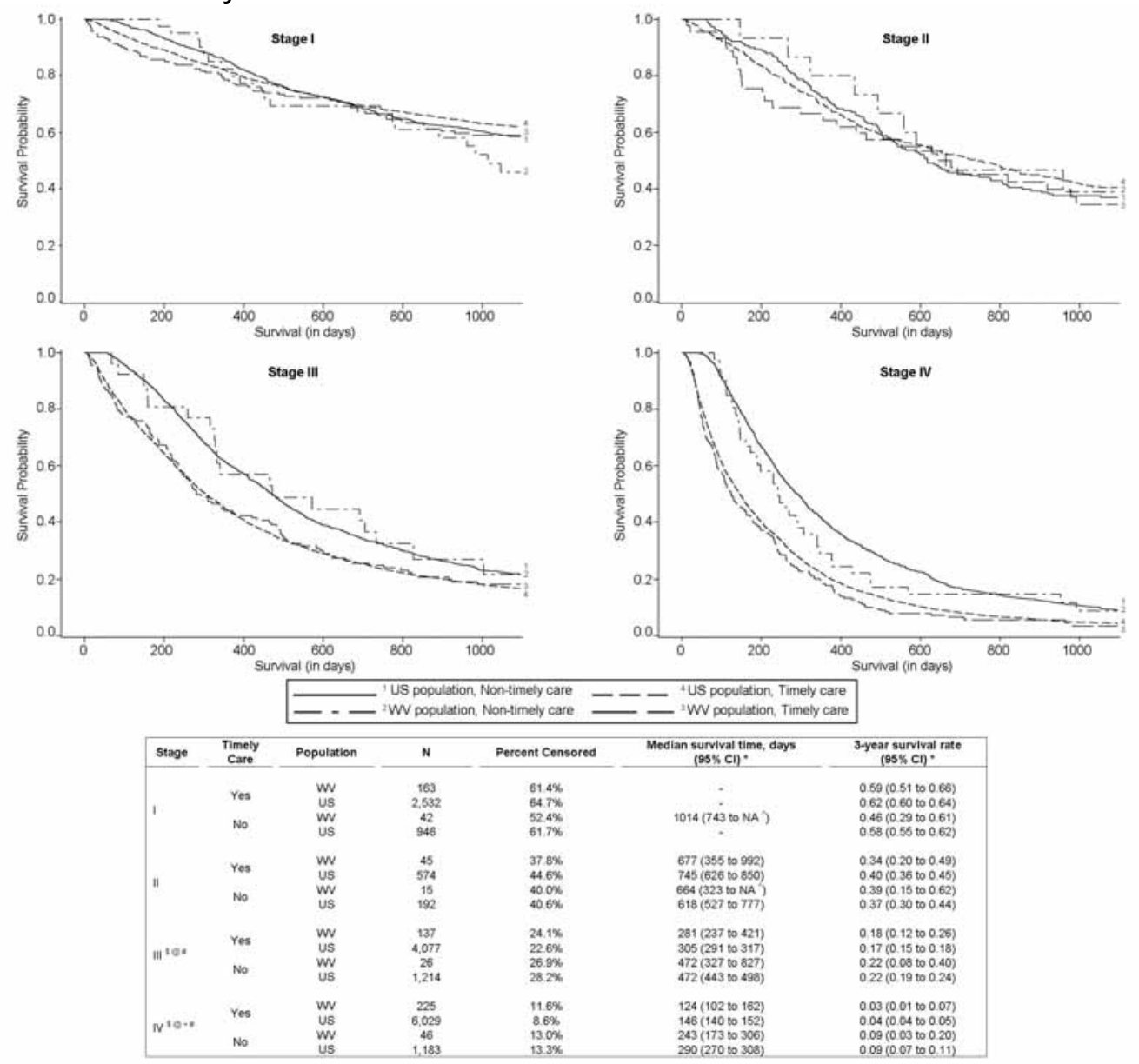

WV $=$ West Virginia population, US = United States population represented by the Surveillance, Epidemiology and End Results (SEER) population, $\mathrm{Cl}=$ confidence interval, - = median survival time not yet reached.

Stage based on American Joint Committee on Cancer (AJCC), Tumor Node Metastasis (TNM) system.

* Survival times and rates were obtained from Kaplan-Meier survival estimates.

$\wedge$ Upper limit of confidence interval is not available because of censoring.

Timeliness of lung cancer care determined using British Thoracic Society and RAND Corporation clinical opinion-based guidelines for diagnosis and management of lung cancer.

\# Log-rank test $(p \leq 0.05)$ comparing differences in survival by receipt of timely care, among beneficiaries within US population.

+ Log-rank test $(p \leq 0.05)$ comparing differences in survival by receipt of timely care, among beneficiaries within WV population.

$\$$ Log-rank test $(p \leq 0.05)$ comparing population differences in survival among beneficiaries receiving timely care.

@ Log-rank test $(p \leq 0.05)$ comparing population differences in survival among beneficiaries receiving non-timely care.

Source: West Virginia Cancer Registry - Medicare linked data files, 2002-2007, Surveillance, Epidemiology and End Results Medicare linked data files, 2002-2007. 
Table 3.1. Descriptive characteristics of continuously enrolled Medicare Fee-for-service beneficiaries with incident diagnosis of lung cancer in West Virginia and in the United States from 2003 through 2006.

\begin{tabular}{|c|c|c|c|c|}
\hline \multirow{3}{*}{ Characteristics } & \multicolumn{4}{|c|}{ Proportion (\%) } \\
\hline & \multicolumn{2}{|c|}{ NSCLC } & \multicolumn{2}{|c|}{ SCLC } \\
\hline & WV & US & WV & US \\
\hline Overall, n (\%) & $\begin{array}{l}1,641 \\
(85.3)\end{array}$ & $\begin{array}{c}42,089 \\
(86.2)\end{array}$ & $\begin{array}{c}283 \\
(14.7)\end{array}$ & $\begin{array}{l}6,761 \\
(13.8)\end{array}$ \\
\hline \multicolumn{5}{|l|}{ AJCC TNM stage ${ }^{*+\wedge}$} \\
\hline I & 27.1 & 20.8 & 7.1 & 5.5 \\
\hline II & 9.4 & 4.5 & 4.6 & 2.1 \\
\hline III & 23.6 & 29.3 & 25.8 & 30.3 \\
\hline IV & 39.9 & 45.5 & 62.5 & 62.1 \\
\hline \multicolumn{5}{|l|}{ Age (years) ${ }^{* \wedge}$} \\
\hline $66-69$ & 22.6 & 19.1 & 25.8 & 23.8 \\
\hline $70-74$ & 29.9 & 25.9 & 30.0 & 28.9 \\
\hline $75-79$ & 26.3 & 26.0 & 23.7 & 26.1 \\
\hline 80 or more & 21.2 & 28.9 & 20.5 & 21.1 \\
\hline \multicolumn{5}{|l|}{ Gender $^{* \wedge}$} \\
\hline Male & 58.0 & 52.1 & 53.0 & 47.4 \\
\hline Female & 42.0 & 47.9 & 47.0 & 52.6 \\
\hline \multicolumn{5}{|l|}{ Race $^{* \#^{\wedge}}$} \\
\hline Other & 2.1 & 13.3 & 0.7 & 9.4 \\
\hline White & 97.9 & 86.7 & 99.3 & 90.6 \\
\hline \multicolumn{5}{|l|}{ Urban-rural residence $^{* \#+\wedge}$} \\
\hline Metro & 54.2 & 83.1 & 60.4 & 80.1 \\
\hline Urban & 40.1 & 14.9 & 32.5 & 17.3 \\
\hline Rural & 5.7 & 2.0 & 7.1 & 2.6 \\
\hline \multicolumn{5}{|c|}{ Comorbidity, Charlson score ${ }^{* \wedge}$} \\
\hline 0 & 26.9 & 31.9 & 30.0 & 29.7 \\
\hline 1 & 30.0 & 28.6 & 30.0 & 28.5 \\
\hline 2 or more & 43.1 & 39.5 & 39.9 & 41.8 \\
\hline \multicolumn{5}{|l|}{ Year of diagnosis ${ }^{\star \wedge}$} \\
\hline 2003 & 22.1 & 26.7 & 25.1 & 26.0 \\
\hline 2004 & 25.5 & 24.5 & 25.4 & 26.2 \\
\hline 2005 & 25.9 & 24.6 & 25.4 & 24.5 \\
\hline 2006 & 26.6 & 24.2 & 24.0 & 23.3 \\
\hline
\end{tabular}


\# Chi-square test $(p \leq 0.05)$ measuring association between beneficiary characteristics and population type, among beneficiaries with small cell lung cancer.

+ Chi-square test $(p \leq 0.05)$ measuring association between beneficiary characteristics and cancer type, among beneficiaries in West Virginia population.

^ Chi-square test $(p \leq 0.05)$ measuring association between beneficiary characteristics and cancer type, among beneficiaries in United States population.

Source: West Virginia Cancer Registry - Medicare linked data files, 2002-2007, Surveillance, Epidemiology and End Results Medicare linked data files, 2002-2007. 
Table 3.2. Earliest symptoms reported among continuously enrolled Medicare Fee-forservice beneficiaries with incident diagnosis of lung cancer in West Virginia and in the United States from 2003 through 2006.

\begin{tabular}{|c|c|c|c|c|}
\hline \multirow[t]{2}{*}{ Symptom ^ } & \multicolumn{2}{|c|}{$\begin{array}{l}\text { West Virginia } \\
(N=1,702)\end{array}$} & \multicolumn{2}{|c|}{$\begin{array}{l}\text { United States } \\
(N=43,833)\end{array}$} \\
\hline & No. & $\%$ & No. & $\%$ \\
\hline \multicolumn{5}{|l|}{ Symptom of primary tumor } \\
\hline Cough & 262 & 15.4 & 6,143 & 14.0 \\
\hline Weight loss & 88 & 5.2 & 2,087 & 4.8 \\
\hline Dyspnea & 252 & 14.8 & 6,820 & 15.6 \\
\hline Chest pain & 372 & 21.9 & 8,947 & 20.4 \\
\hline Hemoptysis & 0 & 0.0 & 0 & 0.0 \\
\hline Bone pain & 44 & 2.6 & 1,107 & 2.5 \\
\hline Clubbing & 0 & 0.0 & 3 & 0.0 \\
\hline Fever & 35 & 2.1 & 925 & 2.1 \\
\hline Weakness & 254 & 14.9 & 6,519 & 14.9 \\
\hline Superior vena cava obstruction & 1 & 0.1 & 71 & 0.2 \\
\hline Dysphagia & 30 & 1.8 & 680 & 1.6 \\
\hline Wheezing and stridor & 31 & 1.8 & 462 & 1.1 \\
\hline $\begin{array}{l}\text { Symptoms of intrathoracic spread } \\
\text { Symptoms of extrathoracic }\end{array}$ & 37 & 2.2 & 1,228 & 2.8 \\
\hline metastases & 240 & 14.1 & 6,501 & 14.8 \\
\hline Paraneoplastic syndromes & 337 & 19.8 & 9,553 & 21.8 \\
\hline
\end{tabular}

United States population represented by the Surveillance, Epidemiology and End Results (SEER) population.

^Earliest symptoms reported among beneficiaries were identified from the earliest Medicare claim in the year prior to cancer diagnosis, which had an International Classification of Disease (ICD-9) code associated with lung cancer symptom.

Source: West Virginia Cancer Registry - Medicare linked data files, 2002-2007, Surveillance, Epidemiology and End Results Medicare linked data files, 2002-2007. 
Table 3.3. Delays in diagnosis and treatment among continuously enrolled Medicare Fee-for-service beneficiaries with incident diagnosis of lung cancer in West Virginia and in the United States from 2003 through 2006.

\begin{tabular}{|c|c|c|c|c|c|c|}
\hline \multirow{2}{*}{ Type of delay ${ }^{\wedge}$} & \multicolumn{3}{|c|}{ West Virginia } & \multicolumn{3}{|c|}{ United States ${ }^{\sim}$} \\
\hline & $\mathbf{N}$ & $\begin{array}{l}\text { Median } \\
\text { (days) }\end{array}$ & 25-75\% IQR (days) & $\mathbf{N}$ & $\begin{array}{l}\text { Median } \\
\text { (days) }\end{array}$ & $\begin{array}{l}\text { 25-75\% IQR } \\
\text { (days) }\end{array}$ \\
\hline Symptom to diagnosis ${ }^{+}$ & 1,702 & 189 & 39 to 313 & 43,833 & 187 & 36 to 308 \\
\hline \multirow{2}{*}{$\begin{array}{l}\text { Symptom to chest x-ray } \\
\text { Chest } x \text {-ray to specialist visit }\end{array}$} & 1,591 & 9 & 0 to 136 & 37,302 & 15 & 0 to 154 \\
\hline & 662 & 21 & 2 to 109 & 19,066 & 14 & 2 to 69 \\
\hline Referral delay * & 513 & 0 & 0 to 6 & 14,349 & 1 & 0 to 7 \\
\hline Specialist delay ${ }^{*}$ & 662 & 11 & 2 to 73 & 19,066 & 14 & 5 to 63 \\
\hline Diagnosis to treatment ${ }^{*}$ & 1,420 & 22 & 7 to 44 & 32,441 & 25 & 12 to 45 \\
\hline Diagnosis to surgery ${ }^{*}$ & 407 & 29 & 0 to 56 & 7,073 & 33 & 13 to 55 \\
\hline Diagnosis to radiation & 597 & 20 & 8 to 41 & 13,644 & 22 & 10 to 42 \\
\hline Diagnosis to chemotherapy * & 416 & 21 & 11 to 38 & 11,724 & 25 & 13 to 43 \\
\hline \multicolumn{7}{|c|}{ 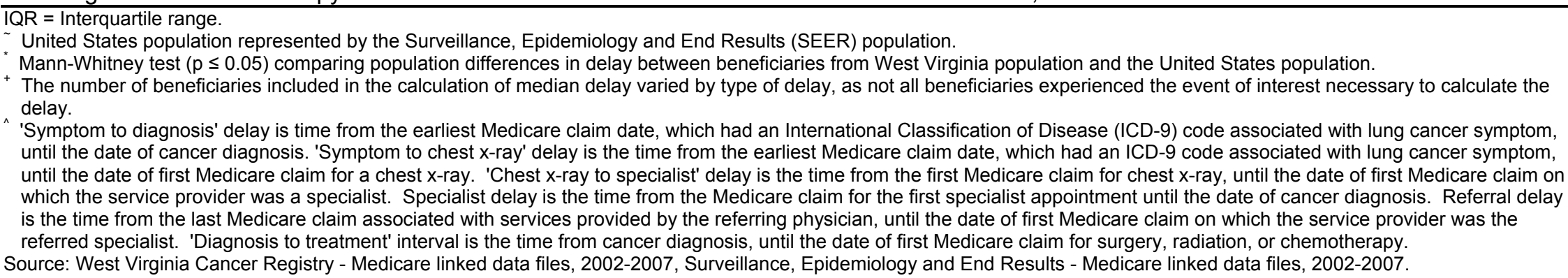 } \\
\hline
\end{tabular}


Table 3.4. Delays (in days) in diagnosis and treatment in relation to clinical characteristics among continuously enrolled Medicare Fee-for-service beneficiaries with incident diagnosis of lung cancer in West Virginia and in the United States from 2003 through 2006.

\begin{tabular}{|c|c|c|c|c|c|c|c|c|}
\hline \multirow{3}{*}{ Characteristics } & \multicolumn{4}{|c|}{ Symptom to diagnosis delay $^{\wedge}$} & \multicolumn{4}{|c|}{ Diagnosis to treatment interval $^{\wedge}$} \\
\hline & \multicolumn{2}{|r|}{ WV } & \multicolumn{2}{|r|}{ US } & \multicolumn{2}{|r|}{ WV } & \multicolumn{2}{|c|}{ US } \\
\hline & $\mathbf{N}$ & Median (IQR) & $\mathbf{N}$ & Median (IQR) & $\mathbf{N}$ & Median (IQR) & $\mathbf{N}$ & Median (IQR) \\
\hline \multicolumn{9}{|c|}{ Lung cancer type ${ }^{\sim \dagger}$} \\
\hline NSCLC \# & 1,456 & 193 (43 to 311$)$ & 37,792 & 188 (38 to 308$)$ & 1,217 & 24 (8 to 48 ) & 27,643 & 27 (13 to 48$)$ \\
\hline SCLC $\#$ & 246 & 155 (21 to 314$)$ & 6,041 & 178 (27 to 306$)$ & 203 & 14 (7 to 28$)$ & 4,798 & 18 (8 to 31$)$ \\
\hline \multicolumn{9}{|c|}{ AJCC TNM stage ${ }^{+\sim} @ \dagger$} \\
\hline $1^{\#}$ & 418 & 222 (66 to 319$)$ & 8,428 & 219 (63 to 319$)$ & 388 & 29 (6 to 55$)$ & 6,878 & 34 (15 to 58$)$ \\
\hline${ }{ }^{\#}$ & 154 & 215 (69 to 314$)$ & 1,847 & $188(40$ to 311$)$ & 133 & 29 (11 to 56$)$ & 1,682 & 33 (17 to 56$)$ \\
\hline $\mathrm{III}^{\#}$ & 407 & 175 (35 to 308$)$ & 12,916 & 189 (37 to 307$)$ & 342 & 22 (8 to 41$)$ & 9,679 & 26 (13 to 47$)$ \\
\hline $\mathrm{IV}^{\#}$ & 723 & 167 (28 to 307$)$ & 20,642 & 169 (28 to 302$)$ & 557 & 19 (7 to 35$)$ & 14,202 & 20 (9 to 37$)$ \\
\hline \multicolumn{9}{|l|}{ Age (years) ${ }^{+\sim \dagger}$} \\
\hline $66-69$ & 384 & 152 (23 to 307 ) & 8,441 & 146 (24 to 293 ) & 355 & 22 (8 to 45 ) & 7,404 & 24 (11 to 43$)$ \\
\hline $70-74^{\#}$ & 509 & 187 (43 to 307 ) & 11,487 & 174 (31 to 304$)$ & 454 & 22 (7 to 42$)$ & 9,483 & 25 (12 to 46$)$ \\
\hline $75-79^{\#}$ & 442 & 195 (44 to 308 ) & 11,477 & 197 (42 to 311$)$ & 365 & 22 (10 to 43 ) & 8,559 & 25 (12 to 46$)$ \\
\hline 80 or more ${ }^{\#}$ & 367 & 223 (54 to 322 ) & 12,428 & 213 (54 to 315 ) & 246 & 20 (7 to 49$)$ & 6,995 & 26 (12 to 48 ) \\
\hline \multicolumn{9}{|l|}{ Gender $^{+}$- } \\
\hline Male ${ }^{\#}$ & 921 & 151 (31 to 295 ) & 21,904 & 162 (27 to 299$)$ & 783 & 21 (7 to 42 ) & 16,645 & 25 (12 to 45$)$ \\
\hline Female ${ }^{*} \#$ & 781 & 225 (60 to 322$)$ & 21,929 & 209 (49 to 315$)$ & 637 & 22 (8 to 48 ) & 15,796 & 25 (12 to 46$)$ \\
\hline \multicolumn{9}{|l|}{ Race $^{\sim \dagger}$} \\
\hline Other & 30 & 221 (77 to 325$)$ & 5,500 & 191 (41 to 313 ) & 21 & 26 (15 to 56$)$ & 3,846 & 27 (12 to 51$)$ \\
\hline White ${ }^{\#}$ & 1,672 & 189 (39 to 312$)$ & 38,333 & 187 (36 to 307$)$ & 1,399 & 21 (7 to 44$)$ & 28,595 & 25 (12 to 45$)$ \\
\hline
\end{tabular}

\section{Urban-rural} residence 


$\begin{array}{lcccccccc}\text { Metro }^{\#} & 943 & 181(34 \text { to } 309) & 36,248 & 190(38 \text { to } 308) & 778 & 21(7 \text { to } 48) & 27,020 & 25(12 \text { to } 46) \\ \text { Urban }^{*} & 656 & 194(42 \text { to } 317) & 6,648 & 167(30 \text { to } 304) & 551 & 22(8 \text { to } 43) & 4,759 & 25(12 \text { to } 43) \\ \text { Rural }^{\#} & 103 & 209(78 \text { to } 298) & 937 & 169(27 \text { to } 299) & 91 & 19(7 \text { to } 41) & 662 & 25(12 \text { to } 44)\end{array}$

\section{Comorbidity,}

\section{Charlson score ${ }^{+\sim}$}

\begin{tabular}{|c|c|c|c|c|c|c|c|c|}
\hline $0 *$ & 388 & 29 (8 to 218$)$ & 12,127 & 43 (11 to 222 ) & 368 & 22 (9 to 45$)$ & 10,271 & 24 (12 to 43 ) \\
\hline $1^{\#}$ & 518 & 171 (47 to 304$)$ & 12,932 & 171 (40 to 296$)$ & 450 & 21 (7 to 43$)$ & 9,832 & 25 (12 to 45$)$ \\
\hline 2 or more ${ }^{\#}$ & 796 & 253 (112 to 329$)$ & 18,774 & 259 (122 to 331$)$ & 602 & $22(7$ to 44$)$ & 12,338 & 26 (12 to 47$)$ \\
\hline
\end{tabular}

WV = West Virginia population, US = United States population represented by the Surveillance, Epidemiology and End Results (SEER) population, NSCLC = Non-Small Cell Lung
Cancer, SCLC = Small Cell Lung Cancer, AJCC = American Joint Committee on Cancer, TNM = Tumor Node Metastasis, IQR $=25-75 \%$ Interquartile range.

Mann-Whitney test $(p \leq 0.05)$ comparing population differences in 'symptom to diagnosis' delay between beneficiaries from West Virginia population and the United States

population.

\# Mann-Whitney test $(p \leq 0.05)$ comparing population differences in 'diagnosis to treatment' interval between beneficiaries from West Virginia population and the United States population.

+ Kruskal-Wallis/Mann-Whitney test $(p \leq 0.05)$ comparing differences in 'symptom to diagnosis' delay among beneficiaries within West Virginia population.

@ Kruskal-Wallis/Mann-Whitney test $(p \leq 0.05)$ comparing differences in 'diagnosis to treatment' interval among beneficiaries within West Virginia population.

Kruskal-Wallis/Mann-Whitney test $(p \leq 0.05)$ comparing differences in 'symptom to diagnosis' delay among beneficiaries within the United States population.

† Kruskal-Wallis/Mann-Whitney test $(p \leq 0.05)$ comparing differences in 'diagnosis to treatment' interval among beneficiaries within the United States population.

'Symptom to diagnosis' delay is time from the earliest Medicare claim date, which had an International Classification of Disease (ICD-9) code associated with lung cancer symptom,

until the date of cancer diagnosis. 'Diagnosis to treatment' interval is the time from cancer diagnosis, until the date of first Medicare claim for surgery, radiation, or chemotherapy.

Source: West Virginia Cancer Registry - Medicare linked data files, 2002-2007, Surveillance, Epidemiology and End Results - Medicare linked data files, $2002-2007$. 
Table 3.5. Descriptive characteristics by receipt of timely lung cancer care, based on clinical opinion-based guidelines, among continuously enrolled Medicare Fee-forservice beneficiaries with incident diagnosis of lung cancer in West Virginia and in the United States from 2003 through 2006.

\begin{tabular}{|c|c|c|c|c|c|c|c|c|}
\hline \multirow{3}{*}{ Characteristics } & \multicolumn{4}{|c|}{ Timely Care $^{\sim}$} & \multicolumn{4}{|c|}{ Non-timely Care } \\
\hline & \multicolumn{2}{|c|}{ WV } & \multicolumn{2}{|c|}{ US } & \multicolumn{2}{|c|}{ WV } & \multicolumn{2}{|c|}{ US } \\
\hline & No. & $\%^{\#}$ & No. & $\%{ }^{\#}$ & No. & $\%^{\#}$ & No. & $\%{ }^{\#}$ \\
\hline Overall & 1,118 & 78.7 & 25,139 & 77.5 & 302 & 21.3 & 7,302 & 22.5 \\
\hline \multicolumn{9}{|c|}{ Lung cancer type $^{+\wedge}$} \\
\hline NSCLC & 935 & 76.8 & 20,960 & 75.8 & 282 & 23.2 & 6,683 & 24.2 \\
\hline SCLC & 183 & 90.2 & 4,179 & 87.1 & 20 & 9.9 & 619 & 12.9 \\
\hline \multicolumn{9}{|c|}{ AJCC TNM stage ${ }^{+\wedge}$} \\
\hline I & 287 & 74.0 & 4,924 & 71.6 & 101 & 26.0 & 1,954 & 28.4 \\
\hline II & 99 & 74.4 & 1,220 & 72.5 & 34 & 25.6 & 462 & 27.5 \\
\hline III & 271 & 79.2 & 7,315 & 75.6 & 71 & 20.8 & 2,364 & 24.4 \\
\hline IV & 461 & 82.8 & 11,680 & 82.2 & 96 & 17.2 & 2,522 & 17.8 \\
\hline \multicolumn{9}{|l|}{ Age (years) ${ }^{\wedge}$} \\
\hline 66-69 & 279 & 78.6 & 5,857 & 79.1 & 76 & 21.4 & 1,547 & 20.9 \\
\hline $70-74$ & 365 & 80.4 & 7,330 & 77.3 & 89 & 19.6 & 2,153 & 22.7 \\
\hline $75-79$ & 284 & 77.8 & 6,642 & 77.6 & 81 & 22.2 & 1,917 & 22.4 \\
\hline 80 or more & 190 & 77.2 & 5,310 & 75.9 & 56 & 22.8 & 1,685 & 24.1 \\
\hline \multicolumn{9}{|l|}{ Gender } \\
\hline Male & 626 & 79.9 & 12,953 & 77.8 & 157 & 20.1 & 3,692 & 22.2 \\
\hline Female & 492 & 77.2 & 12,186 & 77.1 & 145 & 22.8 & 3,610 & 22.9 \\
\hline \multicolumn{9}{|l|}{ Race ${ }^{\wedge}$} \\
\hline Other & 14 & 66.7 & 2,818 & 73.3 & 7 & 33.3 & 1,028 & 26.7 \\
\hline White & 1,104 & 78.9 & 22,321 & 78.1 & 295 & 21.1 & 6,274 & 21.9 \\
\hline \multicolumn{9}{|l|}{$\begin{array}{l}\text { Urban-rural } \\
\text { residence }^{\wedge}\end{array}$} \\
\hline Metro & 596 & 76.6 & 20,833 & 77.1 & 182 & 23.4 & 6,187 & 22.9 \\
\hline Urban & 446 & 80.9 & 3,777 & 79.4 & 105 & 19.1 & 982 & 20.6 \\
\hline Rural & 76 & 83.5 & 529 & 79.9 & 15 & 16.5 & 133 & 20.1 \\
\hline \multicolumn{9}{|l|}{$\begin{array}{l}\text { Comorbidity, } \\
\text { Charlson score }\end{array}$} \\
\hline 0 & 284 & 77.2 & 8,123 & 79.1 & 84 & 22.8 & 2,148 & 20.9 \\
\hline 1 & 361 & 80.2 & 7,638 & 77.7 & 89 & 19.8 & 2,194 & 22.3 \\
\hline 2 or more & 473 & 78.6 & 9,378 & 76.0 & 129 & 21.4 & 2,960 & 24.0 \\
\hline \multicolumn{9}{|l|}{ Year of diagnosis ^ } \\
\hline 2003 & 264 & 79.8 & 6,762 & 79.1 & 67 & 20.2 & 1,786 & 20.9 \\
\hline
\end{tabular}




\begin{tabular}{lllllllll}
$2004^{*}$ & 306 & 83.2 & 6,450 & 78.7 & 62 & 16.8 & 1,749 & 21.3 \\
2005 & 278 & 77.0 & 6,214 & 77.5 & 83 & 23.0 & 1,804 & 22.5 \\
2006 & 270 & 75.0 & 5,713 & 74.4 & 90 & 25.0 & 1,963 & 25.6 \\
\hline
\end{tabular}

WV = West Virginia population, US = United States population represented by the Surveillance, Epidemiology and End Results (SEER) population, NSCLC $=$ Non-Small Cell Lung Cancer, SCLC $=$ Small Cell Lung Cancer, AJCC $=$ American Joint Committee on Cancer, TNM = Tumor Node Metastasis.

- Timeliness of lung cancer care determined using British Thoracic Society and RAND Corporation clinical opinion-based guidelines

for diagnosis and management of lung cancer.

\# Proportions reported are row percentages of beneficiaries receiving timely care, or non-timely care, within WV or the US population.

Chi-square test $(p \leq 0.05)$, measuring association between receipt of timely care and population type, among beneficiaries within each row category.

+ Chi-square test $(p \leq 0.05)$ measuring association between beneficiary characteristics and receipt of timely care, among beneficiaries in West Virginia population.

^ Chi-square test $(p \leq 0.05)$ measuring association between beneficiary characteristics and receipt of timely care, among beneficiaries in United States population.

Source: West Virginia Cancer Registry - Medicare linked data files, 2002-2007, Surveillance, Epidemiology and End Results Medicare linked data files, 2002-2007. 
Table 3.6. Factors associated with receipt of timely lung cancer care, based on clinical opinion-based guidelines, among continuously enrolled Medicare Fee-for-service beneficiaries with incident diagnosis of lung cancer in West Virginia and in the United States from 2003 through 2006.

\section{Odds Ratio (95\% Confidence Interval)}

\begin{tabular}{|c|c|c|c|}
\hline & Model 1: WV & Model 2: US & Model 3: WV + US \\
\hline Intercept (p-value) & 0.11 & 0.07 & 0.09 \\
\hline \multicolumn{4}{|l|}{ Population } \\
\hline WV & NA & NA & $1.03(0.85$ to 1.24$)$ \\
\hline US & NA & NA & 1 (Ref) \\
\hline \multicolumn{4}{|l|}{ Lung cancer type } \\
\hline NSCLC & $0.40^{* * *}(0.24$ to 0.66$)$ & $0.51^{* * *}(0.47$ to 0.56$)$ & $0.51^{* * *}(0.47$ to 0.56$)$ \\
\hline SCLC & 1 (Ref) & $1($ Ref) & 1 (Ref) \\
\hline \multicolumn{4}{|l|}{ AJCC TNM stage } \\
\hline 1 & $0.67^{*}(0.48$ to 0.93$)$ & $0.59^{* * *}(0.55$ to 0.64$)$ & $0.59^{* * *}(0.56$ to 0.64$)$ \\
\hline II & 0.69 (0.43 to 1.09$)$ & $0.60^{* * *}(0.53$ to 0.68$)$ & $0.60^{* * *}(0.54$ to 0.68$)$ \\
\hline III & 0.83 (0.58 to 1.19$)$ & $0.68^{* * *}(0.64$ to 0.73$)$ & $0.69^{* * *}(0.64$ to 0.73$)$ \\
\hline IV & 1 (Ref) & 1 (Ref) & 1 (Ref) \\
\hline \multicolumn{4}{|l|}{ Age (years) } \\
\hline $66-69$ & 1.06 (0.70 to 1.59$)$ & $1.10^{*}(1.02$ to 1.20$)$ & $1.10^{*}(1.01$ to 1.19$)$ \\
\hline $70-74$ & 1.24 (0.84 to 1.85$)$ & 1.02 (0.94 to 1.10$)$ & $1.02(0.95$ to 1.10$)$ \\
\hline $75-79$ & $1.06(0.71$ to 1.58$)$ & 1.07 (1.00 to 1.16$)$ & 1.07 (0.99 to 1.15$)$ \\
\hline 80 or more & 1 (Ref) & 1 (Ref) & 1 (Ref) \\
\hline \multicolumn{4}{|l|}{ Gender } \\
\hline Male & 1.16 (0.89 to 1.52$)$ & 1.05 (0.99 to 1.10$)$ & 1.05 (1.00 to 1.11$)$ \\
\hline Female & 1 (Ref) & 1 (Ref) & 1 (Ref) \\
\hline \multicolumn{4}{|l|}{ Race } \\
\hline Other & 0.60 (0.21 to 1.69$)$ & $0.79^{* * *}(0.73$ to 0.86$)$ & $0.79^{* * *}(0.73$ to 0.86$)$ \\
\hline White & 1 (Ref) & 1 (Ref) & 1 (Ref) \\
\hline \multicolumn{4}{|l|}{$\begin{array}{l}\text { Urban-rural } \\
\text { residence }\end{array}$} \\
\hline Metro & 0.63 (0.33 to 1.19$)$ & $0.89(0.72$ to 1.11$)$ & $0.86(0.70$ to 1.06$)$ \\
\hline Urban & 0.91 (0.48 to 1.73$)$ & $1.01(0.80$ to 1.26$)$ & $1.00(0.80$ to 1.23$)$ \\
\hline Rural & 1 (Ref) & 1 (Ref) & 1 (Ref) \\
\hline \multicolumn{4}{|l|}{$\begin{array}{l}\text { Comorbidity, } \\
\text { Charlson } \\
\text { score }\end{array}$} \\
\hline 0 & 0.85 (0.61 to 1.17$)$ & $1.13^{* * *}(1.06$ to 1.20$)$ & $1.12^{* * *}$ (1.05 to 1.19$)$ \\
\hline 1 & 1.07 (0.78 to 1.47$)$ & $1.08^{*}(1.01$ to 1.15$)$ & $1.07^{*}(1.01$ to 1.14$)$ \\
\hline 2 or more & 1 (Ref) & 1 (Ref) & 1 (Ref) \\
\hline
\end{tabular}




\author{
Percentage \\ with some \\ college \\ education ${ }^{\wedge}$ \\ 0.0-0.10 \\ 0.70 (0.24 to 2.08$)$ \\ 0.62 (0.01 to 0.69$)$ \\ 0.60 (0.51 to 0.72$)$ \\ $0.11-0.20$ \\ 1.01 (0.74 to 1.37 ) \\ 0.69 (0.11 to 0.75$)$ \\ 1.02 (1.00 to 1.90$)$ \\ 1 (Ref) \\ 1 (Ref) \\ 1 (Ref)

\section{Median \\ household \\ income ${ }^{\wedge}$}

$\begin{array}{lccc}0-25000 & 0.74(0.33 \text { to } 1.63) & 0.89^{*}(0.80 \text { to } 0.98) & 0.89^{*}(0.80 \text { to } 0.98) \\ 25001-50000 & 1.03(0.49 \text { to } 2.17) & 0.93(0.84 \text { to } 1.01) & 0.93 \text { (0.85 to } 1.02) \\ \geq 50001 & 1 \text { (Ref) } & 1 \text { (Ref) } & 1 \text { (Ref) }\end{array}$ \\ WV = West Virginia population, US = United States population represented by the Surveillance, Epidemiology and End Results \\ (SEER) population, Ref = reference category, NA = Not Applicable, NSCLC = Non-Small Cell Lung Cancer, SCLC $=$ Small Cell \\ Lung Cancer, AJCC = American Joint Committee on Cancer, TNM = Tumor Node Metastasis. \\ * Estimates are statistically significant $(p \leq 0.05)$. \\ ** Estimates are statistically significant $(p \leq 0.01)$. \\ **** Estimates are statistically significant $(p \leq 0.001)$. \\ $\wedge$ Census tract level measures of beneficiaries socioeconomic status. \\ Model 1: WV population $(N=1,420)$, Fit Statistics: -2 restricted log pseudo-likelihood $=6639.58$, Covariance parameter estimates: \\ Intercept $=$ county, estimate $=0.14$, standard error $=0.10$. \\ Model 2: US population $(\mathrm{N}=32,441)$, Fit Statistics: -2 restricted log pseudo-likelihood $=150424.20$, Covariance parameter \\ estimates: Intercept $=$ county, estimate $=0.09$, standard error $=0.02$. \\ Model 3: Combined WV + US population ( $\mathrm{N}=33,861)$, Fit Statistics: -2 restricted log pseudo-likelihood $=157037.00$, Covariance \\ parameter estimates: Intercept $=$ county, estimate $=0.09$, standard error $=0.02$. \\ Timeliness of lung cancer care determined using British Thoracic Society and RAND Corporation clinical opinion-based guidelines \\ for diagnosis and management of lung cancer. \\ Source: West Virginia Cancer Registry - Medicare linked data files, 2002-2007, Surveillance, Epidemiology and End Results - \\ Medicare linked data files, 2002-2007.
}


Table 3.7. Three-year median survival time and survival rate by cancer type, and by receipt of timely lung cancer care, based on clinical opinion-based guidelines, among continuously enrolled Medicare Fee-for-service beneficiaries with incident diagnosis of lung cancer in West Virginia and in the United States from 2003 through 2004.

\begin{tabular}{|c|c|c|c|c|}
\hline & \multicolumn{2}{|c|}{ Timely Care } & \multicolumn{2}{|c|}{ Non-timely Care } \\
\hline & WV & US & WV & US \\
\hline \multicolumn{5}{|l|}{ Overall ${ }^{\$ @ \# ~}$} \\
\hline $\mathrm{N}$ & 570 & 13,212 & 129 & 3,535 \\
\hline Percent censored & $30.9 \%$ & $25.2 \%$ & $31.8 \%$ & $32.8 \%$ \\
\hline Median survival time, days $(95 \% \mathrm{Cl})$ * & 299 (262 to 364$)$ & 273 (266 to 282$)$ & 467 (344 to 692) & 491 (466 to 508) \\
\hline 3-year survival rate $(95 \% \mathrm{Cl})$ * & $0.26(0.22$ to 0.30$)$ & $0.21(0.20$ to 0.22$)$ & $0.27(0.19$ to 0.35$)$ & $0.28(0.27$ to 0.30$)$ \\
\hline \multicolumn{5}{|l|}{ NSCLC ${ }^{\$ @ \#}$} \\
\hline $\mathrm{N}$ & 473 & 10,949 & 122 & 3,269 \\
\hline Percent censored & $34.7 \%$ & $27.9 \%$ & $32.8 \%$ & $33.9 \%$ \\
\hline Median survival time, days $(95 \% \mathrm{Cl})$ * & 364 (276 to 460$)$ & 281 (271 to 291$)$ & 472 (344 to 705$)$ & 500 (479 to 520$)$ \\
\hline 3-year survival rate $(95 \% \mathrm{CI})$ * & $0.30(0.26$ to 0.35$)$ & $0.24(0.23$ to 0.25$)$ & $0.28(0.20$ to 0.37$)$ & $0.29(0.28$ to 0.31$)$ \\
\hline \multicolumn{5}{|l|}{ SCLC $^{\$+\#}$} \\
\hline $\mathrm{N}$ & 97 & 2,263 & 7 & 266 \\
\hline Percent censored & $12.4 \%$ & $12.4 \%$ & $14.3 \%$ & $20.3 \%$ \\
\hline Median survival time, days $(95 \% \mathrm{Cl})$ * & 236 (164 to 270$)$ & 252 (239 to 266$)$ & 427 (113 to 958$)$ & 372 (324 to 428$)$ \\
\hline 3-year survival rate $(95 \% \mathrm{Cl})$ * & $0.06(0.02$ to 0.12$)$ & 0.07 (0.06 to 0.09$)$ & 0 & $0.16(0.11$ to 0.21$)$ \\
\hline \multicolumn{5}{|c|}{$\begin{array}{l}\text { WV }=\text { West Virginia population, US = United States population represented by the Surveillance, Epidemiology and End Results }(\mathrm{SEER}) \text { population, NSCLC = Non-Small cell lung } \\
\text { cancer, SCLC }=\text { Small cell lung cancer, } \mathrm{Cl}=\text { confidence interval. } \\
\text { * Survival times and rates were obtained from Kaplan-Meier survival estimates. } \\
\tilde{\$} \text { Timeliness of lung cancer care determined using British Thoracic Society and RAND Corporation clinical opinion-based guidelines for diagnosis and management of lung cancer. } \\
\text { @ Log-rank test }(p \leq 0.05) \text { comparing population differences in survival among beneficiaries receiving timely care. } \\
\text { \# Log-rank test }(p \leq 0.05) \text { comparing population differences in survival among beneficiaries receiving non-timely care. } \\
\text { + Log-rank test }(p \leq 0.05) \text { comparing differences in survival by receipt of timely care, among beneficiaries within US population. } \\
\text { Sogrank test }(p \leq 0.05) \text { comparing differences in survival by receipt of timely care, among beneficiaries within WV population. }\end{array}$} \\
\hline
\end{tabular}


Table 3.8. Lung cancer mortality risk associated with receipt of non-timely lung cancer care, based on clinical opinion-based guidelines, among continuously enrolled Medicare Fee-for-service beneficiaries with incident diagnosis of lung cancer in West Virginia and in the United States from 2003 through 2004.

Hazard Ratio (95\% Confidence Interval)

Model 1: WV Model 2: US

Model 3: WV + US

\section{Population \\ WV \\ US \\ Timeliness of care
Non-timely care
Timely care
Lung cancer type
NSCLC
SCLC}

AJCC TNM stage

I
II
III
IV

Age (years)

66-69

$70-74$

75-79

80 or more

$$
\begin{gathered}
0.16^{* * *}(0.12 \text { to } 0.22) \\
0.28^{* * *}(0.20 \text { to } 0.40) \\
0.49^{* * *}(0.39 \text { to } 0.62) \\
1 \text { (Ref) }
\end{gathered}
$$

$$
\begin{gathered}
\left.0.75^{*} \text { (0.60 to } 0.95\right) \\
1 \text { (Ref) } \\
\left.0.78^{*} \text { (0.61 to } 0.99\right) \\
1 \text { (Ref) }
\end{gathered}
$$

NA

NA

$$
\begin{gathered}
0.68^{* * *}(0.66 \text { to } 0.71) \\
1 \text { (Ref) }
\end{gathered}
$$

$$
\begin{gathered}
0.94^{* *}(0.90 \text { to } 0.98) \\
1 \text { (Ref) }
\end{gathered}
$$

$$
\begin{gathered}
0.93^{* *}(0.89 \text { to } 0.98) \\
1 \text { (Ref) }
\end{gathered}
$$

$$
\begin{gathered}
0.69^{* * *}(0.66 \text { to } 0.72) \\
1 \text { (Ref) }
\end{gathered}
$$

$$
\begin{gathered}
0.15^{* * *}(0.14 \text { to } 0.16) \\
0.28^{* * *}(0.25 \text { to } 0.31) \\
0.52^{* * *}(0.50 \text { to } 0.54) \\
1 \text { (Ref) }
\end{gathered}
$$

$$
\begin{gathered}
0.15^{\star \star *}(0.14 \text { to } 0.16) \\
0.28^{\star \star *}(0.25 \text { to } 0.31) \\
0.52^{* * *}(0.50 \text { to } 0.54) \\
1 \text { (Ref) }
\end{gathered}
$$

$$
\begin{gathered}
0.70^{\star * *}(0.66 \text { to } 0.75) \\
0.75^{\star * *}(0.71 \text { to } 0.79) \\
\left.0.80^{* * *} \text { ( } 0.77 \text { to } 0.84\right) \\
1 \text { (Ref) }
\end{gathered}
$$

$$
\begin{gathered}
0.71^{* * *}(0.67 \text { to } 0.75) \\
0.75^{\star * *}(0.71 \text { to } 0.79) \\
0.81^{* * *}(0.77 \text { to } 0.85) \\
1 \text { (Ref) }
\end{gathered}
$$

\section{Gender \\ Male \\ Female}

1.10 (0.91 to 1.32$)$
1 (Ref)

$$
\begin{gathered}
1.24^{* * *}(1.20 \text { to } 1.28) \\
1 \text { (Ref) }
\end{gathered}
$$

$1.23^{* * *}$ (1.19 to 1.27$)$ 1 (Ref)

\subsection{7 (0.61 to 2.61)}

1 (Ref)

$$
\begin{gathered}
0.97 \text { (0.90 to } 1.04) \\
1 \text { (Ref) }
\end{gathered}
$$

0.97 (0.91 to 1.04$)$

1 (Ref)

$$
\begin{gathered}
0.99 \text { (0.62 to } 1.58) \\
1.18 \text { (0.73 to } 1.91) \\
1 \text { (Ref) }
\end{gathered}
$$

$$
\begin{gathered}
1.00(0.88 \text { to } 1.14) \\
0.99(0.87 \text { to } 1.13) \\
1 \text { (Ref) }
\end{gathered}
$$

1.01 (0.89 to 1.14$)$

1.01 (0.88 to 1.15 )

1 (Ref)

\section{Comorbidity, Charlson} score

$$
\begin{aligned}
& 0 \\
& 1 \\
& 2 \text { or more }
\end{aligned}
$$

\author{
$0.92(0.74$ to 1.14$)$ \\ 0.93 (0.76 to 1.14 ) \\ 1 (Ref)
}
$0.87^{* * *}$ (0.83 to 0.91$)$
$0.90^{* * *}$ (0.86 to 0.94$)$ 1 (Ref)




\section{Percentage with some college education ${ }^{\wedge}$}
$0.0-0.10$
$0.11-0.20$
$\geq 0.21$

0.99 (0.43 to 2.29$)$
0.86 (0.69 to 1.07$)$
1 (Ref)

1.18 (0.66 to 2.11$)$

0.96 (0.56 to 1.63 )

$$
\begin{gathered}
1.91^{* *}(1.18 \text { to } 3.11) \\
1.89^{* *}(1.15 \text { to } 3.05) \\
1 \text { (Ref) }
\end{gathered}
$$

$1.15^{*}$ (0.56 to 2.36$)$

0.89 (0.72 to 1.09$)$

1 (Ref)

\section{Median household income ${ }^{\wedge}$}

$0-25000$
$25001-50000$
$\geq 50001$

1 (Ref)

\author{
$1.22^{* * *}(1.13$ to 1.33$)$
$1.10^{*}(1.02$ to 1.19$)$ \\ $1.22^{* * *}(1.13$ to 1.33$)$
$1.10^{*}(1.02$ to 1.19$)$
}

$1.22^{* * *}(1.13$ to 1.33$)$

1 (Ref)

WV = West Virginia population, US = United States population represented by the Surveillance, Epidemiology and End Results (SEER) population, NSCLC $=$ Non-Small Cell Lung Cancer, SCLC $=$ Small Cell Lung Cancer, AJCC $=$ American Joint Committee on Cancer, TNM = Tumor Node Metastasis, Ref = reference category, NA = Not Applicable.

* Estimates are statistically significant $(p \leq 0.05)$.

*** Estimates are statistically significant $(p \leq 0.01)$.

Estimates are statistically significant $(p \leq 0.001)$.

Census tract level measures of beneficiaries socioeconomic status.

Model 1: WV population ( $N=699)$, Fit Statistics: -2 log likelihood $=5767.84$ (without covariates) and 5511.39 (with covariates), Global null hypothesis: Likelihood ratio chi-square test $=256.4(p \leq 0.05)$.

Model 2: US population ( $\mathrm{N}=16,747)$, Fit Statistics: -2 log likelihood $=223470.70$ (without covariates) and 217646.99 (with covariates), Global null hypothesis: Likelihood ratio chi-square test $=5823.7(p \leq 0.05)$.

Model 3: Combined WV + US population ( $N=17,446)$, Fit Statistics: -2 log likelihood $=233349.14$ (without covariates) and 227268.20 (with covariates), Global null hypothesis: Likelihood ratio chi-square test $=6075.9(p \leq 0.05)$.

Timeliness of lung cancer care determined using British Thoracic Society and RAND Corporation clinical opinion-based guidelines for diagnosis and management of lung cancer.

Source: West Virginia Cancer Registry - Medicare linked data files, 2002-2007, Surveillance, Epidemiology and End Results Medicare linked data files, 2002-2007. 
Table 3.9. Adjusted lung cancer mortality risk associated with receipt of non-timely lung cancer care, based on clinical opinion-based guidelines, by cancer type and stage, among continuously enrolled Medicare Fee-for-service beneficiaries with incident diagnosis of lung cancer in West Virginia and in the United States from 2003 through 2004.

$\begin{array}{ccc}\text { Hazard Ratio ^ }(95 \% \text { Confidence Interval) } \\ \text { WV } & \\ 0.77^{*}(0.60 \text { to } 0.98) & & 0.68^{* * *}(0.65 \text { to } 0.71) \\ 0.33^{* * *}(0.19 \text { to } 0.57) & & 0.68^{* * *}(0.60 \text { to } 0.78)\end{array}$

$\begin{array}{ccc}\text { AJCC TNM stage } & & \\ \text { I } & 1.22(0.73 \text { to } 2.06) & 1.01(0.90 \text { to } 1.13) \\ \text { II } & 0.69(0.30 \text { to } 1.56) & 1.04(0.82 \text { to } 1.31) \\ \text { III } & 0.78(0.49 \text { to } 1.23) & 0.71^{* * *}(0.66 \text { to } 0.76) \\ \text { IV } & 0.53^{* * *}(0.39 \text { to } 0.74) & 0.58^{* * *}(0.55 \text { to } 0.62)\end{array}$

WV = West Virginia population, US = United States population represented by the Surveillance, Epidemiology and End Results (SEER) population, NSCLC $=$ Non-Small Cell Lung Cancer, SCLC $=$ Small Cell Lung Cancer, AJCC = American Joint Committee on Cancer, TNM = Tumor Node Metastasis.

* Estimates are statistically significant $(p \leq 0.05)$.

**** Estimates are statistically significant $(p \leq 0.001)$.

Hazard ratios associated with receipt of non-timely care (Reference: Receipt of timely care), adjusted for age, gender, race, urbanrural residence, comorbidity, and census tract level measure of education and income.

Timeliness of lung cancer care determined using British Thoracic Society and RAND Corporation clinical opinion-based guidelines for diagnosis and management of lung cancer.

Stage I: WV: $N=205$, US: $N=3,478$; Stage II: WV: $N=60$, US: $N=766$; Stage III: WV: $N=163$, US: $N=5,291 ;$ Stage IV: WV: $N=$ 271, US: $N=7,212$. NSCLC: WV: $N=595$, US: $N=14,218$; SCLC: $W V: N=104$, US: $N=2,529$.

Source: West Virginia Cancer Registry - Medicare linked data files, 2002-2007, Surveillance, Epidemiology and End Results Medicare linked data files, 2002-2007. 


\section{Bibliography}

(1) U.S. National Institutes of Health. National Cancer Institute: SEER Cancer Statistics Review, 1973-2008. Available at:

http://seer.cancer.gov/csr/1975_2009_pops09/index.html. Accessed on: January 15, 2013.

(2) Ihde DC, Minna JD. Non-small cell lung cancer. Part I: Biology, diagnosis, and staging. Curr Probl Cancer 1991; 15(2):61-104.

(3) National Cancer Institute: $P D Q \circledR$ Small Cell Lung Cancer Treatment. Bethesda, MD: National Cancer Institute. Date last modified 1/20/2012. Available at: http://www.cancer.gov/cancertopics/pdq/treatment/small-celllung/healthprofessional. Accessed on January 19, 2013.

(4) BTS recommendations to respiratory physicians for organising the care of patients with lung cancer. The Lung Cancer Working Party of the British Thoracic Society Standards of Care Committee. Thorax 1998; 53 Suppl 1:S1-S8.

(5) Reifel, J. L. Lung cancer. Asch, S. M.; Kerr, E. A.; Hamilton, E. G.; Reifel, J. L., and McGlynn, E. A. Quality of care for oncologic condition and HIV: a review of the literature and quality indicators. RAND; 2000; pp. 133-71. Rec \#: 657. 2011.

(6) Alberts WM, Bepler G, Hazelton T et al. Lung cancer. Practice organization. Chest 2003; 123(1 Suppl):332S-337S.

(7) Leo F, Venissac N, Poudenx M et al. Multidisciplinary management of lung cancer: how to test its efficacy? J Thorac Oncol 2007; 2(1):69-72.

(8) Neal RD, Allgar VL, Ali N et al. Stage, survival and delays in lung, colorectal, prostate and ovarian cancer: comparison between diagnostic routes. $\mathrm{Br} \mathrm{J}$ Gen Pract 2007; 57(536):212-219.

(9) Devbhandari MP, Soon SY, Quennell P et al. UK waiting time targets in lung cancer treatment: are they achievable? Results of a prospective tracking study. $\mathrm{J}$ Cardiothorac Surg 2007; 2:5.

(10) Comber H, Cronin DP, Deady S et al. Delays in treatment in the cancer services: impact on cancer stage and survival. Ir Med J 2005; 98(8):238-239.

(11) Salomaa ER, Sallinen S, Hiekkanen $\mathrm{H}$ et al. Delays in the diagnosis and treatment of lung cancer. Chest 2005; 128(4):2282-2288.

(12) Lewis NR, Le J, I, Baldwin DR. Under utilisation of the 2-week wait initiative for lung cancer by primary care and its effect on the urgent referral pathway. $\mathrm{Br} \mathrm{J}$ Cancer 2005; 93(8):905-908. 
(13) Lee J, Marchbank A, Goldstraw P. Implementation of the British Thoracic Society recommendations for organising the care of patients with lung cancer: the surgeon's perspective. Ann R Coll Surg Engl 2002; 84(5):304-308.

(14) Campbell NC, Elliott AM, Sharp L et al. Impact of deprivation and rural residence on treatment of colorectal and lung cancer. $\mathrm{Br} \mathrm{J}$ Cancer 2002; 87(6):585-590.

(15) Aragoneses FG, Moreno N, Leon P et al. Influence of delays on survival in the surgical treatment of bronchogenic carcinoma. Lung Cancer 2002; 36(1):59-63.

(16) Melling PP, Hatfield AC, Muers MF et al. Lung cancer referral patterns in the former Yorkshire region of the UK. Br J Cancer 2002; 86(1):36-42.

(17) Koyi H, Hillerdal G, Branden E. Patient's and doctors' delays in the diagnosis of chest tumors. Lung Cancer 2002; 35(1):53-57.

(18) Bozcuk H, Martin C. Does treatment delay affect survival in non-small cell lung cancer? A retrospective analysis from a single UK centre. Lung Cancer 2001; 34(2):243-252.

(19) Spurgeon P, Barwell F, Kerr D. Waiting times for cancer patients in England after general practitioners' referrals: retrospective national survey. BMJ 2000; 320(7238):838-839.

(20) Kesson E, Bucknall CE, McAlpine LG et al. Lung cancer--management and outcome in Glasgow, 1991-92. Br J Cancer 1998; 78(10):1391-1395.

(21) Christensen ED, Harvald T, Jendresen $M$ et al. The impact of delayed diagnosis of lung cancer on the stage at the time of operation. Eur J Cardiothorac Surg $1997 ; 12(6): 880-884$.

(22) Riedel RF, Wang X, McCormack M et al. Impact of a multidisciplinary thoracic oncology clinic on the timeliness of care. J Thorac Oncol 2006; 1(7):692-696.

(23) Dransfield MT, Lock BJ, Garver RI, Jr. Improving the lung cancer resection rate in the US Department of Veterans Affairs Health System. Clin Lung Cancer 2006; 7(4):268-272.

(24) Liu DM, Kwee SA. Demographic, treatment, and survival patterns for Native Hawaiians with lung cancer treated at a community medical center from 1995 to 2001. Pac Health Dialog 2004; 11(2):139-145.

(25) Quarterman RL, McMillan A, Ratcliffe MB et al. Effect of preoperative delay on prognosis for patients with early stage non-small cell lung cancer. J Thorac Cardiovasc Surg 2003; 125(1):108-113.

(26) Finlay GA, Joseph B, Rodrigues CR et al. Advanced presentation of lung cancer in Asian immigrants: a case-control study. Chest 2002; 122(6):1938-1943. 
(27) Yorio JT, Xie Y, Yan J et al. Lung cancer diagnostic and treatment intervals in the United States: a health care disparity? J Thorac Oncol 2009; 4(11):1322-1330.

(28) Gould MK, Ghaus SJ, Olsson JK et al. Timeliness of care in veterans with nonsmall cell lung cancer. Chest 2008; 133(5):1167-1173.

(29) Bardell T, Belliveau $P$, Kong $W$ et al. Waiting times for cancer surgery in Ontario: 1984-2000. Clin Oncol (R Coll Radiol ) 2006; 18(5):401-409.

(30) Simunovic $M$, Theriault ME, Paszat $L$ et al. Using administrative databases to measure waiting times for patients undergoing major cancer surgery in Ontario, 1993-2000. Can J Surg 2005; 48(2):137-142.

(31) Johnston GM, MacGarvie VL, Elliott $D$ et al. Radiotherapy wait times for patients with a diagnosis of invasive cancer, 1992-2000. Clin Invest Med 2004; 27(3):142156.

(32) Ringbaek T, Borgeskov S, Lange $P$ et al. Diagnostic and therapeutic process and prognosis in suspected lung cancer. Scand Cardiovasc J 1999; 33(6):337-343.

(33) Kashiwabara K, Koshi S, Itonaga $\mathrm{K}$ et al. Outcome in patients with lung cancer found on lung cancer mass screening roentgenograms, but who did not subsequently consult a doctor. Lung Cancer 2003; 40(1):67-72.

(34) Kanashiki $\mathrm{M}$, Satoh $\mathrm{H}$, Ishikawa $\mathrm{H}$ et al. Time from finding abnormality on massscreening to final diagnosis of lung cancer. Oncol Rep 2003; 10(3):649-652.

(35) Buccheri G, Ferrigno D. Lung cancer: clinical presentation and specialist referral time. Eur Respir J 2004; 24(6):898-904.

(36) Annakkaya AN, Arbak P, Balbay O et al. Effect of symptom-to-treatment interval on prognosis in lung cancer. Tumori 2007; 93(1):61-67.

(37) Myrdal G, Lambe M, Hillerdal G et al. Effect of delays on prognosis in patients with non-small cell lung cancer. Thorax 2004; 59(1):45-49.

(38) Behringer, B. (1994). Health care services in Appalachia. In: Couto, R. A., Simpson, N. K., and Harris, G. (eds.), Sowing Seeds in the Mountains, Community-based Coalitions for Cancer Prevention and Control. NIH Publication No. 94-3779:62-80. Bethesda, MD: NIH, National Cancer Institute.

(39) Newell-Withrow C. A glance at Appalachia. J Cult Divers 1997; 4(4):129-131.

(40) Monroe AC, Ricketts TC, Savitz LA. Cancer in rural versus urban populations: a review. J Rural Health 1992; 8(3):212-220.

(41) Ricketts, T. C. (Ed.) 1999. Rural health in the United States. New York, NY: Oxford University Press. 
(42) Cancer death rates--Appalachia, 1994-1998. MMWR Morb Mortal Wkly Rep 2002; 51(24):527-529.

(43) West Virginia Health Care Authority (WVHCA) West Virginia State Health Plan. 2010. Available at: http://www.hcawv.org/PolicyPlan/shpBmat/shpProPiper.pdf. Accessed on: September 17, 2011.

(44) United States Cancer Statistics: 1999-2006 Incidence, WONDER On-line Database. United States Department of Health and Human Services, Centers for Disease Control and Prevention and National Cancer Institute; 2010. Available at http://wonder.cdc.gov/cancer-v2006.html. Accessed on: January 15, 2013.

(45) United States Cancer Statistics: 1999-2006 Mortality, WONDER On-line Database. United States Department of Health and Human Services, Centers for Disease Control and Prevention; 2010. Available at: http://wonder.cdc.gov/CancerMort-v2006.html. Accessed on: January 15, 2013.

(46) State-specific prevalence and trends in adult cigarette smoking--United States, 1998-2007. MMWR Morb Mortal Wkly Rep 2009; 58(9):221-226.

(47) Casto BC, Sharma S, Fisher JL et al. Oral cancer in Appalachia. J Health Care Poor Underserved 2009; 20(1):274-285.

(48) Wingo PA, Howe HL, Thun MJ et al. A national framework for cancer surveillance in the United States. Cancer Causes Control 2005; 16(2):151-170.

(49) Silverstein MD, Nietert PJ, Ye X et al. Access to care and stage at diagnosis for patients with lung cancer and esophageal cancer: analysis of the Savannah River Region Information System cancer registry data. South Med J 2002; 95(8):900-908.

(50) Hall HI, Uhler RJ, Coughlin SS et al. Breast and cervical cancer screening among Appalachian women. Cancer Epidemiol Biomarkers Prev 2002; 11(1):137-142.

(51) Casey MM, Thiede CK, Klingner JM. Are rural residents less likely to obtain recommended preventive healthcare services? Am J Prev Med 2001; 21(3):182188.

(52) Wright JS, Champagne F, Dever GE et al. A comparative analysis of rural and urban mortality in Georgia, 1979. Am J Prev Med 1985; 1(1):22-29.

(53) Amey $\mathrm{CH}$, Miller MK, Albrecht SL. The role of race and residence in determining stage at diagnosis of breast cancer. J Rural Health 1997; 13(2):99-108.

(54) Halpern MT, Holden DJ. Disparities in timeliness of care for U.S. Medicare patients diagnosed with cancer. Curr Oncol 2012; 19(6):e404-e413. 
(55) Warren JL, Klabunde CN, Schrag D et al. Overview of the SEER-Medicare data: content, research applications, and generalizability to the United States elderly population. Med Care 2002; 40(8 Suppl):IV-18.

(56) Nadpara PA, Madhavan SS. Linking Medicare, Medicaid, and Cancer Registry data to study the burden of cancers in West Virginia. Medicare Medicaid Res Rev 2012; 2(4):E1-E25.

(57) Mountain CF. A new international staging system for lung cancer. Chest 1986; 89(4 Suppl):225S-233S.

(58) Mountain CF. Revisions in the International System for Staging Lung Cancer. Chest 1997; 111(6):1710-1717.

(59) Agreement Between the SEER \& Medicare Claims Regarding the Month of Diagnosis. Available at: http://healthservices.cancer.gov/seermedicare/considerations/date.html. Accessed on: January 15, 2013.

(60) Charlson ME, Pompei P, Ales KL et al. A new method of classifying prognostic comorbidity in longitudinal studies: development and validation. J Chronic Dis 1987; 40(5):373-383.

(61) Deyo RA, Cherkin DC, Ciol MA. Adapting a clinical comorbidity index for use with ICD-9-CM administrative databases. J Clin Epidemiol 1992; 45(6):613-619.

(62) Romano PS, Roos LL, Jollis JG. Adapting a clinical comorbidity index for use with ICD-9-CM administrative data: differing perspectives. J Clin Epidemiol 1993; 46(10):1075-1079.

(63) US Census Bureau. 2000 Census of Population and Housing, Summary File 3: Washington, DC: US Census Bureau; 2002. Available at: http://www.census.gov/census2000/sumfile3.html. Accessed on : October 15, 2011.

(64) SAS Institute Inc. SAS 9.1.3 Help and Documentation. SAS Institute Inc., Cary, NC; 2000-2004.

(65) Lin DY, Wei LJ. The robust inference for the Cox Proportional Hazards Model. J Am Stat Assoc 1989; 84(408):1074-1078.

(66) Geddes DM. The natural history of lung cancer: a review based on rates of tumour growth. $\mathrm{Br} \mathrm{J}$ Dis Chest 1979; 73(1):1-17.

(67) O'Rourke N, Edwards R. Lung cancer treatment waiting times and tumour growth. Clin Oncol (R Coll Radiol ) 2000; 12(3):141-144. 
(68) Deegan PC, Heath L, Brunskill J et al. Reducing waiting times in lung cancer. J R Coll Physicians Lond 1998; 32(4):339-343.

(69) Vital signs: current cigarette smoking among adults aged $>/=18$ years--United States, 2005-2010. MMWR Morb Mortal Wkly Rep 2011; 60(35):1207-1212.

(70) Potosky AL, Riley GF, Lubitz JD et al. Potential for cancer related health services research using a linked Medicare-tumor registry database. Med Care 1993; 31(8):732-748.

(71) Doebbeling BN, Wyant DK, McCoy KD et al. Linked insurance-tumor registry database for health services research. Med Care 1999; 37(11):1105-1115.

(72) Cooper GS, Yuan Z, Stange KC et al. The sensitivity of Medicare claims data for case ascertainment of six common cancers. Med Care 1999; 37(5):436-444.

(73) Du X, Freeman JL, Warren JL et al. Accuracy and completeness of Medicare claims data for surgical treatment of breast cancer. Med Care 2000; 38(7):719727.

(74) Brooks JM, Chrischilles E, Scott S et al. Information gained from linking SEER Cancer Registry Data to state-level hospital discharge abstracts. Surveillance, Epidemiology, and End Results. Med Care 2000; 38(11):1131-1140.

(75) Hewitt M, Simone JV. Enhancing Data Systems to Improve the Quality of Cancer Care. Washington, DC: National Academies Press; 2000.

(76) The Kaiser Family Foundation. Medicare and Medicare Advantage enrollment. Available at:

http://www.statehealthfacts.org/comparecat.jsp?cat=6\&rgn=6\&rgn=1. Accessed on : January 15, 2013.

(77) Olsson JK, Schultz EM, Gould MK. Timeliness of care in patients with lung cancer: a systematic review. Thorax 2009; 64(9):749-756.

(78) Beckles MA, Spiro SG, Colice GL et al. Initial evaluation of the patient with lung cancer: symptoms, signs, laboratory tests, and paraneoplastic syndromes. Chest 2003; 123(1 Suppl):97S-104S. 
CHAPTER 4 


\title{
CHAPTER 4:
}

\author{
PATTERNS OF RECEIPT OF TOBACCO-USE CESSATION COUNSELING \\ SERVICES AND ASSOCIATED HEALTH OUTCOMES AMONG ELDERLY MEDICARE \\ FEE-FOR-SERVICE BENEFICIARIES WITH LUNG CANCER, AND WITH A HISTORY \\ OF TOBACCO USE, IN WEST VIRGINIA
}

\section{Introduction}

Tobacco use is the leading preventable cause of lung cancer in the United States (US). It accounts for $90 \%$ of all lung cancer cases, and for $87 \%$ of all lung cancer deaths in the US. ${ }^{1}$ The causal association of tobacco use with lung cancer is one of the most thoroughly documented causal relationships in biomedical research. ${ }^{2 ; 3}$ More individuals die of lung cancer each year than the next three most common cancers combined (colon, breast, and prostate), and the efforts to decrease lung cancer mortality have been focused on early detection and treatment of lung cancer and smoking avoidance and cessation. ${ }^{4-7}$

Clinical practice guidelines for preventive care in lung cancer have been published by American Society of Clinical Oncology (ASCO), authors Biesalski et al, Cancer Guidance Group (CGG), College des Medecins du Quebec, National Cancer Institute (NCl), US Department of Health and Human Services (DHHS), and US Preventive Services Task Force..$^{8-13}$ While these guidelines recommend smoking cessation among asymptomatic individuals, it is strongly encouraged among individuals diagnosed with lung cancer. This is because, growing evidence suggests that smoking may compromise the effectiveness of lung cancer treatment, reduce the tolerance of 
patients for lung cancer treatment, and increase the risk of complications. ${ }^{14}$ Specifically, continued smoking following lung cancer diagnosis can interfere with cancer therapies, such as radiation therapy and chemotherapy, increase risk of infection due to surgery and decrease post-operative wound healing. ${ }^{14}$

Prior research has shown smoking to be common among patients at the time of lung cancer diagnosis, and that patients continue to smoke following diagnosis. In one study of smoking behavior among 840 adults with stage I non-small cell lung cancer (NSCLC), $60 \%$ of patients were smokers at the time of diagnosis, and only $40 \%$ of them had quit smoking after two years. ${ }^{15}$ However, almost $90 \%$ of patients had made one or more attempts to quit smoking, suggesting an increased motivation to quit. ${ }^{15}$ Continued smoking after lung cancer diagnosis was associated with lower quality of life among patients in one study. ${ }^{16}$ Among lung cancer patients receiving surgery, a history of smoking doubled the likelihood of complications in another study. ${ }^{17}$

Continued smoking, following lung cancer diagnosis, also increases the risk of metachronous tumors/new primary cancer for up to 20 years after original diagnosis. ${ }^{14}$ In two studies of survivors of small cell lung cancer (SCLC), the risk of a second cancer was higher among those who continued to smoke, and the risk was particularly higher following curative-intent therapy. ${ }^{18 ; 19}$ However, in individuals who stopped smoking at the time of diagnosis, the risk was no higher than in those who had stopped smoking at least six months before diagnosis.

Studies examining survival outcomes associated with continued smoking have reported mixed results. In one study of patients with SCLC, continued smokers had the poorest survival, followed by patients who had quit at diagnosis, and then by patients 
who had quit on average 2.5 years before diagnosis. ${ }^{20}$ However, survival curves of recent ex-smokers did not differ statistically from continued smokers. In another study, no significant differences in prognosis in resected stage I NSCLC patients, were observed on the basis of smoking status. ${ }^{21}$ Regardless of its impact on survival, promoting smoking cessation among lung cancer patients at the time of diagnosis is much needed. Time of cancer diagnosis has also been described as a teachable moment for intervening with smokers and providing cessation treatment. ${ }^{22}$

Given the fact that smoking is common among patients with lung cancer, preventive care services, such as tobacco-use cessation counseling can have a profound impact on health outcomes. To that end, many insurance agencies including Medicare cover tobacco-use cessation counseling services. Beginning in March 2005, the Centers for Medicare and Medicaid Services (CMS) began providing coverage for tobacco-use cessation counseling for outpatient and hospitalized beneficiaries, who were smokers and had a disease or adverse health effect that is tobacco related or who were taking a medication whose metabolism or effect is affected by tobacco use. ${ }^{23}$ However, the use of such services and its impact on health outcomes among elderly lung cancer patients remains unknown. To this end, the main focus of this study is to determine the patterns of receipt of tobacco-use cessation counseling services among elderly Medicare Fee-for-service (FFS) beneficiaries with lung cancer and with a history of tobacco use in a state population. Specifically, the objectives of this study include: (1) to determine the proportion of elderly lung cancer patients receiving tobacco-use cessation counseling services; (2) to determine the factors associated with receipt of tobacco-use cessation counseling services among elderly lung cancer patients; (3) to 
determine survival benefits associated with receipt of tobacco-use cessation counseling services among elderly lung cancer patients; and (4) to determine lung cancer mortality risk associated with non-receipt of tobacco-use cessation counseling services among elderly lung cancer patients.

\section{Methods}

\section{Data sources}

This retrospective study was conducted using cancer registry linked Medicare data files for the years 2004 through 2007. While cancer registry data files provide clinical, demographic, cause of death, initial treatment, and tobacco-use history information for elderly individuals with lung cancer in selected geographic regions, the Medicare administrative data files provided the health service claims information for care provided by physicians, inpatient hospital stays, hospital outpatient clinics, home health care agencies, skilled nursing facilities, and hospice programs.

Specifically, the West Virginia Cancer Registry (WVCR) - Medicare linked data files were used to estimate the receipt to tobacco-use cessation counseling services and associated health outcomes among elderly lung cancer patients with a history of tobacco use. The WVCR-Medicare linked data files are similar in structure to the well known Surveillance, Epidemiology, and End Results (SEER) - Medicare linked data files, and represent data from the West Virginia (WV) Cancer Registry, which does not participate in the SEER program. Unlike the SEER-Medicare data files, the WVCRMedicare data files contain information on history of tobacco use among individuals 
diagnosed with lung cancer, and were therefore used for this study. Details on the creation of WVCR-Medicare linked data files can be found elsewhere. ${ }^{24}$ West Virginia is also the third most rural state in the nation, and is the only state situated entirely within the Appalachian region, a region well known for cancer disparities. ${ }^{25}$ The state has the second highest lung cancer death rate and the highest smoking prevalence rate $(26.8 \%)$ in the nation. ${ }^{26}$ During 2002-2006, the age-adjusted lung cancer incidence rate (WV: 481.5 per 100,000, US: 378.5 per 100,000), and mortality rate (WV: 390.6 per 100,000, US: 310.8 per 100,000) among the elderly were higher in the state in comparison to rest of the country. ${ }^{27 ; 28}$ Fifty of the 55 counties in the state are designated as medically underserved areas, and all or part of 40 counties in the state are classified as health professional shortage areas. ${ }^{29}$ The state is similar to many other rural and medically underserved states, and therefore serves as an excellent laboratory for studying and addressing lung cancer disparities in the rural and medically underserved population.

\section{Study population}

We initially identified all Medicare FFS beneficiaries, aged 66 years and older with an incident lung cancer diagnosis between July 1, 2005 and October 31, 2007, and with a history of tobacco use from the WVCR-Medicare linked data files. Lung cancer diagnosis was identified among individuals in the cancer registry files using International Classification of Diseases for Oncology (ICD-O) codes (C34.0, C34.1, C34.2, C34.3, C34.8, C34.9, and C33.9). Lung cancer stage was identified using American Joint Committee on Cancer (AJCC), Tumor Node Metastasis (TNM), $6^{\text {th }}$ edition stage..$^{30 ; 31}$ 
While Medicare eligibility starts at age 65 , we only included beneficiaries aged 66 years and older at the time of diagnosis, so that we would have a full year of Medicare claims before lung cancer diagnosis for assessing comorbidity. We then excluded individuals with multiple primary cancer diagnosis or whose diagnosis was made only at the time of death (death certificate review/autopsy diagnosis). We also excluded beneficiaries who were enrolled in Medicare managed care plan or who had non-continuous Medicare Part A and Part B enrollment in the year prior to diagnosis, and during the two months following diagnosis. This is because their Medicare files would not have complete health services usage information. The remaining cohort (Cohort A) of continuously enrolled elderly Medicare FFS beneficiaries was then used to determine the proportion of beneficiaries receiving tobacco-use cessation counseling services, and to determine the factors associated with receipt of tobacco-use cessation counseling services.

Given the limited years of data available for follow up in our data sources, we identified a separate cohort to determine association between receipt of tobacco-use cessation counseling services and survival outcomes. Specifically, we selected beneficiaries aged 66 years and older, with an incident lung cancer diagnosis (Stages IIV) between July 1, 2005 and December 31, 2005, and with a history of tobacco use from the WVCR-Medicare linked data files. We then excluded individuals with multiple primary cancer diagnosis or whose diagnosis was made only at the time of death (death certificate reviewlautopsy diagnosis). We also excluded beneficiaries who were enrolled in Medicare managed care plan or who had non-continuous Medicare Part A and Part B enrollment, in the year prior to diagnosis and during the year following diagnosis. The remaining cohort (Cohort B) was then followed for two years following 
the incident lung cancer diagnosis to determine lung cancer specific mortality. This cohort was then used to determine survival benefits associated with receipt of tobaccouse cessation counseling services, and to determine lung cancer mortality risk associated with non-receipt of tobacco-use cessation counseling services.

\section{Assessing receipt of tobacco-use cessation counseling services}

In both cohort A and B, continuously enrolled elderly Medicare FFS beneficiaries were followed for two months following incident lung cancer diagnosis to determine receipt of tobacco-use cessation counseling services. A cessation counseling session refers to face-to-face patient contact by the practitioner following an incident lung cancer diagnosis and can be minimal (3 minutes or less), intermediate (3-10 minutes), or intensive (greater than 10 minutes). Tobacco-use cessation counseling services were identified from the Medicare claim data files using appropriate Current Procedural Terminology (CPT) codes (Appendix 4.1).

\section{Dependent variables}

The primary outcome of interest was receipt of tobacco-use cessation counseling services, which was categorized as: (a) receipt, or (b) non-receipt. Survival time in days was calculated for each beneficiary from the time of incident lung cancer diagnosis to date of death or the two year follow-up cutoff date, which ever came first. To estimate lung cancer specific survival, beneficiaries who were not found to be deceased by the cutoff date, or who died due to causes other than lung cancer were censored at that time and considered to be alive. We measured lung cancer specific survival instead of 
overall survival, since we wanted to determine the association between receipt of tobacco-use cessation counseling services and survival.

\section{Independent variables}

The main independent variables were lung cancer type and stage, age at diagnosis, gender, race, urban-rural residence, Charlson comorbidity index score, census tract level measures of education and income, and receipt of minimally appropriate clinical guideline based lung cancer care. These variables were considered in our analysis because of their prognostic significance. Lung cancer type was categorized based on cell histology. Beneficiaries with ICD-O histology codes $8000-8040$ or $8046-9989$ were categorized as NSCLC, and those with codes $8041-8045$ were categorized as SCLC. Lung cancer stage was categorized based on AJCC TNM staging system. ${ }^{30 ; 31}$ Age at diagnosis was categorized as 66-69 years, 70-74 years, 75-79 years, and 80 years and older. Given that the WV population is predominantly White, race was classified as White and others. Based on Rural-Urban Continuum codes developed by the US Department of Agriculture (USDA), urban-rural residence was categorized as Metro, Urban, and Rural. Charlson comorbidity index score was calculated using diagnosis and procedure codes reported in Medicare inpatient claims from the year prior to the incident lung cancer diagnosis. ${ }^{32-34}$ Comorbidities related to cancer were excluded from the index score. The Charlson comorbidity index score was used to categorize comorbidity into three groups: 0,1 and 2 or more, with a higher score indicating a greater burden of comorbid illness. 
Given the lack of individual socioeconomic status measures in our data sources, we used as proxy, the year 2000 US Census tract level measures of college education and income. ${ }^{35}$ Specifically, we used the percentage of individuals in the census tract with some college education as a proxy measure for education, and categorized it based on tertile distribution as $0 \%-0.10 \%, 0.11 \%-0.20 \%$, and $0.21 \%$ or greater. Similarly, we used median household income at the census tract level as a proxy measure of income, and categorized it based on tertile distribution as $\$ 0-25,000$, $\$ 25,000-50,000$, and $\$ 50,001$ or more.

To account for the variability in receipt of lung cancer treatment while estimating lung cancer mortality risk associated with non-receipt of tobacco-use cessation counseling services, we estimated the receipt of minimally appropriate clinical guideline based lung cancer care among beneficiaries in cohort B. Specifically, continuously enrolled elderly Medicare FFS beneficiaries in cohort B were followed for one year following incident lung cancer diagnosis to determine receipt of minimally appropriate clinical guideline based lung cancer care (hereafter referred to as 'minimally appropriate care'). Minimally appropriate care was defined using the American College of Chest Physicians (ACCP) evidence-based guidelines for diagnosis and management of lung cancer, published in January, $2003 .^{36}$ We choose ACCP evidence-based guidelines, as they are the most comprehensive of all published clinical guidelines. ${ }^{36-40}$ Figure 4.1 shows the algorithm adapted from the ACCP guidelines, and used to determine receipt of minimally appropriate care. Lung cancer specific treatments and procedures were identified from the Medicare claim data files using appropriate International Classification of Diseases (ICD-9) diagnosis and procedure codes, Healthcare Common 
Procedure Coding System (HCPCS) codes, Current Procedural Terminology (CPT) codes and revenue center codes (Appendix 4.1).

\section{Data Analysis}

The Pearson chi-square test was used to determine unadjusted associations between categorical variables of interest. Hierarchical generalized logistic model was constructed with PROC GLIMMIX procedure in SAS $9.2^{41}$ to assess the association between independent variables and the receipt of tobacco-use cessation counseling services. In the model, the estimated probability of a beneficiary receiving tobacco-use cessation counseling services conditioned on a set of predictor variables was modeled. The hierarchical model was chosen as individual measures of socioeconomic status were not available in our data sources, and that we relied on census tract level measures of education and income. This was done by treating census tract as a random effect to account for potential correlation among beneficiaries within the same county. Odds ratios, $95 \%$ confidence intervals, and two-sided p-values were calculated for each predictor.

Nonparametric estimates of the survivor function by receipt of tobacco-use cessation counseling services were calculated using the Kaplan-Meier method. The log-rank test was used to assess the statistical significance of the differences between the survival curves. Two-year survival estimates were also computed by receipt of tobacco-use cessation counseling services.

Two multivariate Cox proportional hazards models were constructed to estimate lung cancer mortality risk associated with non-receipt of tobacco-use cessation 
counseling services. While the first model controlled for variability in beneficiary's clinical and sociodemographic characteristics, the second model additionally controlled for the variability in receipt of lung cancer treatment. To evaluate the proportional hazards assumption, we plotted smoothed Schoenfeld residuals against time and found no evidence of a systematic deviation from proportional hazards in any model. Variance in Cox models were adjusted to account for patient clustering at the census tract level by use of the robust inference of Lin and Wei. ${ }^{42}$ Adjusted hazard ratios, 95\% confidence intervals and their two-sided p-values were calculated for each predictor.

All data were analyzed using the SAS Version 9.2 (SAS Institute, Cary, NC) statistical software package. ${ }^{41}$ Results were considered to be statistically significant when $p \leq 0.05$. This study was approved by the West Virginia Institutional Review Board, and is in full compliance with federal, state, and institutional regulations and guidelines.

\section{Results}

Based on study inclusion and exclusion criteria, we identified 922 continuously enrolled elderly Medicare FFS beneficiaries in cohort A. Table 4.1 shows the distribution of clinical and sociodemographic characteristics of these beneficiaries by type of lung cancer. Overall, majority of beneficiaries had late stage disease, were in the age group 70-74 years, were of white race, resided in metro areas, and had comorbidity scores of two or more. While a majority of these beneficiaries had NSCLC (82.8\%), the distribution of beneficiary characteristics by lung cancer type did not vary significantly, 
except by cancer stage. Specifically, compared to beneficiaries with SCLC, beneficiaries with NSCLC were diagnosed at earlier stages $(p \leq 0.05)$.

Receipt of tobacco-use cessation counseling services

Table 4.2 shows the descriptive characteristics of beneficiaries by receipt of tobaccouse cessation counseling services. Overall, the proportion of beneficiaries receiving tobacco-use cessation counseling services was high (76.7\%) in the study population. Receipt of tobacco-use cessation counseling services was higher among beneficiaries with early stage disease compared to those with late stage disease $(p \leq 0.05)$. Compared to older beneficiaries, the proportion of beneficiaries receiving tobacco-use cessation counseling services was also higher among younger beneficiaries, and the proportions significantly decreased with increase in age. Receipt of tobacco-use cessation counseling services was also higher among beneficiaries residing in rural areas as compared to those residing in non-rural areas $(p \leq 0.05)$. Variations in receipt of tobacco-use cessation counseling services by lung cancer type, gender, race, comorbidity score, and year of diagnosis were not observed among beneficiaries in the study population.

Factors associated with receipt of tobacco-use cessation counseling services Controlling for all sociodemographic variables, age remained a strong predictor of receipt of tobacco-use cessation counseling services (Table 4.3). Compared to beneficiaries aged 80 years and older, beneficiaries aged 66 to 69 years were more than twice likely to receive tobacco-use cessation counseling services, and these odds 
gradually decreased with increase in age. Other significant predictors of receipt of tobacco-use cessation counseling services were lung cancer stage and rural-urban residence. Specifically, beneficiaries with early stage disease were $55-65 \%$ more likely to receive tobacco-use cessation counseling services as compared to those with late stage disease. However, the likelihood of receipt of tobacco-use cessation counseling services was lower among beneficiaries residing in non-rural areas as compared to those residing in rural areas. Lung cancer type, gender, race, comorbidity, and census tract level measure of education and urban-rural residence were not statistically significant in the model.

Survival benefits associated with receipt of tobacco-use cessation counseling services Figure 4.2 compares the two year Kaplan-Meier survival curves by receipt of tobaccouse cessation counseling services in cohort B. The unadjusted two year survival rates and median survival times were significantly greater among beneficiaries receiving tobacco-use cessation counseling services as compared to those not receiving such services $(p \leq 0.05)$. Specifically, for beneficiaries who received tobacco-use cessation counseling services, the two year median survival time exceeded by 159 days in the study population $(p \leq 0.05)$.

Lung cancer mortality risk associated with non-receipt of tobacco-use cessation counseling services

Controlling for variability in beneficiary's clinical and sociodemographic characteristics, the adjusted lung cancer mortality risk among beneficiaries not receiving tobacco-use 
cessation counseling services was higher, but not significant (Table 4.4). The magnitude of this risk decreased slightly after controlling for variability in receipt of minimally appropriate care among beneficiaries. Receipt of minimally appropriate care, early stage disease, young age, rural residence, higher comorbid illness, and higher education, were the only factors independently associated with lower lung cancer specific mortality in the study population.

\section{Discussion}

Smoking is common among patients diagnosed with lung cancer. Promoting smoking cessation in these patients is important, as continued smoking has substantial adverse effects on treatment effectiveness, risk of second primary malignancies, and quality of life. Lung cancer diagnosis can be used by healthcare providers as a teachable moment for smoking cessation, as a patient's motivation and interest in smoking cessation may increase after such an event. In this study, using cancer registry-linked Medicare administrative data files, we determined the patterns of receipt of tobacco-use cessation counseling services among elderly Medicare FFS beneficiaries with lung cancer and with a history of tobacco use.

Tobacco-use cessation counseling services were received by more than half of all elderly Medicare FFS beneficiaries in the study population. The use of these services was higher among younger beneficiaries, and after controlling for other factors, increasing age at diagnosis was associated with decline in receipt of tobacco-use cessation counseling services. This finding may have resulted from variation in physician practice patterns, and/or individual treatment preferences. Compared to 
younger individuals, poor prognosis is common among older individuals, and that may influence physician's decision to not provide tobacco-use cessation counseling services. This observed variation in receipt of tobacco-use cessation counseling services may also be related to differences in disease severity, and burden of comorbid illness among beneficiaries. Furthermore, older individuals with poor prognosis may choose to not receive such services, regardless of its impact on health outcomes. Receipt of tobaccouse cessation counseling was also higher among elderly with early stage disease, as compared to those with late stage disease. This finding is expected, as beneficiaries with early stage disease are good candidates for curative therapy, and are expected to survive longer than those with late stage disease. Therefore, beneficiaries with early stage disease can expect to have substantial benefits in health outcomes following smoking cessation, as compared to those with late stage disease. This finding is similar to that reported in one study, where patients with late stage disease were less likely to enroll in smoking cessation programs as compared to those with early stage disease. ${ }^{43}$ Surprisingly, receipt of tobacco-use cessation counseling was found to be higher among beneficiaries residing in rural areas as compared to those residing in non-rural areas. This finding may have resulted from the fact that prevalence of smoking is higher among beneficiaries in rural areas, and that awareness of risks associated with continued smoking may be higher among these individuals and their providers, resulting in increased receipt of tobacco-use cessation counseling services.

Prior studies of impact of smoking cessation following lung cancer diagnosis on survival outcomes have shown mixed results. Although in this study we could not determine the success or failure of tobacco-use cessation counseling attempt, receipt of 
such services by beneficiaries was associated with longer survival times. However, it is very likely that this finding may have resulted from the increased disease severity among beneficiaries who did not receive tobacco-use cessation counseling services. When controlled for, such variability in patient clinical and sociodemographic characteristics, the adjusted lung cancer mortality risk was higher, but not significant, among beneficiaries not receiving tobacco-use cessation counseling services. Even after controlling for the variability in lung cancer care received among beneficiaries, the adjusted lung cancer mortality risk remained unchanged. Receipt of minimally appropriate care, early stage disease, young age, rural residence, higher comorbid illness, and higher education, were the only factors independently associated with lower lung cancer mortality risk. This finding is expected, as prognosis is better among beneficiaries receiving minimally appropriate care and among those with early stage disease. Although findings from this study show no increase in adjusted lung cancer mortality risk among beneficiaries not receiving tobacco-use cessation counseling services, promoting smoking cessation at any stage of the disease is important.

The findings from this study are subject to several limitations. A major limitation of this study is the lack of information on success or failure of tobacco-use cessation counseling attempts among beneficiaries receiving such services. Specifically, the data sources used for this study do not capture information on whether or not a beneficiary quit smoking following the receipt of tobacco-use cessation counseling services. Such information is necessary to accurately quantify the health benefits associated with receipt of tobacco-use cessation counseling services. Given the limited years of followup data, the frequency and intensity of tobacco-use cessation counseling attempts 
among beneficiaries was also not examined in this study. Also, any variation in type of counseling services offered by different providers was not captured in our data sources, and was not controlled for in our analysis. Although we used cancer registry-linked claims data, an inherent limitation of using administrative claims data for epidemiologic studies is the possibility of misclassification as a result of coding errors. ${ }^{44 ; 45}$ However, claims data have been evaluated for their utility as a source of epidemiologic or health services information in cancer patients. ${ }^{44-48}$ Increasing the use of these types of data to assess the quality of cancer care also has been identified as a priority by the Institute of Medicine. ${ }^{49}$ Studies using claims data are typically population-based and have the potential to address a number of priority questions regarding the quality of cancer care and health care disparities. These population-based studies provide valuable information for future planning and prioritization of health programs that improve cancer outcomes. Therefore, there is an increasing interest in analyzing large health claims databases to assess treatment and outcomes for cancer. ${ }^{44 ; 45 ; 49}$

The results of this study are generalizable only to the elderly Medicare FFS population, aged 66 years and older, as encounter data for Medicare recipients enrolled in the managed care plan were not available for this study. There was a small increase in the percentage of Medicare recipients enrolled in managed care during the study years; in 2007 it was $\sim 16 \%$ in WV population. ${ }^{50}$ Information on care received by the Medicare recipients outside of the Medicare system or through non-Medicare providers was also not available in the claims data for our study. However, Medicare is the largest and the most comprehensive insurance provider to the elderly in the US. Racial 
disparities in cancer outcomes could not be ascertained in this study, as the population was predominantly White.

One of the inclusion criteria for cohort selection in this study was continuous enrollment in Medicare Part A and B during the study period. This resulted in the noninclusion of individuals with non-continuous enrollment and the loss of individuals who were enrolled intermittently. Although the WV legislative rule requires cancer reporting sources to provide patient's tobacco-use history to the WVCR, few records with missing information on patient's tobacco-use history were identified and therefore excluded from these study. It is very likely that these individuals may have been diagnosed at the time of death (death certificate review/autopsy diagnosis) or the cancer reporting source may have failed to collect information on their tobacco-use history. We acknowledge that our definition of receipt of minimally appropriate care may be too narrow, and that given the heterogeneity of patients seen by physicians, receipt of no therapy may still be considered as appropriate care. None the less, our definition of receipt of minimally appropriate care provides a conceptual framework to assess and control for treatment variability among beneficiaries. Because of limited data availability at the time of study, we were unable to conduct a long-term (5-10 year) follow-up to assess the health outcomes associated with receipt of tobacco-use cessation counseling services. Individual-level socioeconomic measures of educational attainment, marital status, and family income were also unavailable for this study. However, aggregate measures of socioeconomic status at the census tract level from 2000 decennial census data were used as a proxy. Finally our assessment of tobacco-use cessation counseling services is limited to the data recorded in the claims. Future studies can overcome the barriers 
seen in this study by collecting data on success/failure of counseling attempts, and physician behaviors/patient preferences in using tobacco-use cessation counseling services.

Significant reduction in lung cancer mortality can be achieved if elderly receive timely and medically effective treatments. Promoting smoking cessation through tobacco-use cessation counseling services is of vital importance to ensure success of such treatments. The diagnosis of lung cancer can be used as a teachable moment for smoking cessation. Although smoking cessation is beneficial, barriers to successful smoking cessation attempt include patient's unwillingness to quit, comorbid conditions, or lack of access to care. ${ }^{43}$ Given that motivation to quit smoking may vary among smokers, physicians may benefit by understanding the underlying motivational issues through application of theories of behavior change. Specifically, the Stages of Change Model suggests that most individuals attempting to quit smoking may go through several predictable stages, from pre-contemplation to contemplation to preparation and, finally, to action. Successful counseling would help to move patients along these stages, until they are more motivated to quit.

This study is the first of its kind to determine the patterns of receipt of tobaccouse cessation counseling services among elderly Medicare FFS beneficiaries with lung cancer, and with a history of tobacco use. Although preventive care services, such as tobacco-use cessation counseling services are covered under Medicare program, underutilization of these services among elderly lung cancer patients with a history of tobacco use, is a concern. Most patients with smoking-related cancer would be motivated to quit smoking at the time of diagnosis, and promoting smoking cessation in 
these individuals may improve health outcomes. Although some encouraging results have been demonstrated with use of tobacco-use cessation counseling services in this study, more empirical studies of such interventions are needed. Also, future cancer prevention efforts should be directed towards promoting smoking cessation in rural populations, such as West Virginia, where the smoking prevalence rates are the highest in the nation. In the long run, these cancer prevention efforts can help reduce the incidence of lung cancer, which in turn can help reduce the burden of lung cancer mortality. 
Figure 4.1. Algorithm adapted from American College of Chest Physicians (ACCP) evidence-based guidelines for diagnosis and management of lung cancer published in January, 2003, and used to determine receipt of minimally appropriate clinical guideline based lung cancer care.

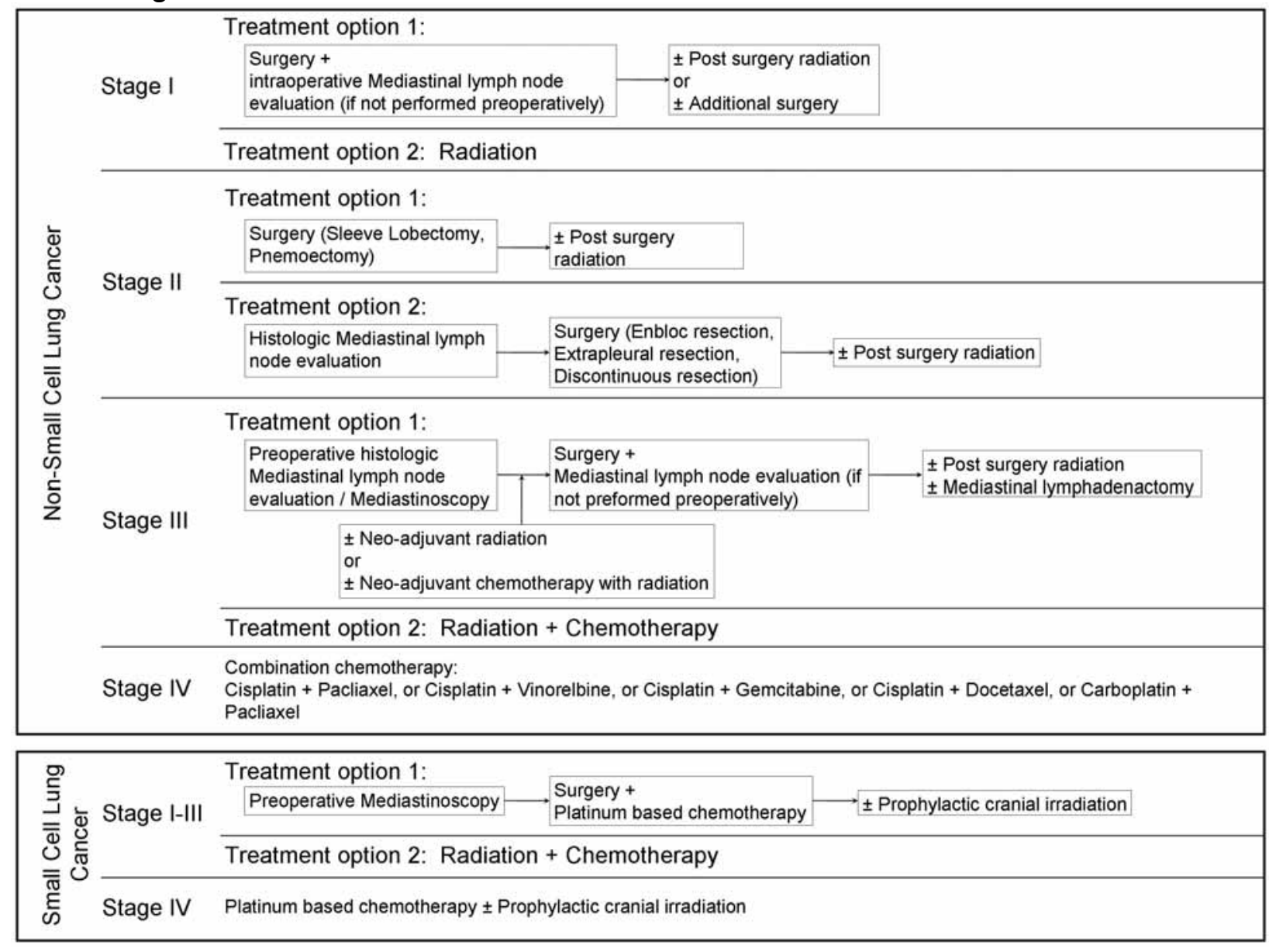


Figure 4.2. Kaplan-Meier survival curves (with $95 \%$ confidence limits) by receipt of tobacco-use cessation counseling services among continuously enrolled Medicare Feefor-service beneficiaries with an incident diagnosis of lung cancer (Stages I-IV) and with a history of tobacco use in West Virginia, July 2005 through December 2005. Curves (unadjusted) show cause-specific mortality.

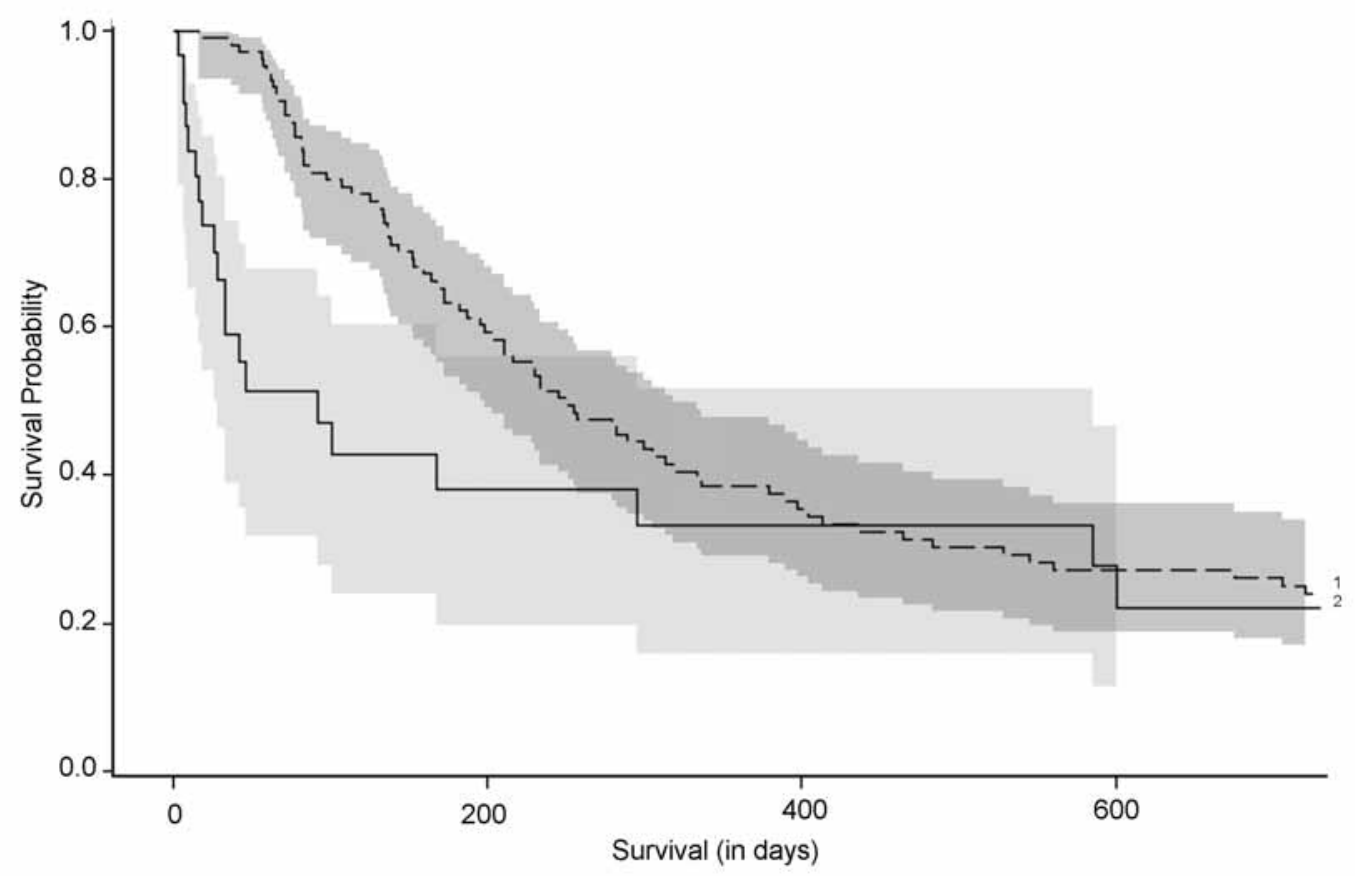

\begin{tabular}{|c|c|c|c|c|}
\hline & \multicolumn{4}{|c|}{$\begin{array}{l}-\left(-{ }^{1} \text { Receipt of tobacco-use cessation counseling services }\right. \\
{ }_{2} \text { Non-receipt of tobacco-use cessation counseling services }\end{array}$} \\
\hline & $\mathrm{N}$ & $\begin{array}{l}\text { Percent } \\
\text { Censored }\end{array}$ & $\begin{array}{l}\text { Median survival time, days } \\
(95 \% \mathrm{Cl})^{*}\end{array}$ & $\begin{array}{l}\text { 3-year survival rate } \\
(95 \% \mathrm{Cl})^{\star}\end{array}$ \\
\hline Receipt - & 107 & 28.0 & 251 (198 to 318 ) & $0.24(0.16$ to 0.33$)$ \\
\hline Non-receipt & 33 & 39.4 & 92 (28 to 585$)$ & $0.22(0.08$ to 0.41$)$ \\
\hline
\end{tabular}

$\mathrm{Cl}=$ confidence interval.

Survival times and rates were obtained from Kaplan-Meier survival estimates.

Receipt of tobacco-use cessation counseling services.

Log-rank test $(p \leq 0.05)$ comparing differences in survival by receipt of tobacco-use cessation counseling services.

Source: West Virginia Cancer Registry - Medicare linked data files, 2004-2007. 
Table 4.1. Descriptive characteristics of continuously enrolled Medicare Fee-for-service beneficiaries with an incident diagnosis of lung cancer and with a history of tobacco use in West Virginia, July 2005 through October 2007.

\begin{tabular}{|c|c|c|}
\hline \multirow{2}{*}{ Characteristics } & \multicolumn{2}{|c|}{ Proportion (\%) } \\
\hline & NSCLC & SCLC \\
\hline Overall, n (\%) & $\begin{array}{c}764 \\
(82.8)\end{array}$ & $\begin{array}{c}158 \\
(17.1)\end{array}$ \\
\hline \multicolumn{3}{|l|}{ AJCC TNM stage * } \\
\hline 1 & 17.9 & 4.4 \\
\hline II & 8.5 & 1.3 \\
\hline III & 22.0 & 21.5 \\
\hline IV & 27.6 & 38.0 \\
\hline Unstaged & 24.0 & 34.8 \\
\hline \multicolumn{3}{|l|}{ Age (years) } \\
\hline $66-69$ & 23.4 & 28.5 \\
\hline $70-74$ & 29.8 & 27.2 \\
\hline $75-79$ & 24.9 & 25.3 \\
\hline 80 or more & 21.9 & 19.0 \\
\hline \multicolumn{3}{|l|}{ Gender } \\
\hline Male & 57.3 & 50.0 \\
\hline Female & 42.7 & 50.0 \\
\hline \multicolumn{3}{|l|}{ Race } \\
\hline Other & 2.2 & 0.0 \\
\hline White & 97.8 & 100.0 \\
\hline \multicolumn{3}{|l|}{ Urban-rural residence } \\
\hline Metro & 55.8 & 58.2 \\
\hline Urban & 38.9 & 34.8 \\
\hline Rural & 5.4 & 7.0 \\
\hline \multicolumn{3}{|c|}{ Comorbidity, Charlson score } \\
\hline 0 & 20.7 & 24.7 \\
\hline 1 & 30.1 & 26.6 \\
\hline 2 or more & 49.2 & 48.7 \\
\hline \multicolumn{3}{|l|}{ Year of diagnosis } \\
\hline 2005 (July-Dec) & 21.1 & 19.6 \\
\hline 2006 & 47.0 & 47.5 \\
\hline 2005 (Jan-Oct) & 31.9 & 32.9 \\
\hline \multicolumn{3}{|c|}{$\begin{array}{l}\text { NSCLC }=\text { Non-Small Cell Lung Cancer, SCLC = Small Cell Lung Cancer, AJCC = } \\
\text { Tumor Node Metastasis. } \\
\text { Chi-square test }(p \leq 0.05) \text { measuring association between beneficiary character } \\
\text { West Virginia. } \\
\text { Source: West Virginia Cancer Registry - Medicare linked data files, 2004-2007. }\end{array}$} \\
\hline
\end{tabular}


Table 4.2. Descriptive characteristics by receipt of tobacco-use cessation counseling services, among continuously enrolled Medicare Fee-for-service beneficiaries with an incident diagnosis of lung cancer and with a history of tobacco use in West Virginia, July 2005 through October 2007.

\begin{tabular}{|c|c|c|c|c|}
\hline \multirow{2}{*}{ Characteristics } & \multicolumn{2}{|c|}{ Receipt ${ }^{\sim}$} & \multicolumn{2}{|c|}{ Non-receipt } \\
\hline & No. & $\%$ & No. & $\%$ \\
\hline Overall & 707 & 76.7 & 215 & 23.3 \\
\hline \multicolumn{5}{|l|}{ Lung cancer type } \\
\hline NSCLC & 595 & 77.9 & 169 & 22.1 \\
\hline SCLC & 112 & 70.9 & 46 & 29.1 \\
\hline \multicolumn{5}{|l|}{ AJCC TNM stage * } \\
\hline I & 126 & 87.5 & 18 & 12.5 \\
\hline II & 58 & 86.6 & 9 & 13.4 \\
\hline III & 156 & 77.2 & 46 & 22.8 \\
\hline IV & 196 & 72.3 & 75 & 27.7 \\
\hline Unstaged & 171 & 71.8 & 67 & 28.2 \\
\hline \multicolumn{5}{|l|}{ Age (years) * } \\
\hline $66-69$ & 182 & 81.3 & 42 & 18.8 \\
\hline $70-74$ & 224 & 82.7 & 47 & 17.3 \\
\hline $75-79$ & 172 & 74.8 & 58 & 25.2 \\
\hline 80 or more & 129 & 65.5 & 68 & 34.5 \\
\hline \multicolumn{5}{|l|}{ Gender } \\
\hline Male & 388 & 75.0 & 129 & 25.0 \\
\hline Female & 319 & 78.8 & 86 & 21.2 \\
\hline \multicolumn{5}{|l|}{ Race } \\
\hline Other & 12 & 70.6 & 5 & 29.4 \\
\hline White & 695 & 76.8 & 210 & 23.2 \\
\hline \multicolumn{5}{|l|}{$\begin{array}{l}\text { Urban-rural } \\
\text { residence }\end{array}$} \\
\hline Metro & 387 & 74.7 & 131 & 25.3 \\
\hline Urban & 271 & 77.0 & 81 & 23.0 \\
\hline Rural & 49 & 94.2 & 3 & 5.8 \\
\hline \multicolumn{5}{|l|}{$\begin{array}{l}\text { Comorbidity, } \\
\text { Charlson score }\end{array}$} \\
\hline 0 & 147 & 74.6 & 50 & 25.4 \\
\hline 1 & 216 & 79.4 & 56 & 20.6 \\
\hline 2 or more & 344 & 75.9 & 109 & 24.1 \\
\hline \multicolumn{5}{|l|}{ Year of diagnosis } \\
\hline 2005 (July-Dec) & 146 & 76.0 & 46 & 24.0 \\
\hline
\end{tabular}


NSCLC $=$ Non-Small Cell Lung Cancer, SCLC $=$ Small Cell Lung Cancer, AJCC $=$ American Joint Committee on Cancer, TNM $=$ Tumor Node Metastasis.

Receipt of tobacco-use cessation counseling services.

* Chi-square test $(p \leq 0.05)$ measuring association between beneficiary characteristics and receipt of tobacco-use cessation counseling services, among beneficiaries in West Virginia.

Source: West Virginia Cancer Registry - Medicare linked data files, 2004-2007. 
Table 4.3. Factors associated with receipt of tobacco-use cessation counseling services among continuously enrolled Medicare Fee-for-service beneficiaries with an incident diagnosis of lung cancer and with a history of tobacco use in West Virginia, July 2005 through October 2007.

\begin{tabular}{|c|c|c|c|}
\hline & Odds Ratio & $\begin{array}{c}\text { 95\% Confidence } \\
\text { Interval }\end{array}$ & p-value \\
\hline Intercept (p-value) & NA & NA & 0.24 \\
\hline \multicolumn{4}{|l|}{ Lung cancer type } \\
\hline NSCLC & 1.31 & 0.86 to 1.99 & 0.20 \\
\hline SCLC & & 1 (Ref) & \\
\hline \multicolumn{4}{|l|}{ AJCC TNM stage } \\
\hline Unstaged & 1.05 & 0.70 to 1.59 & 0.81 \\
\hline 1 & $2.65^{* *}$ & 1.47 to 4.80 & $<0.01$ \\
\hline II & $2.55^{*}$ & 1.16 to 5.59 & 0.02 \\
\hline III & 1.16 & 0.74 to 1.81 & 0.52 \\
\hline IV & & 1 (Ref) & \\
\hline \multicolumn{4}{|l|}{ Age (years) } \\
\hline $66-69$ & $2.58^{* * *}$ & 1.60 to 4.15 & $<0.001$ \\
\hline $70-74$ & $2.69^{\star \star \star}$ & 1.71 to 4.25 & $<0.001$ \\
\hline $75-79$ & $1.68^{\star}$ & 1.08 to 2.61 & 0.02 \\
\hline 80 or more & & 1 (Ref) & \\
\hline \multicolumn{4}{|l|}{ Gender } \\
\hline Male & 0.83 & 0.59 to 1.16 & 0.27 \\
\hline Female & & 1 (Ref) & \\
\hline \multicolumn{4}{|l|}{ Race } \\
\hline Other & 0.68 & 0.20 to 2.34 & 0.52 \\
\hline White & & 1 (Ref) & \\
\hline \multicolumn{4}{|l|}{$\begin{array}{l}\text { Urban-rural } \\
\text { residence }\end{array}$} \\
\hline Metro & $0.16^{\star *}$ & 0.04 to 0.55 & $<0.01$ \\
\hline Urban & $0.19^{* *}$ & 0.05 to 0.67 & $<0.01$ \\
\hline Rural & & 1 (Ref) & \\
\hline
\end{tabular}

Comorbidity, Charlson score

$\begin{array}{ll}0 & 0.93 \\ 1 & 1.27 \\ 2 \text { or more } & \end{array}$

$\begin{array}{ll}0.61 \text { to } 1.41 & 0.74 \\ 0.86 \text { to } 1.88 & 0.23 \\ 1 \text { (Ref) } & \end{array}$

Percentage with some college education 
$0.0-0.10$

$0.11-0.20$

$\geq 0.21$

\section{Median household \\ income}

\begin{tabular}{lccc}
$0-25000$ & 0.79 & 0.27 to 2.35 & 0.67 \\
$25001-50000$ & 0.89 & 0.32 to 2.51 & 0.83 \\
$\geq 50001$ & 1 (Ref) & \\
\hline
\end{tabular}

NSCLC $=$ Non-Small Cell Lung Cancer, SCLC $=$ Small Cell Lung Cancer, AJC Tumor Node Metastasis, Ref $=$ reference category, NA = Not Applicable.

* Estimates are statistically significant $(p \leq 0.05)$.

** Estimates are statistically significant $(p \leq 0.01)$.

*t** Estimates are statistically significant $(p \leq 0.001)$.

^ Census tract level measures of beneficiaries socioeconomic status.

WV population $(N=956)$, Fit Statistics: -2 restricted log pseudo-likelihood $=4308.15$, Covariance parameter estimates: Intercept $=$ county, estimate $=0.17$, standard error $=0.16$.

Source: West Virginia Cancer Registry - Medicare linked data files, 2004-2007. 
Table 4.4. Lung cancer mortality risk associated with non-receipt of tobacco cessation counseling services among continuously enrolled Medicare Fee-for-service beneficiaries with an incident diagnosis of lung cancer (Stages I-IV) and with a history of tobacco use in West Virginia, July 2005 through December 2005.

\begin{tabular}{|c|c|c|}
\hline & \multicolumn{2}{|c|}{ Hazard Ratio (95\% Confidence Interval) } \\
\hline & Model 1 & Model 2 \\
\hline \multicolumn{3}{|l|}{$\begin{array}{l}\text { Tobacco-use cessation } \\
\text { counseling services }\end{array}$} \\
\hline Non-receipt & $1.78(0.87$ to 3.64$)$ & $1.22(0.59$ to 2.51$)$ \\
\hline Receipt & 1 (Ref) & 1 (Ref) \\
\hline \multicolumn{3}{|l|}{ Appropriateness of care ${ }^{-}$} \\
\hline In-appropriate care & NA & $2.34^{* *}(1.38$ to 3.95$)$ \\
\hline Minimally appropriate care & NA & 1 (Ref) \\
\hline \multicolumn{3}{|l|}{ Lung cancer type } \\
\hline NSCLC & $1.04(0.64$ to 0.1 .71$)$ & $0.68(0.39$ to 1.17$)$ \\
\hline SCLC & 1 (Ref) & 1 (Ref) \\
\hline \multicolumn{3}{|l|}{ AJCC TNM stage } \\
\hline I & $0.06^{* * *}(0.02$ to 0.18$)$ & $0.08^{* * *}(0.03$ to 0.23$)$ \\
\hline II & $0.30^{* *}(0.12$ to 0.74$)$ & $0.33^{*}(0.14$ to 0.82$)$ \\
\hline III & $0.51^{* *}(0.31$ to 0.82$)$ & 0.67 (0.42 to 1.06$)$ \\
\hline IV & 1 (Ref) & 1 (Ref) \\
\hline \multicolumn{3}{|l|}{ Age (years) } \\
\hline $66-69$ & $0.46^{*}(0.22$ to 0.94$)$ & $0.48^{*}(0.24$ to 0.96$)$ \\
\hline $70-74$ & 0.69 (0.31 to 1.55$)$ & 0.78 (0.36 to 1.68$)$ \\
\hline $75-79$ & $0.48^{*}(0.24$ to 0.96$)$ & $0.45^{*}(0.22$ to 0.91$)$ \\
\hline 80 or more & 1 (Ref) & 1 (Ref) \\
\hline \multicolumn{3}{|l|}{ Gender } \\
\hline Male & $0.62(0.37$ to 1.03$)$ & $0.70(0.43$ to 1.13$)$ \\
\hline Female & 1 (Ref) & 1 (Ref) \\
\hline \multicolumn{3}{|l|}{ Race } \\
\hline Other & 0.70 (0.11 to 4.28$)$ & 0.85 (0.16 to 4.42$)$ \\
\hline White & 1 (Ref) & 1 (Ref) \\
\hline \multicolumn{3}{|l|}{ Urban-rural residence } \\
\hline Metro & $3.12^{*}(1.22$ to 7.96$)$ & $3.06^{*}(1.11$ to 8.46$)$ \\
\hline Urban & 2.63 (0.96 to 7.21$)$ & 2.45 (0.86 to 6.97$)$ \\
\hline Rural & 1 (Ref) & 1 (Ref) \\
\hline \multicolumn{3}{|l|}{$\begin{array}{l}\text { Comorbidity, Charlson } \\
\text { score }\end{array}$} \\
\hline 0 & $2.44^{* * *}(1.46$ to 4.08$)$ & $2.66^{* \star *}$ (1.56 to 4.55$)$ \\
\hline 1 & 0.77 (0.43 to 1.39$)$ & $0.79(0.44$ to 1.43$)$ \\
\hline
\end{tabular}


2 or more

\section{Percentage with some college education ${ }^{\wedge}$}
0.0-0.10
$7.77^{\star \star *}(2.50$ to 9.08$)$
$7.24^{* * *}(2.23$ to 9.98$)$
$0.11-0.20$
0.67 (0.45 to 1.01$)$
0.79 (0.51 to 1.25$)$
$\geq 0.21$
1 (Ref)
1 (Ref)

\section{Median household income ${ }^{\wedge}$ \\ $0-25000$}

25001-50000

$\geq 50001$
$0.76(0.26$ to 2.19$)$
$1.27(0.57$ to 2.80$)$ 1 (Ref)
$0.69(0.26$ to 1.83$)$

1.18 (0.61 to 2.28$)$ 1 (Ref)

NSCLC = Non-Small Cell Lung Cancer, SCLC = Small Cell Lung Cancer, AJCC = American Joint Committee on Cancer, TNM = Tumor Node Metastasis, Ref = reference category, NA = Not Applicable.

* Estimates are statistically significant $(p \leq 0.05)$.

** Estimates are statistically significant $(p \leq 0.01)$

$* *$ Estimates are statistically significant $(p \leq 0.001)$.

${ }^{\wedge}$ Census tract level measures of beneficiaries socioeconomic status.

Minimally appropriate care determined using American College of Chest Physicians (ACCP) evidence-based guidelines for diagnosis and management of lung cancer published in January, 2003.

Model 1: $N=140$, Fit Statistics: -2 log likelihood = 835.92 (without covariates) and 758.44 (with covariates), Global null hypothesis: Likelihood ratio chi-square test $=77.48(p \leq 0.05)$.

Model 2: $N=140$, Fit Statistics: -2 log likelihood = 835.92 (without covariates) and 750.10 (with covariates), Global null hypothesis: Likelihood ratio chi-square test $=85.82(p \leq 0.05)$.

Source: West Virginia Cancer Registry - Medicare linked data files, 2004-2007. 


\section{Bibliography}

(1) Peto R, Lopez AD, Boreham J, et al. Mortality from smoking in developed countries 1950-2000: indrect estimates from national vital statistics. Oxford, UK: Oxford University Press, 1994.

(2) US Department of Health, and Human Services (US-DHHS). Reducing the health consequences of smoking: 25 years of progress; a report of the Surgeon General. Washington, DC: US Goverment Printing Office, 1989.

(3) Zaridze D,.Peto R Tobacco: a major international health hazard. Lyon, France: International Agency for Research on Cancer, 1986.

(4) Kelley MJ, McCrory DC. Prevention of lung cancer: summary of published evidence. Chest 2003; 123(1 Suppl):50S-59S.

(5) Greenlee RT, Hill-Harmon MB, Murray T et al. Cancer statistics, 2001. CA Cancer J Clin 2001; 51(1):15-36.

(6) American Cancer Society. Cancer Facts and Figures, 2012. Available at:http://www.cancer.org/acs/groups/content/@epidemiologysurveilance/docume nts/document/acspc-031941.pdf. Accessed on: January 15, 2013.

(7) U.S. National Institutes of Health. National Cancer Institute: SEER Cancer Statistics Review, 1973-2008. Available at: http://seer.cancer.gov/csr/1975_2009_pops09/index.html. Accessed on: January 15, 2013.

(8) Cancer Guidence Group. Guidance on commissioning ancer services; improving outcomes in lung cancer: the manual. London, JK: National Health Service Executive, 1998.

(9) Colllege des medecins du Quebec. Clinical practice guidelines: smoking prevention and cessation; May 1999. Available at:

http://www.cmq.org/tabacang.pdf. Accessed on: August 16, 2012.

(10) National Cancer Institute. Lung cancer (PDQ): prevention; March 2001. Available at: http://www.cancer.gov/cancer_information/pdq. Accessed on: December 16,2012 .

(11) Fiore MC, Bailey WC, Cohen SJ, et al. Treating tobacco use and dependence: clinical practice guideline. Rockville, MD: US Department of Health and Human Services, Public Health Service, 2000.

(12) US Preventive Services Task Force. Screening for lung cancer. In: Guide to clinical preventive services. 2nd ed. Baltimore, MD: Williams \& Wilkins, 1996; 135-139. 
(13) Biesalski HK, Bueno de MB, Chesson A et al. Consensus statement on lung cancer. Lung Cancer Panel. Eur J Cancer Prev 1997; 6(4):316-322.

(14) National Cancer Institute: $P D Q \circledast$ Smoking in cancer care. Bethesda, MD: National Cancer Institute. Date last modified 10/23/2012. Available at: http://www.cancer.gov/cancertopics/pdq/supportivecare/smokingcessation/Health Professional. Accessed on January 19, 2013.

(15) Gritz ER, Nisenbaum R, Elashoff RE et al. Smoking behavior following diagnosis in patients with stage I non-small cell lung cancer. Cancer Causes Control 1991; 2(2):105-112.

(16) Garces YI, Yang P, Parkinson J et al. The relationship between cigarette smoking and quality of life after lung cancer diagnosis. Chest 2004; 126(6):17331741.

(17) Kearney DJ, Lee TH, Reilly JJ et al. Assessment of operative risk in patients undergoing lung resection. Importance of predicted pulmonary function. Chest 1994; 105(3):753-759.

(18) Richardson GE, Tucker MA, Venzon DJ et al. Smoking cessation after successful treatment of small-cell lung cancer is associated with fewer smoking-related second primary cancers. Ann Intern Med 1993; 119(5):383-390.

(19) Tucker MA, Murray N, Shaw EG et al. Second primary cancers related to smoking and treatment of small-cell lung cancer. Lung Cancer Working Cadre. J Natl Cancer Inst 1997; 89(23):1782-1788.

(20) Johnston-Early A, Cohen MH, Minna JD et al. Smoking abstinence and small cell lung cancer survival. An association. JAMA 1980; 244(19):2175-2179.

(21) Gail MH, Eagan RT, Feld R et al. Prognostic factors in patients with resected stage I non-small cell lung cancer. A report from the Lung Cancer Study Group. Cancer 1984; 54(9):1802-1813.

(22) Gritz ER, Fingeret MC, Vidrine DJ et al. Successes and failures of the teachable moment: smoking cessation in cancer patients. Cancer 2006; 106(1):17-27.

(23) Centers for Medicare and Medicaid Services: National Coverage Determination for Smoking and Tobacco-Use Cessation Counseling (210.4). Available at: http://www.cms.hhs.gov/mcd. Accessed on January 19, 2013.

(24) Nadpara PA, Madhavan SS. Linking Medicare, Medicaid, and Cancer Registry data to study the burden of cancers in West Virginia. Medicare Medicaid Res Rev 2012; 2(4):E1-E25.

(25) Cancer death rates--Appalachia, 1994-1998. MMWR Morb Mortal Wkly Rep 2002; 51(24):527-529. 
(26) Vital signs: current cigarette smoking among adults aged $>/=18$ years--United States, 2005-2010. MMWR Morb Mortal Wkly Rep 2011; 60(35):1207-1212.

(27) United States Cancer Statistics: 1999-2006 Incidence, WONDER On-line Database. United States Department of Health and Human Services, Centers for Disease Control and Prevention and National Cancer Institute; 2010. Available at http://wonder.cdc.gov/cancer-v2006.html. Accessed on: January 15, 2013.

(28) United States Cancer Statistics: 1999-2006 Mortality, WONDER On-line Database. United States Department of Health and Human Services, Centers for Disease Control and Prevention; 2010. Available at: http://wonder.cdc.gov/CancerMort-v2006.html. Accessed on: January 15, 2013.

(29) West Virginia Health Care Authority (WVHCA) West Virginia State Health Plan. 2010. Available at: http://www.hcawv.org/PolicyPlan/shpBmat/shpProPiper.pdf. Accessed on: September 17, 2011.

(30) Mountain CF. A new international staging system for lung cancer. Chest 1986; 89(4 Suppl):225S-233S.

(31) Mountain CF. Revisions in the International System for Staging Lung Cancer. Chest 1997; 111(6):1710-1717.

(32) Charlson ME, Pompei $\mathrm{P}$, Ales $\mathrm{KL}$ et al. A new method of classifying prognostic comorbidity in longitudinal studies: development and validation. J Chronic Dis 1987; 40(5):373-383.

(33) Deyo RA, Cherkin DC, Ciol MA. Adapting a clinical comorbidity index for use with ICD-9-CM administrative databases. J Clin Epidemiol 1992; 45(6):613-619.

(34) Romano PS, Roos LL, Jollis JG. Adapting a clinical comorbidity index for use with ICD-9-CM administrative data: differing perspectives. J Clin Epidemiol 1993; 46(10):1075-1079.

(35) US Census Bureau. 2000 Census of Population and Housing, Summary File 3: Washington, DC: US Census Bureau; 2002. Available at: http://www.census.gov/census2000/sumfile3.html. Accessed on : October 15, 2011.

(36) Diagnosis and management of lung cancer: ACCP evidence-based guidelines. American College of Chest Physicians. Chest 2003; 123(1 Suppl):D-337S.

(37) Pfister DG, Johnson DH, Azzoli CG et al. American Society of Clinical Oncology treatment of unresectable non-small-cell lung cancer guideline: update 2003. J Clin Oncol 2004; 22(2):330-353. 
(38) Clinical practice guidelines for the treatment of unresectable non-small-cell lung cancer. Adopted on May 16, 1997 by the American Society of Clinical Oncology. J Clin Oncol 1997; 15(8):2996-3018.

(39) National Comprehensive Cancer Network and American Cancer Society: Lung Cancer: Treatment Guidelines for Patients. Version 1, December 2001. Available at: http://www.nccn.org. Accessed on: January 15, 2013.

(40) National Cancer Institute: Physician Data Query Cancer Information Summaries. Available at: http://www.nci.nih.gov/cancerinfo/pdf/treatment/non-small-celllung/healthprofessional/. Accessed on: January 15, 2013.

(41) SAS Institute Inc. SAS 9.1.3 Help and Documentation. SAS Institute Inc., Cary, NC; 2000-2004.

(42) Lin DY, Wei LJ. The robust inference for the Cox Proportional Hazards Model. J Am Stat Assoc 1989; 84(408):1074-1078.

(43) Martinez E, Tatum KL, Weber DM et al. Issues related to implementing a smoking cessation clinical trial for cancer patients. Cancer Causes Control 2009; 20(1):97-104.

(44) Potosky AL, Riley GF, Lubitz JD et al. Potential for cancer related health services research using a linked Medicare-tumor registry database. Med Care 1993; 31(8):732-748.

(45) Doebbeling BN, Wyant DK, McCoy KD et al. Linked insurance-tumor registry database for health services research. Med Care 1999; 37(11):1105-1115.

(46) Cooper GS, Yuan Z, Stange KC et al. The sensitivity of Medicare claims data for case ascertainment of six common cancers. Med Care 1999; 37(5):436-444.

(47) Du X, Freeman JL, Warren JL et al. Accuracy and completeness of Medicare claims data for surgical treatment of breast cancer. Med Care 2000; 38(7):719727.

(48) Brooks JM, Chrischilles E, Scott S et al. Information gained from linking SEER Cancer Registry Data to state-level hospital discharge abstracts. Surveillance, Epidemiology, and End Results. Med Care 2000; 38(11):1131-1140.

(49) Hewitt M, Simone JV. Enhancing Data Systems to Improve the Quality of Cancer Care. Washington, DC: National Academies Press; 2000.

(50) The Kaiser Family Foundation. Medicare and Medicare Advantage enrollment. Available at:

http://www.statehealthfacts.org/comparecat.jsp?cat=6\&rgn=6\&rgn=1. Accessed on : January 15, 2013. 
CHAPTER 5 


\section{CHAPTER 5:}

\section{SUMMARY AND CONCLUSIONS}

\section{Study Summary}

In the United States (US), lung cancer is the second most diagnosed cancer and the leading cause of cancer deaths in both men and women. ${ }^{1 ; 2}$ It causes more deaths than the next three most common cancers combined (colon, breast, and prostate). ${ }^{1-3}$ The number of deaths due to lung cancer has increased approximately 4.3\% between 1999 and 2008 from 152,156 to $158,656 .^{4}$ The elderly carry a disproportionate burden of lung cancer and this pattern is expected to persist as the estimated number of elderly in the US doubles to nearly 70 million by 2030 .

Significant improvements have been made during the past decade in treatment and survival after the diagnosis of cancer. ${ }^{5}$ Still, substantial disparities exist in both cancer outcomes and the receipt of guideline-based cancer-related health care. ${ }^{6}$ Lack of timely and high quality cancer care is still a concern and it might be attributable to variations in the use of appropriate standards of care and the resulting treatment variations. $^{7 ; 8}$

A significant reduction in lung cancer mortality can be achieved if elderly patients receive timely and medically effective therapies. Unfortunately, many rural areas of the US are economically underdeveloped and medically underserved. ${ }^{9 ; 10}$ The elderly in these regions carry a higher burden of lung cancer compared to their urban

counterparts. ${ }^{11}$ These rural areas are also known to report a higher prevalence of lung cancer and a higher crude all-cause mortality rates among elderly. ${ }^{12}$ One such area is 
the Appalachian region, a population representing $8.1 \%$ of the total US population. ${ }^{13}$ West Virginia (WV) is the only state situated entirely within the Appalachian region and is the third most rural state in the nation. ${ }^{13}$ Fifty of the 55 counties in the state are designated as medically underserved areas, and all or part of 40 counties in the state are classified as health professional shortage areas. ${ }^{14}$ During 2002-2006, the ageadjusted lung cancer incidence rate (WV: 481.5 per 100,000, US: 378.5 per 100,000), and mortality rate (WV: 390.6 per 100,000, US: 310.8 per 100,000) among the elderly was higher in the state in comparison to rest of the country. ${ }^{15 ; 16}$ Interestingly, the proportional difference in age-adjusted lung cancer mortality rates, among the elderly from WV and the US, was lower than the difference in age-adjusted lung cancer incidence rates. This might suggest better survival outcomes among elderly lung cancer patients in WV as compared to the US; however, such a hypothesis remains unexplored. The observed lung cancer disparities in rural populations can be attributed to limited access to quality medical care facilities; less access to or utilization of early cancer detection programs; increased prevalence of behavioral risk factors, such as tobacco use and sedentary life style, and socioeconomic factors, such as low income and education. ${ }^{17-23}$ In addition to being medically underserved, the rural population may also experience variations in the quality, availability, and accessibility of services when compared to their urban counterparts. ${ }^{24}$

Using cancer registry linked Medicare data files, this study compared the appropriateness and timeliness of lung cancer care among elderly, in a representative rural and medically underserved WV state population, with a representative US population. The study also determines the patterns of receipt of tobacco-use cessation 
counseling services among elderly lung cancer patients with a history of tobacco use. The purpose of this study was to fill critical gaps in clinical guideline based lung cancer care and outcomes literature. First, the study examined the appropriateness of lung cancer care and associated health outcomes among WV-US elderly populations. While numerous studies have examined lung cancer treatment variations in the US, comprehensive evaluation of variations in clinical guideline based lung cancer care and its impact on health outcomes in the elderly remains unexplored. Furthermore, no information is currently available about geographic variations in clinical guideline based lung cancer care and associated health outcomes among WV-US elderly populations. Therefore, we investigate and compare the appropriateness of lung cancer care based on clinical guidelines and associated health outcomes among elderly Medicare fee-forservice (FFS) beneficiaries in a representative rural and medically underserved WV state population, and in a representative US population.

The second study examined the timeliness of lung cancer care among the elderly. Timeliness of care is important dimension of cancer care quality. While numerous studies have examined timeliness of lung cancer care, a majority of them have been conduced in European Union healthcare settings. ${ }^{25-39}$ Few studies performed in the US were either limited to small sample sizes, restricted to non-small cell lung cancer (NSCLC) patients, included both elderly and non-elderly patients, focused on specific demographic subgroups, performed within specific health care settings, or failed to examine health outcomes associated with timely care. ${ }^{40-47}$ As the elderly carry a disproportionate burden of lung cancer in the US, studies that examine timeliness of lung cancer care based on clinical opinion-based guidelines, and the 
associated health outcomes in the elderly are much needed. ${ }^{2}$ Furthermore, there is no study that compares geographic variations in timeliness of lung cancer care based on clinical opinion-based guidelines, and the associated health outcomes among WV-US elderly populations. Therefore, in the second study we investigate and compare the timeliness of lung cancer care based on clinical opinion-based guidelines among elderly Medicare FFS beneficiaries in a representative rural and medically underserved WV state population and in a representative US population.

The third study in this project was conducted with the purpose of determining the receipt of tobacco-use cessation counseling services among elderly lung cancer patients with a history of tobacco use. Smoking is common among patients diagnosed with lung cancer and promoting smoking cessation in these patients is important, as continued smoking has substantial adverse effects on treatment effectiveness, risk of second primary malignancies, and quality of life. In the third study, we examined the patterns of receipt of tobacco-use cessation counseling services among elderly Medicare FFS beneficiaries, with lung cancer and with a history of tobacco use, in a state (West Virginia) population. Together, the three studies provide an in-depth view of patterns of lung cancer care in the WV and US elderly populations, and contribute uniquely to the clinical guideline based lung cancer care and outcomes literature. The results from each of the three studies have been discussed in detail in the previous chapters. Key results from each of the three studies and their implications on lung cancer care are discussed below.

In the first study, treatment patterns varied significantly among beneficiaries with lung cancer in the WV and US populations. Despite availability of various treatment 
options to treat the disease, many beneficiaries did not receive any treatment in either population. Minimally appropriate clinical guideline based lung cancer care (hereafter referred to as 'minimally appropriate care') was only received by less than half of all beneficiaries in each population. However, the likelihood of receipt of minimally appropriate care among beneficiaries in the WV and US populations was not significantly different.

Receipt of minimally appropriate care by beneficiaries was associated with longer survival times in both populations. Although beneficiaries receiving minimally appropriate care in the $\mathrm{WV}$ population had greater median survival times, compared to the US population, their three year survival rates were significantly lower. In both populations, we found the adjusted lung cancer mortality risk significantly higher among beneficiaries not receiving minimally appropriate care than those who did receive such care. However, the magnitude of risk associated with non-receipt of minimally appropriate care was lower in WV population than in the US population. When controlled for the variability associated with receipt of minimally appropriate care and all sociodemographic variables, lung cancer mortality risk was no different among beneficiaries in the WV and US populations.

The second study assessed the timeliness of lung cancer care among elderly in WV-US populations. The study revealed that delays in diagnosis and treatment ranged widely, and also varied significantly among beneficiaries with lung cancer in the WV and US populations. Timely lung cancer care based on clinical opinion-based guidelines (hereafter referred to as 'timely care') was received by most beneficiaries in each population and was highest among those receiving radiotherapy. Contrary to what is 
expected, the proportion of beneficiaries receiving timely care did not vary between the two populations. This study is one of the few that have assessed the influence of timely lung cancer care on survival outcomes. Contrary to what would be expected, the results of this study indicate that non-timely care is not associated with poorer prognosis in lung cancer. This results corroborate finding from earlier studies. ${ }^{26 ; 28 ; 42 ; 48 ; 49}$ As reported in other studies, the association between shorter delay and poorer outcomes was most pronounced in patients with advanced stage disease in both populations. ${ }^{49}$ Compared to the US population, survival outcomes were poorer among beneficiaries receiving non-timely care and among those with late stage disease in the WV population. In both populations, we found the adjusted lung cancer mortality risk significantly lower among beneficiaries not receiving timely care than those who did receive such care. However, the magnitude of risk associated with non-receipt of timely care was higher in the WV population than in the US population. In stratified analysis by cancer type and stage, we again found the adjusted lung cancer mortality risk significantly lower among beneficiaries not receiving timely care than those who did receive such care, and the results were most pronounced in patients with advanced stage disease. After controlling for the variability associated with receipt of timely care and all sociodemographic variables, lung cancer mortality risk was significantly higher among beneficiaries in WV population as compared to the US population. Regardless of its impact on health outcomes, delays in diagnosis and treatment should be avoided, as it may increase psychological stress in patients. ${ }^{50}$

The third study revealed that tobacco-use cessation counseling services were received by more than half of all elderly Medicare FFS beneficiaries in the WV 
population. The use of these services was higher among younger beneficiaries, and after controlling for other factors, increasing age at diagnosis was associated with decline in receipt of tobacco-use cessation counseling services. This finding may have resulted from variation in physician practice patterns, and/or individual treatment preferences. Receipt of tobacco-use cessation counseling was also higher among the elderly with early stage disease as compared to those with late stage disease. This finding is expected, and is similar to that reported in one study, where patients with late stage disease were less likely to enroll in smoking cessation programs, as compared to those with early stage disease. ${ }^{51}$ Surprisingly, receipt of tobacco-use cessation counseling was found to be higher among beneficiaries residing in rural areas, as compared to those residing in non-rural areas. This finding may have resulted from the fact that prevalence of smoking is higher among beneficiaries in rural areas, and that awareness of risks associated with continued smoking may be higher among these individuals and their providers, resulting in increased receipt of tobacco-use cessation counseling services.

Although in this study, we could not determine the success or failure of tobaccouse cessation counseling attempts, receipt of such services by beneficiaries was associated with longer survival times. However, it is very likely that this finding may have resulted from the increased disease severity among beneficiaries who did not receive tobacco-use cessation counseling services. When controlled for such variability in patient clinical and sociodemographic characteristic, the adjusted lung cancer mortality risk was higher, but not significant, among beneficiaries not receiving tobaccouse cessation counseling services. Even after controlling for the variability in lung 
cancer care received among beneficiaries, the adjusted lung cancer mortality risk remained unchanged. Although findings from this study show no increase in adjusted lung cancer mortality risk among beneficiaries not receiving tobacco-use cessation counseling services, promoting smoking cessation at any stage of the disease is important.

To summarize, this project provides an in-depth view of patterns of lung cancer care and outcomes among elderly lung cancer patients from the WV and US populations. Furthermore, the results from this project help to explain the observed geographic disparities in lung cancer mortality among the elderly.

\section{Significance of the study}

Significance of study I: Appropriateness of lung cancer care and associated health outcomes among elderly Medicare FFS beneficiaries in West Virginia and in the United States

The study reveals that although lung cancer diagnostic and management services are covered under Medicare program, underutilization of these services among recipients in the Medicare FFS population is a concern. These results highlight the critical need to address disparities in receipt of minimally appropriate care among recipients in the Medicare FFS population. Reducing observed treatment variations according to individual characteristics can help to improve the use of clinical guideline-based treatments in the elderly, and that in turn would improve health outcomes. The findings from this study can aid policy makers and health care providers to reduce treatment variations in the future. The study also reveals that although lung cancer treatment 
patterns vary between WV-US elderly populations, significant population variation in receipt of minimally appropriate care, and associated lung cancer mortality risk, does not exist. These findings are contrary to what would be expected, given that the WV population is more rural and medically underserved and has higher lung cancer mortality rates, compared to the US population. The finding suggests that observed geographic differences in lung cancer mortality may not be associated with variation in receipt of minimally appropriate care among elderly beneficiaries with an incident diagnosis of lung cancer. Furthermore, higher lung cancer incidence in the WV population, as compared to the US population, may partly explain the disparities seen in lung cancer mortality among these populations. Therefore, this study reveals the urgent need for future cancer prevention efforts directed towards promoting smoking cessation in a rural WV population where the smoking prevalence rates are the highest in the nation. In the long run, these cancer prevention efforts can help to reduce the incidence of lung cancer in this rural population which in turn can help to reduce the geographic disparities in lung cancer mortality.

Significance of study II: Timeliness of lung cancer care and associated health outcomes among elderly Medicare FFS beneficiaries in West Virginia and in the United States

Lung cancer care may require complex coordination of services by medical and surgical specialists, and the traditional approach of referring patients for consultation with multiple specialists in a sequential fashion often results in care that is perceived as slow. Timely lung cancer care based on clinical opinion-based guidelines is important 
to reduce the burden of lung cancer among elderly. The results from this study reveal that although lung cancer diagnostic and management services are covered under the Medicare program, delays in diagnosis and treatment among recipients in the Medicare FFS population exists, and are a concern. Increasing patient awareness of lung cancer symptoms, and better coordination of care among providers, may help to reduce the delays in diagnosis and treatment. Results of this study also emphasize the need to address disparities in receipt of timely care among recipients in the Medicare FFS population. The study also revealed that longer delays in treatment are not associated with poorer prognosis. Nonetheless, delayed care should be avoided as it may increase the risk of disease progression and psychological stress in patients.

Finally, this study reveals that although delays in diagnosis and treatment varied between the WV-US populations, significant population variation in receipt of timely care does not exist. These findings are similar to that observed in the first study and are contrary to what would be expected given that WV population is more rural and medically underserved, and has higher lung cancer mortality rates as compared to the US population. This finding suggests that observed geographic differences in lung cancer mortality may not be associated with variation in receipt of timely care, and may have resulted from differences in lung cancer incidence. Future cancer prevention efforts directed towards promoting smoking cessation can help to reduce the incidence of lung cancer in the rural WV population, which in turn can help reduce the geographic disparities in lung cancer mortality. 
Significance of study III: Patterns of receipt of tobacco-use cessation counseling services usage and associated health outcomes among elderly Medicare FFS beneficiaries with lung cancer and a history of tobacco use in West Virginia Smoking is common among patients diagnosed with lung cancer and promoting smoking cessation among these individuals through tobacco-use cessation counseling services is of vital importance to ensure treatment success. The diagnosis of lung cancer can be used as a teachable moment for smoking cessation. However, the results from this study show that although preventive care services, such as tobaccouse cessation counseling services, are covered under the Medicare program, underutilization of these services among elderly lung cancer patients with a history of tobacco use exists and is a concern. The study also reveals that there are survival benefits associated with receipt of tobacco-use cessation counseling services. However, more empirical studies of such interventions are needed to accurately quantify the benefits of such services. The results suggests that promoting smoking cessation among lung cancer patients in rural populations, such as West Virginia where the smoking prevalence rates are the highest in the nation, is much needed.

\section{Study Limitations}

For each of the three studies, their limitations have been discussed in detail previously. However, a general summary of the overall study limitations has been provided in this section. Although we used cancer registry-linked claims data, an inherent limitation of using administrative claims data for epidemiologic studies is the possibility of

misclassification as a result of coding errors. ${ }^{52 ; 53}$ However, claims data have been 
evaluated for their utility as a source of epidemiologic or health services information in cancer patients. ${ }^{52-56}$ Increasing the use of these types of data to assess the quality of cancer care also has also been identified as a priority by the Institute of Medicine. ${ }^{57}$ Studies using claims data are usually population-based and have the potential to address a number of priority questions regarding the quality of cancer care and health care disparities. These population-based studies provide valuable information for future planning and prioritization of health programs that improve cancer outcomes.

Therefore, there is increasing interest in analyzing large health claims databases to assess treatment and outcomes for cancer. ${ }^{52 ; 53 ; 57}$

The results of this study are generalizable only to the elderly Medicare FFS population, aged 66 years and older, as encounter data for Medicare recipients enrolled in the managed care plan were not available for this study. There was a small increase in the percentage of Medicare recipients enrolled in managed care during the study years in both populations; in 2007 it was $~ 16 \%$ in WV population and $\sim 19 \%$ in the US population. ${ }^{58}$ Information on care received by the Medicare recipients outside of the Medicare system, or through non-Medicare providers, was also not available in the claims data for our study. However, Medicare is the largest and most comprehensive insurance provider for the elderly in the US. Racial disparities in cancer outcomes could not be ascertained in this study as the populations were predominantly White.

One of the inclusion criteria for cohort selection in this study was continuous enrollment in Medicare Part A and B during the study period. This resulted in the noninclusion of individuals with non-continuous enrollment and the loss of individuals who were enrolled intermittently. Because of limited data availability at the time of study, we 
were unable to conduct a long-term (5-10 year) follow-up to assess the health outcomes associated with receipt of minimally appropriate care. Individual-level socioeconomic measures of educational attainment, marital status, and family income were also unavailable for this study. However, aggregate measures of socioeconomic status at the census tract level from 2000 decennial census data were used as a proxy.

In the first study, we acknowledge that various clinical guidelines have been published for lung cancer diagnosis and management, each with recommendations that are more or less are the same. ${ }^{59-63}$ For the purpose of that study, we choose ACCP guidelines for lung cancer management and outcomes, as it is the most comprehensive of all available guidelines. ${ }^{60}$ The algorithm we adapted from these guidelines to identify minimally appropriate care takes into account the limitations in our data sources. Specifically, information on various lung function test results and lung performance scores were not available in our data source, and were not considered in our analysis. However, these indicators of lung performance are most crucial only in planning for chemotherapy in NSCLC stage IV individuals who we excluded from our analysis. Our estimates of proportion of beneficiaries receiving minimally appropriate care may be biased slightly upward, as we included patients who received minimally appropriate care, followed by additional unproven therapies. We also acknowledge that our definition of receipt of minimally appropriate care may be too narrow and that given the heterogeneity of patients seen by physicians, receipt of no therapy may still be considered as appropriate care. None the less, our definition of receipt of minimally appropriate care provides a conceptual framework to assess and compare patterns of care that were prevalent during the years 2002 through 2007. 
In the second study, given the limitations in our data sources, the delays in diagnosis and treatment were defined appropriately, and may not be accurate. Retrospective review of health services usage to estimate date of earliest lung cancer symptoms was limited to the year prior to diagnosis since findings from prior research have shown delays in symptom to diagnosis to be less than a year. ${ }^{64}$ Our estimates of 'symptom to diagnosis' delay may be biased, as beneficiaries in whom earliest symptom date could not be identified were excluded from our analysis. These beneficiaries may either had no health services usage or may had no Medicare claim with an ICD-9 code associated with lung cancer symptom in the year prior to diagnosis. It is less likely that we missed any reported lung cancer symptom as the list of symptoms searched for in this study was comprehensive, and was derived from ACCP guidelines for management and treatment of lung cancer (Appendix 3.1) ${ }^{65}$ Overall, date of earliest lung cancer symptom was identified in $88 \%$ of beneficiaries in WV population, and in $90 \%$ of beneficiaries in the US population. Our estimates of 'symptom to diagnosis' delay may also be biased, as the earliest symptom identified may have been unrelated to lung cancer. We acknowledge that our definition of timely care may be too narrow, and that given the heterogeneity of patients seen by physicians, receipt of non-timely care or no care may still be considered appropriate. None the less, our definition of timely care provides a conceptual framework to assess and compare patterns of care that were prevalent during the years 2002 through 2007.

A major limitation of third study was the lack of information on success or failure of tobacco-use cessation counseling attempts in beneficiaries receiving such services. Specifically, the data sources used for the third study do not capture information on 
whether or not a beneficiary quit smoking following the receipt of tobacco-use cessation counseling services. Such information is necessary to accurately quantify the health benefits associated with receipt of tobacco-use cessation counseling services. Also, any variation in type of counseling services offered by different providers was not captured in our data sources, and was not controlled for in our analysis.

Finally our definition of minimally appropriate versus inappropriate care, timely versus non-timely care, and receipt of tobacco-use cessation counseling service is limited to the data recorded in the claims such as the presence or absence of ICD-9 diagnosis and procedure codes, HCPCS procedure codes, CPT procedure codes and revenue center codes. Future studies can overcome the barriers seen in this study by collecting data on physician behaviors, patient preferences on treatment choices, and success/failure of counseling attempts.

\section{Directions for Future Research}

This study revealed that geographic disparities in lung cancer mortality among elderly from the WV and US populations do not result from variations in appropriateness or timeliness of lung cancer care. Future studies can use both qualitative and quantitative tools to determine if increased lung cancer risk, fragmented health care services structure, and poor accessibility to services help to explain the observed geographic disparities in lung cancer mortality.

Given that the study population in this project was predominately White, racial disparities in lung cancer care and outcomes were not observed. Racial disparities in lung cancer mortality exist as the mortality rates are higher for Blacks (53.4 per 
$100,000)$ as compared to Whites $(50.2$ per 100,000$)$. While Black men have a far higher age-adjusted lung cancer death rate that White men, and Black and White women have similar rates. ${ }^{1 ; 2}$ Future studies can explore the role of treatment variation in observed lung cancer mortality differences by race. While the number of lung cancer deaths among men has reached a plateau, the number is still rising among women. ${ }^{4}$ However, the age-adjusted death rate for lung cancer is higher for men (63.6 per $100,000)$ than for women $(39.0$ per 100,000). Given the fact that women were relatively late adopters of cigarette smoking, future studies can be carried out to determine other factors associated with observed gender disparities.

Given that we could not capture the success or failure of tobacco-use cessation counseling attempts among beneficiaries receiving such services, future studies can be carried out by collecting data on success/failure of counseling attempts and physician behaviors/patient preferences in using tobacco-use cessation counseling services. Such studies can provide the evidence needed to promote tobacco-use cessation counseling services among lung cancer patients with a history of tobacco use.

Finally, our study was limited to retrospective data sources. Future studies can overcome the barriers seen in this project by prospectively collecting data on provider/patient treatment preferences. Prospective data on elderly lung cancer patient experiences, needs, and concerns, as they receive care should be collected in future studies. Future studies could also validate the results seen in our study among younger individuals. While in this project follow up was limited to few years, future studies could be carried out to assess the long-term impact of treatment variation on lung cancer outcomes. 


\section{Bibliography}

(1) American Cancer Society. Cancer Facts and Figures, 2012. Available at:http://www.cancer.org/acs/groups/content/@epidemiologysurveilance/docume nts/document/acspc-031941.pdf. Accessed on: January 15, 2013.

(2) U.S. National Institutes of Health. National Cancer Institute: SEER Cancer Statistics Review, 1973-2008. Available at: http://seer.cancer.gov/csr/1975_2009_pops09/index.html. Accessed on: January 15, 2013.

(3) Greenlee RT, Hill-Harmon MB, Murray T et al. Cancer statistics, 2001. CA Cancer J Clin 2001; 51(1):15-36.

(4) Centers for Disease Control and Prevention. National Center for Health Statistics. National Vital Statistics Report. Deaths: Final Data for 2008. December 2011; 59(10). Available at:

http://www.cdc.gov/nchs/data/nvsr/nvsr59/nvsr59_10.pdf. Accessed on: January 15, 2013.

(5) Eden J, Sinone JV, eds. Assessing the Quality of Cancer Care: an Approach to Measurement in Georgia, Washington, DC: The National Academies Press; 2005.

(6) Harlan LC, Greene AL, Clegg LX et al. Insurance status and the use of guideline therapy in the treatment of selected cancers. J Clin Oncol 2005; 23(36):90799088.

(7) Hewitt M, Simone JV, eds. Ensuring the Quality of Cancer Care. Washington, DC: National Academy Press; 1999.

(8) Hewitt M, Simone JV, eds. Enhancing Data Systems to Improve the Quality of Cancer Care. Washington, DC: National Acadamy Press; 2000.

(9) Behringer, B. (1994). Health care services in Appalachia. In: Couto, R. A., Simpson, N. K., and Harris, G. (eds.), Sowing Seeds in the Mountains, Community-based Coalitions for Cancer Prevention and Control. NIH Publication No. 94-3779:62-80. Bethesda, MD: NIH, National Cancer Institute.

(10) Newell-Withrow C. A glance at Appalachia. J Cult Divers 1997; 4(4):129-131.

(11) Monroe AC, Ricketts TC, Savitz LA. Cancer in rural versus urban populations: a review. J Rural Health 1992; 8(3):212-220.

(12) Ricketts, T. C. (Ed.) 1999. Rural health in the United States. New York, NY: Oxford University Press. 
(13) Cancer death rates--Appalachia, 1994-1998. MMWR Morb Mortal Wkly Rep 2002; 51(24):527-529.

(14) West Virginia Health Care Authority (WVHCA) West Virginia State Health Plan. 2010. Available at: http://www.hcawv.org/PolicyPlan/shpBmat/shpProPiper.pdf. Accessed on: September 17, 2011.

(15) United States Cancer Statistics: 1999-2006 Incidence, WONDER On-line Database. United States Department of Health and Human Services, Centers for Disease Control and Prevention and National Cancer Institute; 2010. Available at http://wonder.cdc.gov/cancer-v2006.html. Accessed on: January 15, 2013.

(16) United States Cancer Statistics: 1999-2006 Mortality, WONDER On-line Database. United States Department of Health and Human Services, Centers for Disease Control and Prevention; 2010. Available at: http://wonder.cdc.gov/CancerMort-v2006.html. Accessed on: January 15, 2013.

(17) State-specific prevalence and trends in adult cigarette smoking--United States, 1998-2007. MMWR Morb Mortal Wkly Rep 2009; 58(9):221-226.

(18) Casto BC, Sharma S, Fisher JL et al. Oral cancer in Appalachia. J Health Care Poor Underserved 2009; 20(1):274-285.

(19) Wingo PA, Howe HL, Thun MJ et al. A national framework for cancer surveillance in the United States. Cancer Causes Control 2005; 16(2):151-170.

(20) Silverstein MD, Nietert PJ, Ye X et al. Access to care and stage at diagnosis for patients with lung cancer and esophageal cancer: analysis of the Savannah River Region Information System cancer registry data. South Med J 2002; 95(8):900-908.

(21) Hall HI, Uhler RJ, Coughlin SS et al. Breast and cervical cancer screening among Appalachian women. Cancer Epidemiol Biomarkers Prev 2002; 11(1):137-142.

(22) Casey MM, Thiede CK, Klingner JM. Are rural residents less likely to obtain recommended preventive healthcare services? Am J Prev Med 2001; 21(3):182188.

(23) Wright JS, Champagne F, Dever GE et al. A comparative analysis of rural and urban mortality in Georgia, 1979. Am J Prev Med 1985; 1(1):22-29.

(24) Amey $\mathrm{CH}$, Miller MK, Albrecht SL. The role of race and residence in determining stage at diagnosis of breast cancer. J Rural Health 1997; 13(2):99-108.

(25) Leo F, Venissac N, Poudenx $\mathrm{M}$ et al. Multidisciplinary management of lung cancer: how to test its efficacy? J Thorac Oncol 2007; 2(1):69-72. 
(26) Neal RD, Allgar VL, Ali N et al. Stage, survival and delays in lung, colorectal, prostate and ovarian cancer: comparison between diagnostic routes. $\mathrm{Br} \mathrm{J}$ Gen Pract 2007; 57(536):212-219.

(27) Devbhandari MP, Soon SY, Quennell P et al. UK waiting time targets in lung cancer treatment: are they achievable? Results of a prospective tracking study. J Cardiothorac Surg 2007; 2:5.

(28) Comber H, Cronin DP, Deady S et al. Delays in treatment in the cancer services: impact on cancer stage and survival. Ir Med J 2005; 98(8):238-239.

(29) Salomaa ER, Sallinen S, Hiekkanen H et al. Delays in the diagnosis and treatment of lung cancer. Chest 2005; 128(4):2282-2288.

(30) Lewis NR, Le J, I, Baldwin DR. Under utilisation of the 2-week wait initiative for lung cancer by primary care and its effect on the urgent referral pathway. $\mathrm{Br} \mathrm{J}$ Cancer 2005; 93(8):905-908.

(31) Lee J, Marchbank A, Goldstraw P. Implementation of the British Thoracic Society recommendations for organising the care of patients with lung cancer: the surgeon's perspective. Ann R Coll Surg Engl 2002; 84(5):304-308.

(32) Campbell NC, Elliott AM, Sharp L et al. Impact of deprivation and rural residence on treatment of colorectal and lung cancer. $\mathrm{Br} \mathrm{J}$ Cancer 2002; 87(6):585-590.

(33) Aragoneses FG, Moreno N, Leon P et al. Influence of delays on survival in the surgical treatment of bronchogenic carcinoma. Lung Cancer 2002; 36(1):59-63.

(34) Melling PP, Hatfield AC, Muers MF et al. Lung cancer referral patterns in the former Yorkshire region of the UK. Br J Cancer 2002; 86(1):36-42.

(35) Koyi H, Hillerdal G, Branden E. Patient's and doctors' delays in the diagnosis of chest tumors. Lung Cancer 2002; 35(1):53-57.

(36) Bozcuk $\mathrm{H}$, Martin $\mathrm{C}$. Does treatment delay affect survival in non-small cell lung cancer? A retrospective analysis from a single UK centre. Lung Cancer 2001; 34(2):243-252.

(37) Spurgeon P, Barwell F, Kerr D. Waiting times for cancer patients in England after general practitioners' referrals: retrospective national survey. BMJ 2000; 320(7238):838-839.

(38) Kesson E, Bucknall CE, McAlpine LG et al. Lung cancer--management and outcome in Glasgow, 1991-92. Br J Cancer 1998; 78(10):1391-1395.

(39) Christensen ED, Harvald T, Jendresen $\mathrm{M}$ et al. The impact of delayed diagnosis of lung cancer on the stage at the time of operation. Eur $\mathrm{J}$ Cardiothorac Surg 1997; 12(6):880-884. 
(40) Riedel RF, Wang X, McCormack M et al. Impact of a multidisciplinary thoracic oncology clinic on the timeliness of care. J Thorac Oncol 2006; 1(7):692-696.

(41) Dransfield MT, Lock BJ, Garver RI, Jr. Improving the lung cancer resection rate in the US Department of Veterans Affairs Health System. Clin Lung Cancer 2006; 7(4):268-272.

(42) Liu DM, Kwee SA. Demographic, treatment, and survival patterns for Native Hawaiians with lung cancer treated at a community medical center from 1995 to 2001. Pac Health Dialog 2004; 11(2):139-145.

(43) Quarterman RL, McMillan A, Ratcliffe MB et al. Effect of preoperative delay on prognosis for patients with early stage non-small cell lung cancer. J Thorac Cardiovasc Surg 2003; 125(1):108-113.

(44) Finlay GA, Joseph B, Rodrigues CR et al. Advanced presentation of lung cancer in Asian immigrants: a case-control study. Chest 2002; 122(6):1938-1943.

(45) Gould MK, Ghaus SJ, Olsson JK et al. Timeliness of care in veterans with nonsmall cell lung cancer. Chest 2008; 133(5):1167-1173.

(46) Yorio JT, Xie Y, Yan J et al. Lung cancer diagnostic and treatment intervals in the United States: a health care disparity? J Thorac Oncol 2009; 4(11):1322-1330.

(47) Halpern MT, Holden DJ. Disparities in timeliness of care for U.S. Medicare patients diagnosed with cancer. Curr Oncol 2012; 19(6):e404-e413.

(48) Annakkaya AN, Arbak P, Balbay O et al. Effect of symptom-to-treatment interval on prognosis in lung cancer. Tumori 2007; 93(1):61-67.

(49) Myrdal G, Lambe M, Hillerdal G et al. Effect of delays on prognosis in patients with non-small cell lung cancer. Thorax 2004; 59(1):45-49.

(50) Deegan PC, Heath $L$, Brunskill J et al. Reducing waiting times in lung cancer. J R Coll Physicians Lond 1998; 32(4):339-343.

(51) Martinez E, Tatum KL, Weber DM et al. Issues related to implementing a smoking cessation clinical trial for cancer patients. Cancer Causes Control 2009; 20(1):97-104.

(52) Potosky AL, Riley GF, Lubitz JD et al. Potential for cancer related health services research using a linked Medicare-tumor registry database. Med Care 1993; 31(8):732-748.

(53) Doebbeling BN, Wyant DK, McCoy KD et al. Linked insurance-tumor registry database for health services research. Med Care 1999; 37(11):1105-1115. 
(54) Cooper GS, Yuan Z, Stange KC et al. The sensitivity of Medicare claims data for case ascertainment of six common cancers. Med Care 1999; 37(5):436-444.

(55) Du X, Freeman JL, Warren JL et al. Accuracy and completeness of Medicare claims data for surgical treatment of breast cancer. Med Care 2000; 38(7):719727.

(56) Brooks JM, Chrischilles E, Scott S et al. Information gained from linking SEER Cancer Registry Data to state-level hospital discharge abstracts. Surveillance, Epidemiology, and End Results. Med Care 2000; 38(11):1131-1140.

(57) Hewitt M, Simone JV. Enhancing Data Systems to Improve the Quality of Cancer Care. Washington, DC: National Academies Press; 2000.

(58) The Kaiser Family Foundation. Medicare and Medicare Advantage enrollment. Available at:

http://www.statehealthfacts.org/comparecat.jsp?cat=6\&rgn=6\&rgn=1. Accessed on : January 15, 2013.

(59) Pfister DG, Johnson DH, Azzoli CG et al. American Society of Clinical Oncology treatment of unresectable non-small-cell lung cancer guideline: update 2003. J Clin Oncol 2004; 22(2):330-353.

(60) Diagnosis and management of lung cancer: ACCP evidence-based guidelines. American College of Chest Physicians. Chest 2003; 123(1 Suppl):D-337S.

(61) Clinical practice guidelines for the treatment of unresectable non-small-cell lung cancer. Adopted on May 16, 1997 by the American Society of Clinical Oncology. J Clin Oncol 1997; 15(8):2996-3018.

(62) National Comprehensive Cancer Network and American Cancer Society: Lung Cancer: Treatment Guidelines for Patients. Version 1, December 2001. Available at: http://www.nccn.org. Accessed on: January 15, 2013.

(63) National Cancer Institute: Physician Data Query Cancer Information Summaries. Available at: http://www.nci.nih.gov/cancerinfo/pdf/treatment/non-small-celllung/healthprofessional/. Accessed on: January 15, 2013.

(64) Olsson JK, Schultz EM, Gould MK. Timeliness of care in patients with lung cancer: a systematic review. Thorax 2009; 64(9):749-756.

(65) Beckles MA, Spiro SG, Colice GL et al. Initial evaluation of the patient with lung cancer: symptoms, signs, laboratory tests, and paraneoplastic syndromes. Chest 2003; 123(1 Suppl):97S-104S. 
APPENDIX 
Appendix 2.1. List of International Classification of Diseases (ICD-9) diagnosis and procedure codes, Healthcare Common Procedure Coding System (HCPCS) codes, Current Procedural Terminology (CPT) codes and revenue center codes, used to identify lung cancer specific treatments and procedures in Medicare claim data files

\section{Surgery:}

ICD-9: 324,3240,3249,3241,325,3250,3259,3250,323,3230,3239,3230,3229, $3220,329,3290,3399,344,3440,3409,3228,4029,326,3260,3401,344,3440$

CPT: $32480,32482,32486,32663,32440,32442,32445,32488,32484,32663$, $32500,32657,38746,32520,32522,32525,32310,32320,32656$

\section{Chemotherapy:}

ICD-9: V5811,V581,V662,V672,9925,9928,0015,3492

CPT: $96400,96405,96406,96408,96410,96412,96414,96420,96422,96423$, $96425,96440,96445,96450,96520,96530,96542,96545,96549$

HCPCS:Q0083,Q0084,Q0085,G0355,G0356,G0357,G0358,G0359,G0360,G036

1,G0362,G0363, G9021-G9032,J9060,J9062,J9265,J9390,J9201,J9170,J9045

\section{Radiation:}

ICD-9: V580,V661,V671,9229,9221,9222,9223,9224,9225,9226,9227,9228

CPT: $77401,77402,77403,77404,77406,77407,77408,77409,77411,77412$, $77413,77414,77416,77417,77418,77427,77431,77432,77470,77499,77520$, $77523,77750-77799$

HCPCS: G0256,G0261

Revenue center: 0330,0333

Mediastinal lymph node evaluation:

ICD-9: $3425,3422,3426,325,3250$

CPT: $39400,32405,39000,39010,39200,39220,32662,38746$

\section{Mediastinoscopy:}

ICD-9: 3422

CPT: $39000,39010,39400$ 
Appendix 3.1. List of International Classification of Diseases (ICD-9) diagnosis and procedure codes, Healthcare Common Procedure Coding System (HCPCS) codes, Current Procedural Terminology (CPT) codes, and revenue center codes used to identify symptoms associated with lung cancer, and lung cancer specific treatments and procedures in Medicare claim data files.

\section{Symptoms associated with lung cancer (ICD-9):}

Symptoms of primary tumor:

Cough

Weight loss

Dyspnea

Chest pain|Pleuritic pain

Hemoptysis

Bone pain

Clubbing

Fever

Weakness

Superior vena cava obstruction

Dysphagia

Wheezing and Stridor
7862,4910

78321

$7860,7861,7862,7863$, $7864,7865,7866,7867$, 7869

$78650,78651,78652,78659$

7863

73390

7815

7806,78060

78079

4592

7872

78607,7861

Symptoms of intrathoracic spread:

Recurrent laryngeal nerve palsy

Pancost tumor/superior sulcus tumor Horner syndrome

Symptoms of extrathoracic metastases:

Headache

Nausealvomiting

Seizures

Confusion

Personality change

Musculoskeletal pain

Syncope

Lympadenopathylenlargement of lymph nodes

Hoarseness

Hepatomegaly

Papilledema
$47830,47831,47832,47833$, 47834

1623

3379
7840

$78701,78702,78703$

78039

2930,2931

3101

7291

7802

7856

78449,78442

7891

$37700,37701,37702,37703$, 
Paraneoplastic syndromes:

Endrocrine

Nonmetastatic hypercalcaemia 27542

Cushing syndrome 2550

Gynecomastia 6111

Hypoglycaemia 2512

Hyperthyroidsm 24290,24291

Carcinoid syndrome 2592

Skeletal

Hypertrophic osteoarthropathy 7312

Neurologic

Mononeuritis multiplex $\quad 3545$

Intestinal pseudo obstruction $\quad 5609$

Lambert Eaton syndrome $\quad 1991,3581$

Encephalomyetitis 3239

Neurotising myelopathy 3369

Cancer associated retinopathy 36210

CollagenIVascular

Dermatomyositis $\quad 7103$

Polymyositis $\quad 7104$

Vasculitis 4476

Systemic lupus erythematosus 7100

Renal

Glomerulonephritis $\quad 5839$

Nephrotic syndrome 5819

Metabolic

Lactic acidosis 2762

Hypouricemia 7906

Systemic

Anorexia $\quad 7830$

Cachexia 7994 
Cutaneous

Acquires hypertrichosis languinosa

7041

Erythema gyratum repens

6951

Erythema multiforme

6951

Tylossi

700

Erythrodermia

6959

Exfoliative dermatitis

69589

Acanthosis nigricans

7012

Pruritus

6989

Urticaria

7089

Hematologic

Anemia

2859

Leukemoid reactions 2888

Thrombocytosis

2899

Thrombocytopenic purpura

2873

Coagulopathies

Thrombophlebitis

4519

Disseminated intravasular coagulation

2866

Chest x-ray:

ICD-9 (V725,8744,8739,8749)

CPT $(71010,71015,71020,71021,71022,71023,71030,71034,71035)$

\section{Surgery:}

ICD-9:

$324,3240,3249,3241,329,3290,3399,344,3440,3409,3228,325,3250,3259,3250$

$323,3230,3239,3230,3229,3220,3220,326,3260,344,3440,3401$

CPT

$32480,32482,32486,32663,32440,32442,32445,32488,32484,32663,32500$, $32657,32310,32320,32656,32520,32522,32525$

\section{Chemotherapy:}

ICD-9: V5811,V581,V662,V672,9925,9928,0015,3492 
CPT:

96400,96405,96406,96408,96410,96412,96414,96420,96422,96423,96425, $96440,96445,96450,96520,96530,96542,96545,96549$

HCPCS: Q0083,Q0084,Q0085,G0355,G0356,G0357,G0358,G0359, G0360,G0361,G0362,G0363, G9021-G9032,J9060,J9062,J9265,J9390, J9201,J9170,J9045

\section{Radiation:}

ICD-9

V580,V661,V671,9229,9221,9222,9223,9224,9225,9226,9227,9228

CPT

$77401,77402,77403,77404,77406,77407,77408,77409,77411$, $77412,77413,77414,77416,77417,77418,77427,77431,77432,77470$, $77499,77520,77523,77750-77799$

HCPCS: G0256,G0261

Revenue center: 0330,0333 
Appendix 4.1. List of International Classification of Diseases (ICD-9) diagnosis and procedure codes, Healthcare Common Procedure Coding System (HCPCS) codes, Current Procedural Terminology (CPT) codes and revenue center codes, used to identify lung cancer specific treatments, procedures, and other health care services in Medicare claim data files.

\section{Surgery:}

ICD-9: $324,3240,3249,3241,325,3250,3259,3250,323,3230,3239,3230,3229$, $3220,329,3290,3399,344,3440,3409,3228,4029,326,3260,3401,344,3440$

CPT: $32480,32482,32486,32663,32440,32442,32445,32488,32484,32663$, $32500,32657,38746,32520,32522,32525,32310,32320,32656$

\section{Chemotherapy:}

ICD-9: V5811,V581,V662,V672,9925,9928,0015,3492

CPT: 96400,96405,96406,96408,96410,96412,96414,96420,96422,96423, $96425,96440,96445,96450,96520,96530,96542,96545,96549$

HCPCS:Q0083,Q0084,Q0085,G0355,G0356,G0357,G0358,G0359,G0360,G036

1,G0362,G0363, G9021-G9032,J9060,J9062,J9265,J9390,J9201,J9170,J9045

\section{Radiation:}

ICD-9: V580,V661,V671,9229,9221,9222,9223,9224,9225,9226,9227,9228

CPT: $77401,77402,77403,77404,77406,77407,77408,77409,77411,77412$, $77413,77414,77416,77417,77418,77427,77431,77432,77470,77499,77520$, $77523,77750-77799$

HCPCS: G0256,G0261

Revenue center: 0330,0333

Mediastinal lymph node evaluation:

ICD-9: $3425,3422,3426,325,3250$

CPT: $39400,32405,39000,39010,39200,39220,32662,38746$

Mediastinoscopy:

ICD-9: 3422

CPT: $39000,39010,39400$

Tobacco-use cessation CPT (99201,99202,99203,99204,99205,99211,99212, counseling services: $\quad 99213,99214,99215,99406,99407, G 0375, G 0376)$ 


\section{CURRICULUM VITAE}

PRAMIT A. NADPARA

357 Dille Street, Apt. 7

Morgantown, WV 26505

Email: pnadpara@mix.wvu.edu

\section{ACADEMIC CREDENTIALS}

August 2007 - April 2013

Ph.D., Department of Pharmaceutical Systems and Policy, School of Pharmacy, West Virginia University

Dissertation Title: Patterns of Lung Cancer Care and Associated Health Outcomes Among Elderly Medicare Fee For Service Beneficiaries in West Virginia and in the United States

January 2005 - May 2007

Master of Science (M.S.), Department of Pharmacy Administration and Allied Health Sciences, School of Pharmacy and Health Sciences, St. John's University

Bachelor of Pharmacy (B. Pharm.), University of Mumbai, Mumbai, India

\section{WORK EXPERIENCE}

June 2009 - Current

Research assistant on a grant "Building the West Virginia Collaborative Health Outcomes Research of Therapies and Services (CoHORTS) Center" funded by the Agency for Healthcare Research and Quality (Grant Nos. P20 HS15930 \& 1 R24 HS018622-03)

- Responsibilities include storage, management, and analysis of limited and public-use data sets

January 2004 - December 2004 Assistant Manager, Biodeal Laboratories Pvt. Ltd., India Interacted directly with management to market pharmaceutical products

- Designed marketing strategies and launched successful cough syrup product

- Conducted market research on upcoming pharmaceutical product market

- Increased total sales turnover by $35 \%$

\section{RESEARCH EXPERIENCE}

January 2010 - January 2012

Linking Medicare, Medicaid, and Cancer Registry Data to Study Burden of Cancers in West Virginia 
Research Assistant on a grant funded by the Agency for Healthcare Research and Quality to create linked West Virginia Cancer Registry-Medicare-Medicaid dataset and to use it to study burden of cancer in West Virginia

August 2009 - August 2011

Studying Patterns of Cervical Cancer Screening, Diagnosis and Follow-up Treatment in a State Medicaid Fee-for Service Population Research assistant on a study funded by the Agency for Healthcare Research and Quality to determine patterns of cervical cancer screening and management of precancerous lesions among women in West Virginia

January 2009 - October 2009

Smoking and breast cancer screening in West Virginia: Opportunities for intervention

Co-investigator on a study to determine the association between smoking and breast cancer screening in West Virginia

\section{TEACHING EXPERIENCE}

August 2011 - December 2011

Graduate Instructor, School of Pharmacy, West Virginia University

- Pharmacy Systems: Responsibilities included lecturing, creating and managing course materials, grading, and facilitating student projects

August 2007 - May 2009

Graduate Teaching Assistant, School of Pharmacy, West Virginia University

- Patient Health Education: Responsibilities included conducting communication skill exercises, evaluating student verbal and non-verbal patient counseling skills, and grading

- Health Promotion and Disease Management and Pharmacy Management: Responsibilities included grading student exercises, facilitating student projects, and management of course materials

July 2005 - December 2006

Graduate Teaching Assistant, School of Pharmacy and Health Sciences, St. John's University

- Teach 5th year Pharm.D students pharmaceutical compounding labs

- Coordinate with laboratory supervisor for smooth running of labs

\section{PUBLICATIONS}

Nadpara P, Madhavan SS. Linking Medicare, Medicaid, and Cancer Registry Data to Study Burden of Cancers in West Virginia. Medicare \& Medicaid Research Review. 2012; 2(4), E1-E25. 
Nadpara P, Madhavan SS, Khanna R, Smith M, Miller LA. Patterns of Cervical Cancer Screening, Diagnosis and Follow-up Treatment in a State Medicaid Fee-for Service Population. Population Health Management. 2012 December; 15(6):362-71.

Tworek C, Nadpara P, Adkins B, Horn K, Dino G, Christy D, Madhavan SS. Smoking and breast cancer screening in West Virginia: Opportunities for intervention. West Virginia Medical Journal. 2009 October; 105 Spec No:48-53.

\section{PRESENTATIONS}

Nadpara P, Madhavan SS, Khanna R, Atkins E, Smith M. Miller LA. "Using Health Claims Data to Study Patterns of Cervical cancer Screening and Diagnosis in a State Medicaid Fee-for-service Population." Poster presented at the International Society for Pharmacoeconomics and Outcomes Research 16th Annual Meeting, Baltimore, MD, May 2011. Value in Health. 2011;14(3):A155. Abstract PCN 5.

Nadpara P, Madhavan SS, Tworek C. "Breast, Prostate, and Colorectal Cancer Screening Behavior and Incidence of Late Stage Cancer Diagnosis in Elderly West Virginians." Poster presented at the International Society for Pharmacoeconomics and Outcomes Research 16th Annual Meeting, Baltimore, MD, May 2011. Value in Health. 2011;14(3):A155. Abstract PCN 6.

Nadpara P, Madhavan SS. "Linking Medicare, Medicaid, Cancer registry Data to Study Burden of Cancers in West Virginia." Poster presented at the International Society for Pharmacoeconomics and Outcomes Research 16th Annual Meeting, Baltimore, MD, May 2011. Value in Health. 2011;14(3):A178. Abstract PCN 128.

Nadpara P, Madhavan SS, Tworek C. "Social Disparities Across the Continuum of Lung Cancer: A Systematic Review of the Literature." Poster presented at the International Society for Pharmacoeconomics and Outcomes Research 15th Annual Meeting, Atlanta, GA, May 2010. Value in Health. 2010; 13(3): A48. Abstract PCN 128.

Nadpara P, Tworek C, Madhavan SS. "Characteristics of Patients and predictors of inhospital Mortality After Hospitalization for Lung cancer in West Virginia." Poster presented at the International Society for Pharmacoeconomics and Outcomes Research 15th Annual Meeting, Atlanta, GA, May 2010. Value in Health. 2010; 13(3): A50. Abstract PCN 137.

Nadpara P, Tworek C, Madhavan SS. "The Cost of Treating Lung Cancer in the United States: An Analysis of the Medical Expenditure Panel Survey." Poster presented at the International Society for Pharmacoeconomics and Outcomes Research 15th Annual Meeting, Atlanta, GA, May 2010. Value in Health. 2010; 13(3): A48. Abstract PCN 131.

Nadpara P. "Health Status and Attitudes Towards Health Insurance in MEPS Sample Population." Poster presented at the International Society for Pharmacoeconomics and 
Outcomes Research 14th Annual Meeting, Orlando, FL, May 2009. Value in Health. 2009; 12(3): A90. Abstract PHP67.

Nadpara P, Wu W, Pantaleo N. "Evaluation of Pharmacist Intervention in Response to Patient Provided Allergy Information." Poster presented at the St. John's University Annual Student Research Day, April 2006, Queens, New York.

\section{CERTIFICATION}

Faculty Development Teaching Scholars Summer Institute 2008 Certificate, West Virginia University

\section{RELEVANT COURSEWORK}

Multivariate Analysis, Secondary Data Analysis, Pharmacoeconomics, Decision Analysis in Healthcare, Social and Behavioral Theory, Survey Research Methods, Research Design and Data Analysis, Statistical Analysis System, Applied Biostatistics, Pharmacoepidemiology, Health Systems

\section{MANUSCRIPT REVIEWER}

Journal of the American Pharmacists Association (JAPhA)

\section{COMPUTER SKILLS}

Statistical Software (SAS, SPSS), Database Development System (Microsoft Visual FoxPro), Decision Analysis Software (DATA TreeAge), Microsoft Office

\section{PROFESSIONAL AFFILIATIONS}

2006-Current 2005-Current

2008-2009

\author{
Member - Rho Chi Pharmaceutical Honor Society \\ Member - International Society for Pharmacoeconomics and \\ Outcomes Research (ISPOR) \\ Secretary - WVU ISPOR Student Chapter
}

